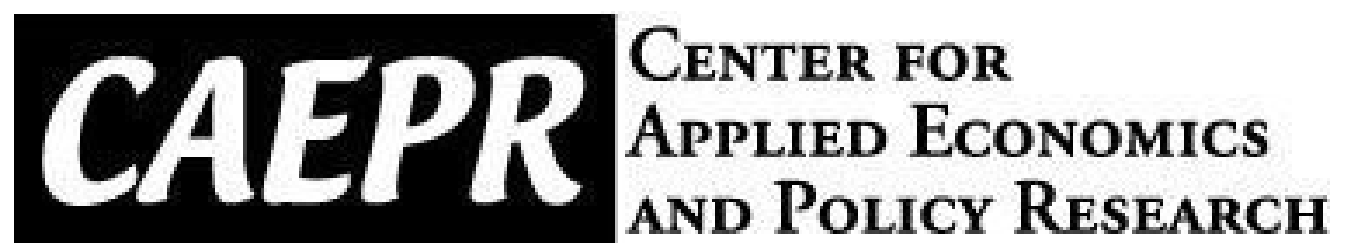

\author{
CAEPR \\ Working Paper \\ \#2018-002
}

Government Spending during Sudden Stop Crises

\author{
Siming Liu \\ Indiana University
}

March 8, 2018

This paper can be downloaded without charge from the Social Science Research Network electronic library at https://papers.ssrn.com/abstract_id=3143681

The Center for Applied Economics and Policy Research resides in the Department of Economics at Indiana University Bloomington. CAEPR can be found on the Internet at: http://www.indiana.edu/ -caepr. CAEPR can be reached via email at caepr@indiana.edu or via phone at 812-855-4050.

(C)2018 by Siming Liu. All rights reserved. Short sections of text, not to exceed two paragraphs, may be quoted without explicit permission provided that full credit, including (C) notice, is given to the source. 


\title{
Government Spending during Sudden Stop Crises
}

\author{
Siming Liu* \\ Indiana University
}

March 8, 2018

\begin{abstract}
This paper studies the effect of government spending policy during sudden stop crises. Using a quarterly dataset of 30 small open economies, I find that government spending is more effective in stimulating consumption and appreciating the real exchange rate during sudden stops than during normal times. To rationalize this, I build a two-sector model with a collateral constraint on external debt. During a recession, an adverse international shock reduces consumption and undermines the value of collateral. The collapsing asset price in turn tightens the financial constraint, deteriorates the real absorption, and sets-in a fully-blown debt-deflation mechanism. In this context, an increase in government purchases exerts a counteracting force by raising asset prices and stimulating real activities. More importantly, if the government can commit to certain paths of spending in the future, the expected real appreciation will further relax the financial constraint today. I use a calibrated model to explore the multiplier effect under different exchange rate regimes, the asymmetric multipliers, and the multipliers under different levels of shock persistence.
\end{abstract}

Keywords: Spending Multiplier; Sudden Stop Crisis; Fisher's Debt-Deflation; Collateral Constraint; Downward Nominal Wage Rigidity.

JEL Classification: E62, F34, F41, F44, H50

${ }^{*}$ Corresponding author: Department of Economics, Indiana University, Bloomington, IN 47405-7104. E-mail: simliu@indiana.edu 


\section{Introduction}

Are government spending multipliers higher during sudden stop crises? While the stimulus packages were hastily put together at the outset of a sudden stop in many countries, the governments of others took the route of austerity. At the center of the debate is the uncertainty regarding the size of fiscal multipliers during small open economy (SOE) financial crises. This paper provides an empirical and theoretical investigation into the effect of government spending shocks on real activities and asset prices. To start, I provide the cross-country evidence that government spending effect depends on the financial status of the economy. Then, I build a model with a financial channel through which Fisher's debt-deflation mechanism can account for the state-dependence of fiscal multipliers.

In the empirical analysis, I construct a panel dataset of 30 small open economies from 1980 to 2016. The sample covers a wide range of countries with different levels of incomes, financial institutions and exchange rate regimes, and it contains most of the sudden stop events in the last two decades that are found in the existing papers (see Calvo et al., 2004, for example). I estimate the government spending multipliers using local projection method, following Ramey \& Zubairy (2014). The shocks are identified assuming that it takes at least one quarter for the government spending to respond to innovations in economic fundamentals. The regression result shows that a positive government spending shock is more effective in increasing consumption and appreciating the real exchange rate during sudden stop crises than during normal times. The strengthened multiplier effect during a sudden stop is more pronounced for the countries under predetermined exchange rates. Moreover, due to the occurrence of sudden stop crises, I find an asymmetric effect of government spending: the multiplier of the fiscal contraction is higher than that of the fiscal expansion, especially during sudden stop episodes. The multiplier is also higher with greater shock persistence.

I show that a simple small open economy model with a financial constraint and downward nominal wage rigidity (DNWR) can partly account for these observations. The model is a twosector economy with limited access to international financial markets. The form of the financial constraint is in spirit of Kiyotaki \& Moore (1997) and Mendoza (2010). Non-tradable goods are produced using labor and capital while the tradable endowment follows a stochastic process. To smooth consumption, the private agents are indebted in the international market, but the amount of borrowing is restricted by the current value of capital. In addition to the constraint on debt, non-tradable good producers face a working-capital constraint in the sense that each firm needs to pledge a fraction of their wage-bill before production takes place, and this also requires capital as collateral. In this paper, I assume that government spending is exogenous and lump-sum taxes are always available.

In the model, an adverse international shock decreases tradable good consumption and reduces the non-tradable good price. Since capital is productive in the non-tradable sector while external debts are denominated in tradable units, a (dynamic) currency mismatch problem arises. The currency depreciation reduces the tradable value of firms' dividends, depressing the capital price. The collapsing capital price in turn lowers the borrowing limit and deteriorates the real absorption. 
As long as the financial constraint becomes binding, the financial accelerator, akin to Fisher's debtdeflation mechanism, is set in motion: this causes a vicious loop of falling consumption demand, drops in capital prices, and the sudden stop of capital inflows. Moreover, since the representative agents are atomistic, they don't incorporate the effect of their decisions on asset prices. That gives rise to the well-known pecuniary externality in the literature (e.g., Bianchi, 2011; Mendoza \& Bianchi, 2015), which calls for policy interventions in the financial markets.

I show that in this environment, an increase in government purchases helps in counteracting the financial deflation and increasing real activities. First of all, the higher government spending appreciates the real exchange rate, creating a positive wealth effect on households. If this effect dominates the traditional negative wealth effect associated with fiscal expansions, private consumption increases. The higher level of consumption reduces the rate at which households discount future returns, driving up the capital price and relaxing the financial constraint. Moreover, due to the currency mismatch, the current capital price is determined by the present value of future dividends. If the government is able to commit to certain paths of fiscal policies in the future, the expected real appreciation will increase the current capital price further. Under a working-capital constraint, the smaller financing cost also encourages the producing firms' labor-hiring. This shrinks the crowdingout effect on non-tradable good consumption as well. Overall, the increase in government purchases is more effective in stimulating consumption and production when the financial constraint binds, and turns the vicious debt-deflation spiral into a virtuous one.

DNWR is well-documented in the literature. Schmitt-Grohé \& Uribe (2016) shows that DNWR provides a channel to capture the important characteristics of an SOE crisis. In my model, I include DNWR to understand how the above mechanism applies to economies under different exchange rate regimes. For a country lacking the ability to depreciate the nominal exchange rate, DNWR prevents the real wage falling beyond some floor during a recession, and the economy is subject to the possibility of involuntary unemployment. Because the wage rigidity makes the economy more demand-driven, an increase in government purchases has a larger stimulative effect on production. That results in the higher multiplier effects on output and consumption volumes. However, the demand channel also interacts with the financial channel. After a positive government spending shock, the overproduction of non-tradable goods dampens the increase in the non-tradable good price and lessens the favorable effect on the price of collateral and the international borrowing. I will show that in the full model this offsetting effect is strong enough that the difference of value-multipliers (the multipliers measured in tradable values) between financial states becomes less significant than the one without DNWR.

Solving the model non-linearly allows me to analyze the state-dependent effect of government spending. Under a pegged exchange rate policy, the model predicts consumption multiplier on impact can be greater than 0 (at 0.37 ) during the identified sudden stop periods and is always negative (at -0.18) in normal times. On the other hand, with a flexible exchange rate, the multiplier increases from -0.31 in normal times to -0.12 in sudden stop periods. Overall, the model is able to reproduce several salient features that are generally consistent with the data: even without 
DNWR, spending multipliers of output and consumption are higher during sudden stops than that during normal times, and the real exchange rate also appreciates more; DNWR makes the government spending more effective in stimulating consumption and output during the crisis; the multiplier associated with a negative shock is higher than that associated with a positive shock; and multipliers in the financial crisis get higher when shocks are more persistent.

In the baseline model, I make the assumption that the aggregate amount of capital in the nontradable sector is fixed. Due to the controversial issue of investment multipliers in the literature, I extend the model to incorporate the channel of capital accumulation. In an investment economy, a positive government spending shock increases the domestic interest rate but it simultaneously relaxes the financial constraint on international borrowing. The investment multiplier depends on the relative strength of the traditional channel and the financial channel discussed throughout this paper. The calibrated model shows that the investment is crowded-in by government spending on average, and the effect is even stronger during a financial crisis.

Sensitivity analysis examine other model specifications such as: the GHH preference (Greenwood et al., 1988), tradable good production, and intermediate exchange rate policy coefficients. The GHH utility eliminates the wealth effect on labor supply, but it also weakens the impact of government spending on the financial constraint. The key result of this paper that government spending has higher multiplier effect during crises still remains, although the difference becomes smaller under GHH utility. Similarly, the financial channel of government spending is also weaker when there is a tradable good production and labor is flexible to move between sectors. Lastly, I show the exchange rate policy is an important factor determining the relative strength between the demand channel and the financial channel after a government spending shock.

Taken together, the findings of this paper highlight the necessity of analyzing the state-dependent effect of government spending. More importantly, the understanding of financial market friction is nontrivial and quantitatively relevant for the conduct of fiscal policy, especially during SOE financial crises.

\subsection{Related Literature}

This paper contributes to the literature studying government spending multipliers in financial recessions. Burgeoning empirical studies provide evidence on the state-dependent effect of government spending and generally find larger multipliers in recessions than in expansions based on U.S. data (e.g., Auerbach \& Gorodnichenko, 2012b; Ramey \& Zubairy, 2014). With a closed economy model, Carrillo \& Poilly (2013) argues that the credit market friction increases spending multipliers during a liquidity trap through the capital accumulation channel. However, the additional multiplier effect in their paper relies on the unresponsiveness of monetary policy at the zero lower bound. Their prediction that inflation has to react more to a government spending shock in recessions than in expansions contradicts the empirical evidence in Dupor \& Li (2015).

Fiscal multiplier research for small open economies is relatively rare $^{1}$. Based on a dataset of 44

\footnotetext{
${ }^{1}$ Empirical evidence of fiscal multipliers in small open economies is controversial. The early papers are Monacelli \&
} 
countries, Ilzetzki et al. (2013) (IMV) finds the output effect of government consumption depends on a list of country characteristics: the level of incomes, exchange rate regimes, and the level of government indebtedness. Similarly, Miyamoto et al. (2016) finds an increase in government purchases causes the real exchange rate to appreciate and increases consumption in developing countries, but has the opposite effect for advanced countries. They emphasize the importance of the real exchange rate in explaining the divergent macro-effect of government purchases. Despite the empirical relevance, the theoretical channels about government spending effects in SOEs are uncertain. One view is that public debt sustainability calls for pro-cyclical fiscal policy (e.g., Cuadra et al., 2010). On the other hand, Sin (2016) proposes that fiscal multipliers are large when the bondfinanced government spending alleviates liquidity frictions in the private financial market. Within my knowledge, this is the first paper using a theoretical model to study the effect of government spending in sudden stop crises. I also emphasize the role of the real exchange rate to account for the mechanism.

The method in this paper employs the real business cycle model featuring an occasionallybinding collateral constraint and the pecuniary externality. Examples are Bianchi (2011), Mendoza \& Bianchi (2015), Benigno et al. (2013), and Schmitt-Grohé \& Uribe (2017). During a financial crisis, the collapsing asset prices restrict borrowing and reduce real absorptions, which makes the financial constraint even tighter. Private agents fail to internalize this effect on the price of collateral, leading to overborrowing in the competitive equilibrium relative to the constrained efficient outcome (as in Bianchi, 2011; Mendoza \& Bianchi, 2015). Because the pecuniary externality creates a role for market intervention, most of these papers investigate the macro-prudential policy and consider the welfare benefit of capital controls. While they conduct normative analysis, the discussions below are mainly positive, and I focus on the macro-effect of government spending.

Using a model similar to mine, Fornaro (2015) evaluates the welfare ranking of different monetary policy rules in a sudden stop prone economy, considering the trade-off between price rigidity and financial stability. Similarly, Ottonello (2012) draws implications on the optimal exchange rate policy in a model where the collateral constraint is based on current income. In contrast, Devereux et al. (2015) explores the combination of capital control and monetary policy in an open economy where both financial friction and domestic price rigidities are present. Given that all these papers focus on either monetary policy or capital control policy, the novelty here lies in that I study the financial aspect of government spending, although I also consider the interaction with different exchange rate regimes in an environment where both nominal and financial frictions exist.

The rest of the paper is organized as follows. Section 2 provides the empirical estimation of government spending multipliers using the cross-country data and motivates the theoretical framework. Section 3 investigates the optimal policy in a three-period model and explores the key mechanisms of this paper. Section 4 sets up the full model and section 5 calibrates it to the Mexican economy. Section 6 presents model predictions and shows how the quantitative features of

Perotti (2010) and Kim \& Roubini (2008). They find an increase in government purchases raises private consumption and depreciates the real exchange rate, which creates a challenge for theoretical models. Ravn et al. (2012) provides a mechanism based on deep habit formation to reconcile these facts. 
the model are consistent with the data. Section 7 provides sensitivity analysis. Section 8 concludes.

\section{Empirical Evidence: Higher Multipliers during Sudden Stop Recessions}

To explore the channel through which the sudden stop event affects fiscal multipliers, I collect a quarterly dataset on GDP components, real exchange rate and current account ratio for a group of small open economies going back to $1981^{2}$. All quantities are denominated in local currency units $^{3}$. The real variables are nominal variables deflated by GDP deflators if they exist, or CPIs if they do not. The real effective exchange rates are indexed numbers based on CPI-adjusted nominal exchange rates.

Consistent with the literature, I define a sudden stop event as the big current account reversal happening amid of deep economic recession ${ }^{4}$. To compare the fiscal policy effect near and away from a sudden stop event, for each identified sudden stop period, I create an 6-quarter event window with 2 periods before and 4 periods after. This provides a clear-cut way to define a sudden stop episode and generally capture the spirit of a "big and sudden" capital flow stop as in Calvo et al. (2004). The definition of exchange rate regime follows Ilzetzki et al. (2013) and Ilzetzki et al. $(2017)^{5}$. These definitions result in a sample dataset of 30 countries with each country having at least one sudden stop event in the history. Fifteen countries are classified as pegging their exchange rates. Details about my empirical strategy are reported in appendix C.

\section{$2.1 \quad$ Econometric Method}

The estimation strategy follows Ramey \& Zubairy (2014) (RZ), which modifies the local projection method in Jordà et al. $(2005)^{6}$. Compared to a structural vector autoregression (SVAR) estimation, this method has two advantages: first, it is more robust to misspecification because it does not impose implicit dynamic restrictions on the shape of the impulse responses; second, it is easy to accommodate state-dependence and to study non-linear issues. This flexibility allows me to extend my baseline regression to a variety of dimensions. The identification follows Blanchard \& Perotti (2002)(BP) that fiscal policy requires at least one period to respond to innovations in economic fundamentals ${ }^{7}$. IMV claims that the validity of this assumption crucially relies on the availability

\footnotetext{
${ }^{2}$ The data coverage is shown in appendix $\mathrm{E}$

${ }^{3}$ I also estimate the model using variables measured in U.S. dollars. The results are reported in appendix C.

${ }^{4}$ Specifically, I denote those periods with GDP 1.5 standard deviations below trend and the reversal of current account-GDP ratio from the last year larger than two standard deviations as sudden stop type of crisis.

${ }^{5}$ More specifically, I include the countries with no legal tender, hard pegs, crawling pegs, and de facto or preannounced bands or crawling bands with margins no larger than $+(-) 2 \%$ as pegged exchange rate regime. All other countries are classified as flexible.

${ }^{6} \mathrm{RZ}$ extends the "three-steps method" of first creating an impulse response and then simulating the fiscal multiplier into a "one-step mehtod" where multipliers can be estimated directly, and they argue that these two methods give the same result if there is no data loss. I mainly use the "one-step method" here but in appendix C, I confirm my baseline result does not change if I use the first one.

${ }^{7} \mathrm{IMV}$ also applies the identification scheme of BP in a panel-data regression. But they only estimate the fiscal multiplier in linear models.
} 
of quarterly data. With lower frequency data, it is much less compelling to assume within period government spending cannot respond to contemporaneous innovations in aggregate states. Given this argument and the short-fun nature of my question, it is reasonable to adopt this empirical strategy. In appendix C, I test the instrument relevance using Kleibergen-Paap rk F statistics in the baseline estimation.

First of all, in a linear regression, I estimate the effect of government spending on key macrovariables:

$$
\sum_{j=0}^{h} x_{i, t+j}=c+\alpha_{i}+m^{x, h} \sum_{j=0}^{h} g_{i, t+j}+\Phi_{h}(L) z_{i, t-1}+u_{i, t+h}
$$

where $i$ is the country index and $t$ is the time indicator. The time horizons are represented by $h=1, \ldots, H$ when I study cumulative effect of government spending. $x$ is the variable of our interest: GDP, consumption, investment and log-difference in real exchange rate ${ }^{8}$. The control vector includes lagged economic fundamentals and fiscal variables,

$$
z_{i, t-1}=\left[g_{i, t-1}, G D P_{i, t-1}, d r e x_{i, t-1}, C A_{i, t-1} / G D P_{i, t-1}\right]^{\prime}
$$

which are lagged values of government consumption, GDP, log-difference in real exchange rate, and current account-GDP ratio. The term $\Phi(L)$ indicates the polynomial of lag operator of degree 4 . The endogenous regressor of the integral of government spending is instrumented by the extracted residuals from an SVAR regression for each country: shock $k_{i, t}=u^{g}\left(g_{i, t}\right)$, which is the orthogonalized part of contemporary government spending observations ${ }^{9}$. The major advantage of this regression is that the estimation of $m^{x, h}$ is directly the cumulative multiplier of $x$ at horizon $h$.

To study the regime-dependent effect of government spending during and away from sudden stop episodes, I estimate the following non-linear regression:

$$
\begin{aligned}
\sum_{j=0}^{h} x_{i, t+j}= & I_{i, t-1} \times\left[c_{A}+\alpha_{A, i}+m_{A}^{x, h} \sum_{j=0}^{h} g_{i, t+j}+\Phi_{A, h}(L) z_{i, t-1}\right] \\
& +\left(1-I_{i, t-1}\right) \times\left[c_{B}+\alpha_{B, i}+m_{B}^{x, h} \sum_{j=0}^{h} g_{i, t+j}+\Phi_{B, h}(L) z_{i, t-1}\right]+u_{i, t+h}
\end{aligned}
$$

Let $A$ denote sudden stop and $B$ denote normal time. The dummy variable $I_{i, t-1}$ indicates whether the shock hits the economy at sudden stop or not. Given everything else the same as before, now the integrals of government spending are instrumented by $I_{i, t-1} \times s h o c k_{i, t}$ and $\left(1-I_{i, t-1}\right) \times s h o c k_{i, t}$. I concentrate on the estimation of coefficients $m_{A}^{h}$ and $m_{B}^{h}$ which are the multipliers in corresponding financial regimes. I report the results of both linear and non-linear regressions in table 1.

\footnotetext{
${ }^{8}$ I focus on the response of real exchange rate because that underlies the key mechanism studied in this paper. Following IMV, I use the difference in log real exchange rate in the regression instead of the levels.

${ }^{9}$ Before running the regression, to identify the government spending shocks, I estimate a four-variable recursively identified SVAR for each country (the same as IMV's) and extract the residuals from the first line equation. Those are the estimated government spending innovations (BP shocks) and are used as instruments in my regression model.
} 


\begin{tabular}{lllll}
\hline & Linear Model & Sudden Stops & Normal Times & HAC p-value \\
\hline \hline GDP & & & & \\
Impact & $0.61(0.15)$ & $0.56(0.50)$ & $0.58(0.15)$ & 0.97 \\
1 year & $1.40(0.21)$ & $1.51(0.42)$ & $1.29(0.24)$ & 0.64 \\
2 year & $0.83(0.18)$ & $1.13(0.29)$ & $0.70(0.21)$ & 0.22 \\
\hline Consumption & & & & \\
Impact & $0.15(0.13)$ & $0.70(0.40)$ & $0.02(0.12)$ & $0.11^{*}$ \\
1 year & $0.83(0.18)$ & $1.60(0.48)$ & $0.58(0.17)$ & $0.05^{* * *}$ \\
2 year & $0.67(0.18)$ & $1.52(0.42)$ & $0.40(0.20)$ & $0.02^{* * *}$ \\
\hline Real Exchange & & & & \\
Impact & $3.99(0.73)$ & $8.67(2.62)$ & $2.95(0.57)$ & $0.03^{* * *}$ \\
1 year & $1.12(0.27)$ & $3.20(0.88)$ & $0.52(0.24)$ & $0.011^{* * *}$ \\
2 year & $-0.21(0.18)$ & $0.59(0.49)$ & $-0.48(0.21)$ & $0.066^{* *}$ \\
\hline
\end{tabular}

a. ${ }^{*}, * * * * *$ indicates the null hypothesis is rejected at significance level of $20 \%, 10 \%$ and $5 \%$, respectively: $\mathbb{H}_{0}: m^{A, h}=m^{B, h}$ b. Before running the regression, I transform the data by taking ratios of each quantity variable over trend real GDP. Therefore, the numbers in the table are directly cumulative multipliers in terms of local currency units.

c. To study the effect on real exchange rate, I use the log difference of real exchange rate index as dependent variable in the regression. The numbers in the table represents the cumulative percentage change in real exchange rate for each dollar increase of government spending.

Table 1: Spending Multipliers during Sudden Stops and Normal Times

\subsection{Estimation Result}

The main goal of this paper is to understand the mechanisms behind the spending multiplier effect when sudden stop crisis happens. Accordingly, in table 1 and figure 1, I report the short-run cumulative multipliers in sudden stop times versus in normal times ${ }^{10}$. Special attention is devoted to the response of the real exchange rate because it is a main driver behind the supposedly large effect of government spending during sudden stops. In the last column of table 1, the p-values are used to test whether there are significant differences between multipliers in different financial states. Given the possibility of correlated residuals across times and countries, I use the heteroscedasticity and autocorrelation-consistent (HAC) standard error. I get the following key finding of this paper:

EMPIRICAL RESULT 1: Government spending is more effective in stimulating consumption and appreciating real exchange rate when the shock happens during sudden stops than during normal times.

First of all, a positive government spending shock is shown to crowd-in consumption and output on average. The multiplier effect peaks 4 quarters after the shocks. The real exchange rate also appreciates (by $4 \%$ on average) on impact, but the effect decays very quickly and turns negative

\footnotetext{
${ }^{10}$ Given the way I define sudden stop episodes, I focus on the analysis of short-run multipliers, mostly within two-years horizon.
} 

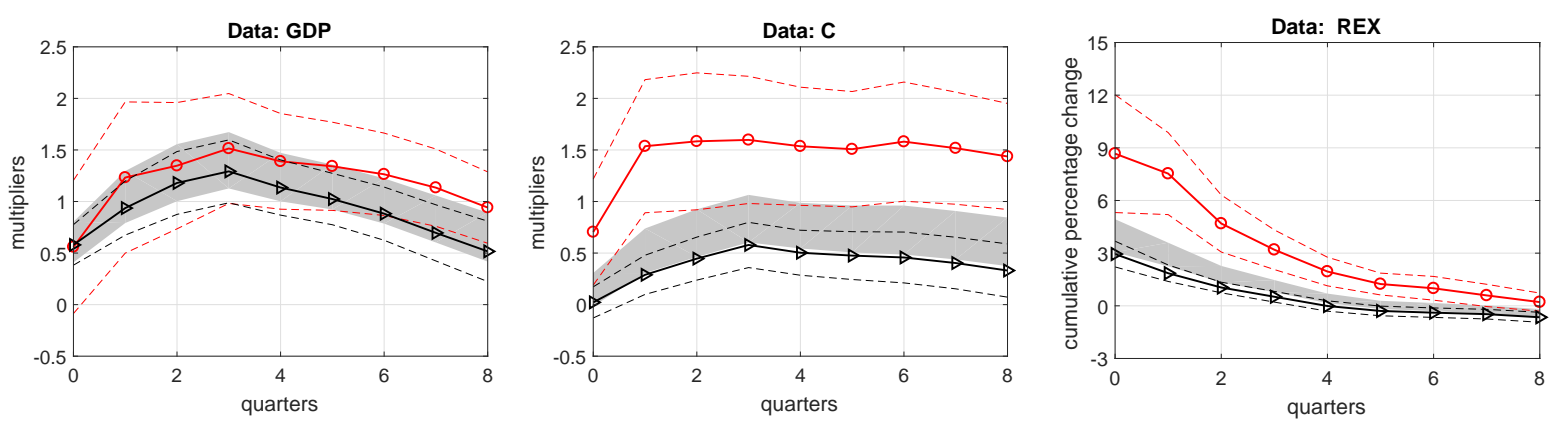

Figure 1: Spending Multipliers of S.S. and N.T.

Note: The figures report volume-multipliers of GDP, consumption and real exchange rate and their $80 \%$ confidence bands. The shaded areas are results from the linear model. The red (black) are regime-dependent multipliers when the shock happens in sudden stop time (normal time). GDP and consumption are denominated in local currency units. y-axis is the cumulative multiplier. For the real exchange rate, y-axis is the cumulative percentage change of the indices when government spending increases by $1 \%$ of GDP.

after two years ${ }^{11}$. Second, comparing the multipliers between financial regimes, one can see that government spending is more effective in stimulating consumption when the shock hits the economy during a sudden stop episode. On average, the consumption multipliers are more than doubled in financially-distressful periods than that in normal times, but due to the large error bands, the state-dependence is only $5 \%$ significant after the first year. The real exchange rate also appreciates more during sudden stops and the error bands of different financial regimes do not overlap.

However, there is no significant difference in GDP multipliers between financial regimes in all time horizons, even though the average value of multipliers in sudden stops becomes slightly higher after the shock hits. This result seems natural given I will show below that sudden stop phenomenon is more closely linked to the collapse of private consumption and real exchange rate. In contrast, the determinants of production activities are more complicated and could be related to other factors, such as domestic nominal and real rigidities or monetary policy. Accommodating these elements would complicate the model and blur the main result and so they are left outside the scope of this paper.

Next, to see how the above result depends on exchange rate policy, I estimate the baseline regression separately for the countries classified as pegging versus flexible exchange rate ${ }^{12}$. The result is in figure 2 which makes me draw the following conclusion:

EMPIRICAL RESULT 2: The higher stimulative effect of government spending shock during a sudden stop is more pronounced for the countries with pegged exchange rates.

One can see from the middle panel of figure 2 that, on average, the consumption multipliers rise from a value around $0(0)$ in normal times to 1 (less than 0.5 ) in sudden stop times for the pegging (flexible) exchange rate countries. Additionally, the real appreciation effect of government spending

\footnotetext{
${ }^{11} \mathrm{My}$ finding that an increase in government spending causes real exchange rate to appreciate in developing countries is consistent with Miyamoto et al. (2016), since most of my countries belong to their sample.

${ }^{12}$ The details in running the extended regression are shown in appendix $\mathrm{C}$
} 

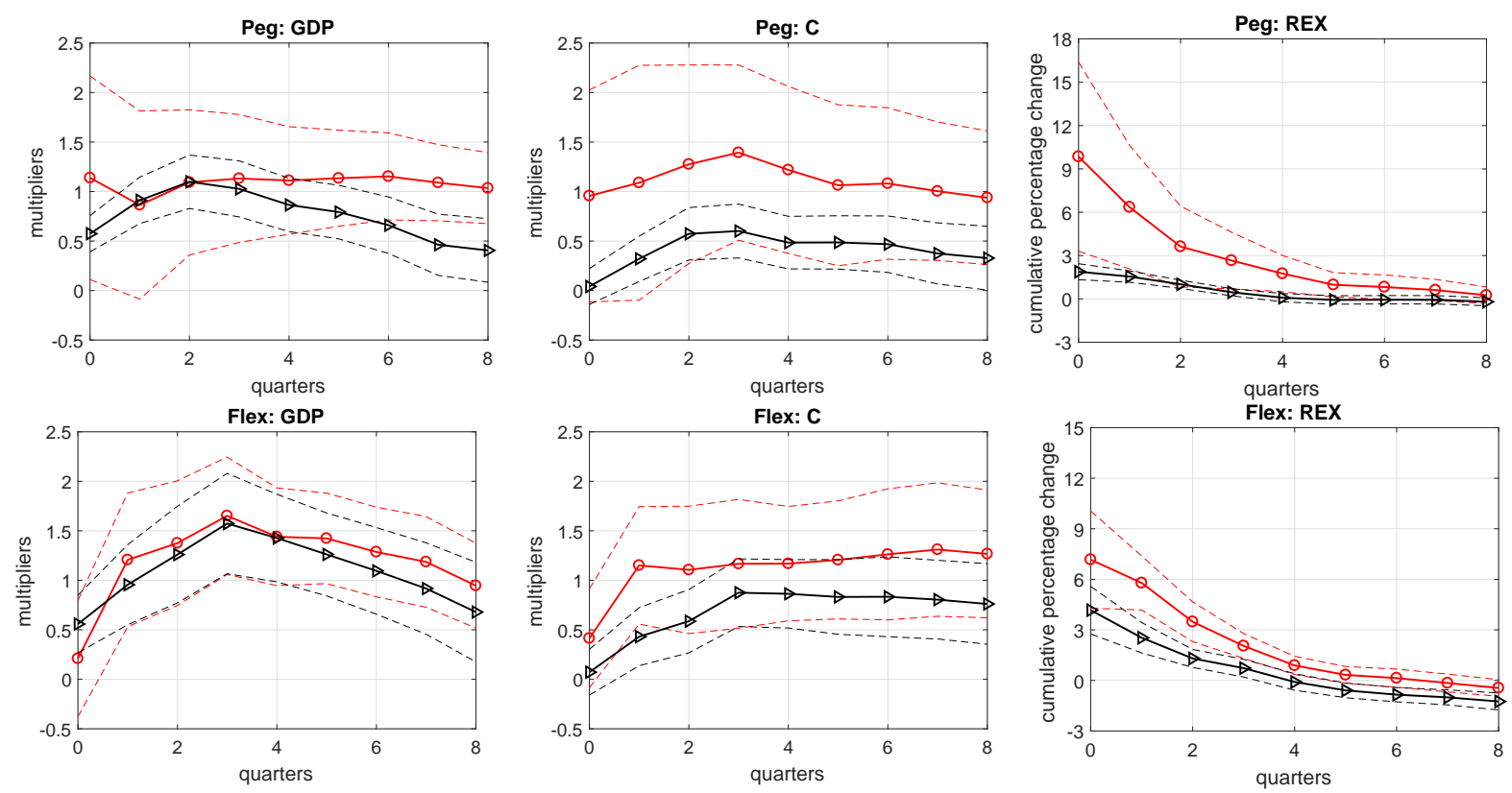

Figure 2: Spending Multipliers of S.S. and N.T. for Different ERR

Note: See the note of figure 1 for details.

during sudden stops is also stronger for peggers than for non-peggers. For output, again, there is no significant difference in multipliers between financial states in all cases, except for peggers, where the average impact multiplier of sudden stops is slightly higher than that of normal times.

The comparison of normal time multipliers between pegging and flexible exchange rate countries contradicts the Mundell-Fleming intuition. For example, one can see that the normal time consumption multipliers in the upper and lower panels are almost the same. In contrast, MundellFlemming predicts a higher fiscal multiplier when the country operates under pegging exchange rate policy because that is when the positive shock is accompanied by a more accommodating monetary policy. I abstract from that consideration in this paper. Pegged exchange rate indeed increases the efficiency of government spending during sudden stops, but not on average.

Given that I have a non-linear model, it is interesting to analyze the fiscal multiplier effect in other dimensions, one of which is the asymmetric effect of a government spending shock. The motivation is that many countries have been adopting fiscal austerity or consolidation over the past decades, and both the media and policy-makers are curious to know their consequences on domestic market ${ }^{13}$. Therefore, I further extend my baseline regression to account for the sign of the government spending shock. Specifically, I divide my sample into periods of "fiscal expansion" and "fiscal contraction" based on whether the extracted SVAR residuals are greater than 0 or not. That results in a regression of two regimes. Then, to examine where the asymmetry comes from, I further augment it with two financial regimes, resulting in a four-regime regression. The result is

\footnotetext{
${ }^{13}$ Pröbsting et al. (2017), Castro et al. (2013), and Anzoategui (2016) study the distortionary effect fiscal austerity measures for periphery European countries. Pragidis et al. (2017) uses a threshold-VAR model to estimate the asymmetric effect of government spending and its state-contingency across U.S. financial cycle.
} 

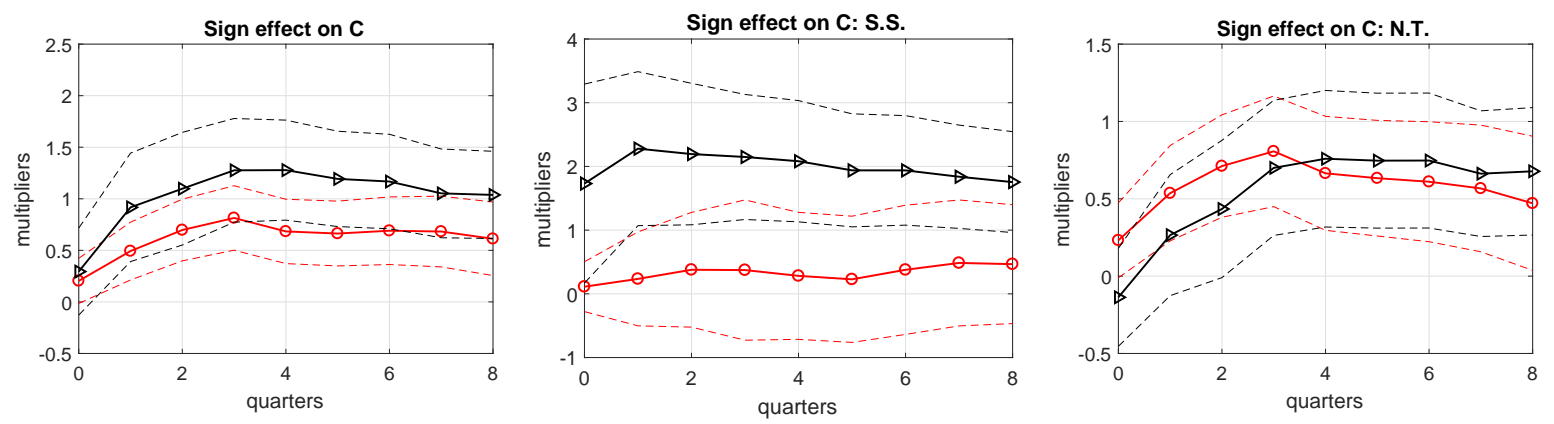

Figure 3: Spending Multipliers of Positive and Negative Shocks: Consumption

Note: See the note of figure 1 for details. Red (black) curves are multipliers associated with positive (negative) shocks. The multipliers of positive and negative shocks are defined in the same way. For example, a positive consumption multiplier means that the private consumption declines after a negative spending shock.

reported in figure 3 and I conclude:

EMPIRICAL RESULT 3: The consumption multiplier associated with a negative spending shock is higher that that associated with a positive spending shock, and the difference mainly comes from sudden stop episodes.

Figure 3 displays the asymmetric effect of government spending on private consumption. In the left panel, the multiplier effect on consumption is larger when it is triggered by a negative shock, although the average difference on impact is small. This later result is natural since we know that only sudden stop periods are the times of great market turbulence where asymmetric effects show up, but sudden stop events are rare in the data. Including financial regimes allows me to prove this point. The middle panel shows that when a sudden stop happens, a negative shock generates quite a large and persistent multiplier effect on consumption, while the multiplier effect of a positive shock is rather muted. However, during normal times, the asymmetry disappears, as in the right panel. As in Pröbsting et al. (2017), fiscal austerity is usually associated with negative, large, persistent government spending shocks that happen during financially-distressful periods. The results here lend support to their view that the long-lasting austerity measures are sufficiently contractionary to private activities so that their benefit is overshadowed by the cost. In order to evaluate the effect of austerity measures comprehensively, the state-dependence of the fiscal multiplier should be taken into consideration.

My last empirical exercise comes from the conjecture that the expectation on future policy conduct might be important for the efficiency of fiscal policy today. I divide my sample into two groups of countries based on the level of spending shock persistence. A "High (low) persistence" country is one with an estimated autocorrelation greater (lower) than a threshold $(0.7)^{14}$. I run the baseline regression separately for these two country groups. From figure 4, I get the following result:

\footnotetext{
${ }^{14}$ I choose the threshold of of 0.7 to make the two groups of countries roughly having the same sample size.
} 

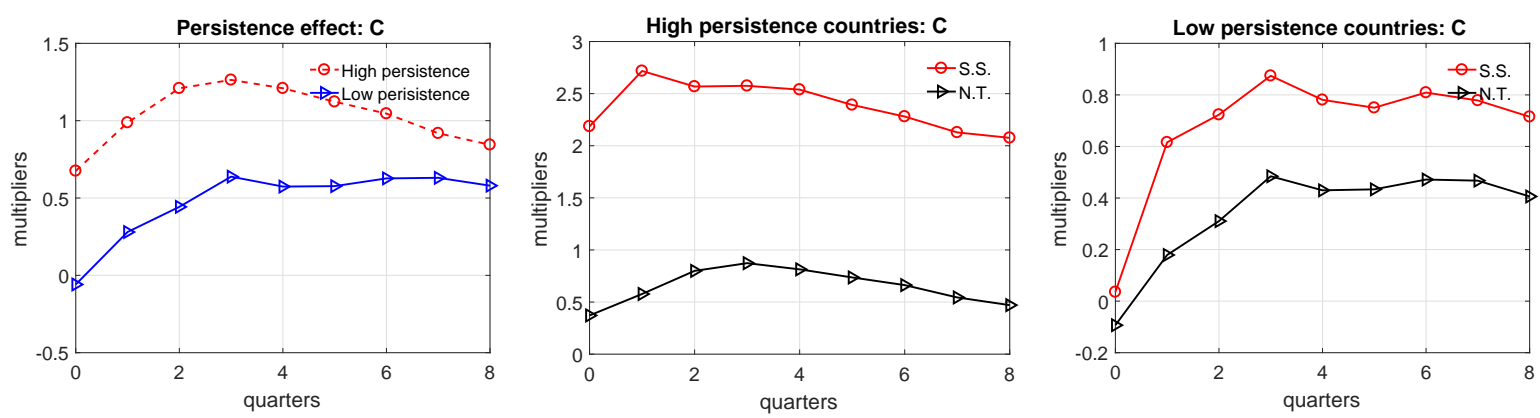

Figure 4: Spending Multipliers of Different Shock Persistence: Consumption

Note: In the left panel, the red (blue) curve is the multipliers for the "high (low) persistence" countries. In the middle and right panels, red (black) curves are the multipliers during sudden stop periods (normal times) separately for each group of countries.

EMPIRICAL RESUlT 4: The spending multiplier is higher when the government spending shock is more persistent.

It is well-documented in the literature (e.g., Auerbach \& Gorodnichenko, 2012a; Ramey, 2011) that part of the effect of government spending comes from private agents' anticipation of future fiscal policy. This may create bias in estimating a fiscal regression without using expectational variables. Here I notice that there is another way the expectational effect matters: through the financial channel. The intuition is that since the collateral price is determined by the present value of future dividends, a financially-constrained economy is more forward-looking and sensitive to future fiscal shocks. Given that higher government spending appreciates the real exchange rate, a more persistent fiscal expansion creates a larger and more desirable impact on the current capital price and allows the agents to better front-load consumption. One can see from figure 3 that the more persistent government spending shock has the higher multiplier effect on consumption on average (left panel). Moreover, the dependence of the fiscal multiplier on financial states is also stronger for the countries with the more persistent fiscal policy (middle and right panels).

I check the robustness of my empirical results in three dimensions. First, I re-estimate the model with all variables denominated in U.S. dollars rather than in local currency units. I find the result becomes more significant. Second, most authors studying fiscal multipliers by local projection method use the "three-step method" of first estimating impulse response, then constructing fiscal multipliers through Monte Carlo simulation. While I rely on the "one-step regression" throughout the paper, I also repeat my baseline exercise based on the "three-step method" and find the same result. Lastly, given that I control for the past GDP and government consumption in the baseline regression, in principle the $\mathrm{BP}$ shocks could be replaced by the current observations of government consumption used as instruments. I confirm my result still holds. The robustness is shown in appendix C.

To sum up, this section provides the cross-country evidence that the fiscal multiplier effect displays several non-linear features. To understand the subdued effect of government spending in a financially-distressed economy, I will develop a three-period model in the next section and start 
from investigating the optimal spending policy.

\section{A Three-Period Model}

In this section, I build a two-sector small open economy. Time is discrete and the economy lasts for three periods: $t=1,2,3$. The representative agents makes consumption, production decisions, and borrows in the international market with interest rate $R^{*}$. The financial market is incomplete and the total amount of borrowing is constrained by the value of capital. There is only uncertainty in the second period which makes the collateral constraint occaionally bind. The government chooses the optimal level of spending in the second and third periods ${ }^{15}$. In order to evaluate the welfare effect of government spending during the crisis, I also assume there exists macro-prudential tax in the first period.

\subsection{Competitive Equilibrium}

There are two sectors: tradable and non-tradable good sector. The non-tradable goods are produced by labor and capital; the tradable goods are endowed and subject to shocks. To simplify, I assume labor is only elastically supplied in the second period and the labor supply is fixed at 1 in the third period. There is a continuum of representative agents/households, with each one of them having the life-time utility of the form

$$
\mathbb{U}=\log \left(c_{1}^{T}\right)+\mathbb{E}_{1}\left[\beta\left(\log \left(c_{2}\right)-\chi \frac{l_{2}^{1+\nu}}{1+\nu}+\eta^{G} \log \left(g_{2}\right)\right)+\beta^{2}\left(\log \left(c_{3}\right)+\eta^{G} \log \left(g_{3}\right)\right)\right],
$$

where $1 / \nu$ is the Frisch elasticity on labor supply. $\chi$ and $\eta^{G}$ are respectively labor disutility and utility weight on public consumption. Both the private and public consumption are composite goods from the two sectors ${ }^{16}$

$$
\begin{gathered}
c_{t}=\left(\omega c_{t}^{T \frac{\theta-1}{\theta}}+(1-\omega) c_{t}^{N \frac{\theta-1}{\theta}}\right)^{\frac{\theta}{1-\theta}}, \\
g_{t}=\left(\omega^{G} g_{t}^{T \frac{\theta-1}{\theta}}+\left(1-\omega^{G}\right) g_{t}^{N \frac{\theta-1}{\theta}}\right)^{\frac{\theta}{1-\theta}},
\end{gathered}
$$

Parameters $\omega$ and $\omega^{G}$ are the tradable weights in the private and public consumption baskets, while $\theta$ is the elasticity of substitution. Notice that the government spending enters the utility function in a separable form, which means the spending policy does not affect the private equilibrium directly. The major role of government spending mainly comes from its general equilibrium effect on asset

\footnotetext{
${ }^{15}$ To consider the net effect of government spending policy, I assume capital controls are not available from the second period onward. The welfare implication of capital control is well-studied in the literature(e.g. Mendoza \& Bianchi (2015)). However, I analyze macro-prudential tax in the first period because that represents the average severity of financial crisis or pecuniary externality.

${ }^{16}$ I include government spending into utility function only to study the optimal policy. In solving the competitive equilibrium, the government spending stays at its steady state.
} 
prices. This section is meant to illustrate how this effect helps in alleviating the severity of a financial crisis.

In each period, the agents choose consumption, labor supply (only $t=2$ ) and capital acquisition (only $t=2$ ). Since $\beta R^{*}<1$, they borrow from foreign investors, but the total amount of borrowing has to be collateralized by domestic capital. More specifically, in period 1 , the agents borrow and make tradable consumption. In period 2, the agents pay-off the debt, use labor for production, buy capital shares, and borrow in the international market. Capital is used for production in the next period and is also taken as collateral. In period 3, the agents collect the return on capital, clear-off their debt balance, and make consumption. Assume that the tradable good is the numeriare. Let $p_{t}^{N}$ denote the relative price of the non-tradable good. The capital price in period $\mathrm{t}$ is $q_{t}^{K}$. The agents' sequential budget constraints are:

$$
\begin{aligned}
& c_{1}^{T}+b_{1}=y_{1}^{T}+\frac{1}{R^{*}} b_{2}\left(1-\tau_{1}^{M P}\right)-T_{1}, \\
& c_{2}^{T}+p_{2}^{N} c_{2}^{N}+b_{2}+q_{2}^{K}\left(k_{3}-1\right)=y_{2}^{T}+p_{2}^{N} F\left(1, l_{2}\right)+\frac{1}{R^{*}} b_{3}-T_{2}, \\
& c_{3}^{T}+p_{3}^{N} c_{3}^{N}+b_{3}=y_{3}^{T}+p_{3}^{N} F\left(k_{3}, 1\right)+q^{c} k_{3}-T_{3} .
\end{aligned}
$$

The sequence $\left\{b_{t+1}\right\}_{t=1}^{2}$ denotes the agents' borrowing amount in tradable units and $k_{3}$ is the capital share bought by each individual agent. The non-tradable production function $F(k, l)=k^{\alpha^{K}} l^{\alpha^{L}}$ is non-increasing-return-to-scale. Notice that since $t=3$ is the terminal period, there is no new borrowing or capital investment. The continuing value of capital $q^{c}$ is set at 0 in the numerical exercise below ${ }^{17}$. I assume there is a debt tax $\tau_{1}^{M P}$ for macro-prudential regulation in the first period, as will be discussed later. The sequence $\left\{T_{t}\right\}_{t=1}^{3}$ is the lump-sum taxes collected by the government to finance its deficit ${ }^{18}$.

In the second period, there is a financial constraint in form of

$$
\frac{1}{R^{*}} b_{3} \leq \kappa q_{2}^{K} k_{3}
$$

where $\kappa$ is the collateral rate. This constraint says foreign creditors restrict loans so that the total value of borrowing at time 2 does not exceed a fraction of the foreign currency value of households' end-of-period capital holdings. A larger value of $\kappa$ allows the agents to borrow more, thus making the private agents more indebted. Taking the initial condition $b_{1}$ and equilibrium prices $\left\{p_{2}^{N}, p_{3}^{N}, q_{2}^{K}\right\}$ as given, the households' problem is to maximize utility (1) subject to the budget constraints (4)-(6) and the financial constraint (7).

I assume the aggregate amount of capital is fixed $k_{3}=1$ and the individual borrowing coincides with the aggregate, $b_{2}=B_{2}$ and $b_{3}=B_{3}$. Both tradable and non-tradable good markets clear in

\footnotetext{
${ }^{17}$ This assumption is crucial here. In the three-period model, I find the continuing value of capital $q^{c}$ determines the shape of the optimal spending policies. However, the welfare implication that optimal government spending can improve asset prices and real absorption always holds. I choose $q_{c}=0$ here because that makes the result of the three-period model consistent with that in the full model.

${ }^{18}$ Like in the optimal policy literature, all distortionary taxes considered here are only for corrective purpose.
} 
every period:

$$
\begin{aligned}
& c_{1}^{T}+B_{1}=\frac{1}{R^{*}} B_{2}+y_{1}^{T}, \\
& c_{2}^{T}+g_{2}^{T}+B_{2}=\frac{1}{R^{*}} B_{3}+y_{2}^{T}, \\
& c_{2}^{N}+g_{2}^{N}=y_{2}^{N}=F\left(1, l_{2}\right), \\
& c_{3}^{T}+g_{3}^{T}+B_{3}=y_{3}^{T}, \\
& c_{3}^{N}+g_{3}^{N}=y_{3}^{N}=F(1,1) .
\end{aligned}
$$

Here, I simplify the first and third period problem in order to focus on discussion the second period financial constraint. Under these simplifying assumptions, the competitive equilibrium can be defined as:

Definition 1. Taking initial condition $b_{1}$ and government's policy $\left\{g_{2}^{N}, g_{2}^{T}, g_{3}^{N}, g_{3}^{T}\right\}$ as given, a competitive equilibrium consists of a set of prices $\left\{p_{2}^{N}, p_{3}^{N}, q_{2}^{K}\right\}$ and a set of allocation choices $\left\{c_{t}^{N}\right\}_{t=2}^{3},\left\{c_{t}^{T}\right\}_{t=1}^{3},\left\{k_{3}, B_{2}, B_{3}, l_{2}\right\}$ such that:

1. Given prices, the consumption, labor, capital and borrowing choices solve the representative agent's problem.

2. The capital market, bond market, and both the tradable and non-tradable goods markets clear in every period.

In order to solve the problem, I take the first order conditions. Since most of the discussions below focus on fiscal policy during financial crisis, first I write the Euler equations in period 2 and 3 as:

$$
\begin{aligned}
& \frac{u_{L}(2)}{u_{C T}(2)}=p_{2}^{N} F_{L}\left(1, l_{2}\right), \\
& {\left[u_{C T}(2)-\mu_{2}\right]=\beta R^{*}\left[u_{C T}(3)\right],} \\
& {\left[u_{C T}(2)-\kappa \mu_{2}\right] q_{2}^{K}=\beta\left\{u_{C T}(3)\left[q^{c}+p_{3}^{N} F_{K}(1,1)\right]\right\},} \\
& p_{t}^{N}=\frac{1-\omega}{\omega}\left(\frac{c_{t}^{T}}{c_{t}^{N}}\right)^{\frac{1}{\theta}}, \quad \text { for } \quad t=2,3 .
\end{aligned}
$$

The Lagrangian multiplier on the collateral constraint is $\mu_{2} \geq 0$. The first equation determines the equilibrium labor at time 2 . Notice that the labor demand is proportional to $p_{2}^{N}$, which means the current real appreciation has a stimulating effect on production. The second equation is the inter-temporal borrowing condition. When the financial constraint binds, the increase in $\mu_{2}$ raises the marginal cost of borrowing. The next two are asset pricing equations that lie at the heart of the 
key mechanisms discussed in this paper. From the third equation, the capital price is determined by the future foreign currency value of dividends discounted by a rate that is proportional to the intertemporal substitution of tradable consumption. The multiplier $\mu_{2}$ increases the value of capital serving as collateral. The last equation determines consumption allocation between sectors. The non-tradable good price is proportional to the ratio of tradable and non-tradable consumption. The financial amplification effect underlies the interaction between these two equations. An averse shock in the tradable sector decreases the non-tradable good price through (16) and at the same time depresses the capital price through (15). We also have the complementary slackness condition:

$$
\mu_{2} \geq 0, \quad \mu_{2}\left(\frac{1}{R^{*}} b_{3}-\kappa q_{2}^{K}\right)=0
$$

At $t=1$, the households only make borrowing decisions, taking future problems as given. The Euler equation is

$$
\left(1-\tau_{1}^{M P}\right) u_{C T}(1)=\beta R^{*} \mathbb{E}\left[u_{C T}(2)\right]
$$

The households choose an optimal level of borrowing so that the marginal benefit equals to the marginal cost. How does the financial crisis affect the first period borrowing? In choosing an optimal level of debt, the households are forward-looking and anticipate the probability and severity of debt crisis in the future. So, they are facing a trade-off between the front-loaded consumption and precautionary savings. I will show below that the optimal spending policy successfully mitigates the cost of crisis and increases the amount of borrowing in normal times.

The solution of the competitive equilibrium is characterized by equation (7)-(18).

\subsection{Optimal Government Spending: Discretionary and Commitment}

It is well-documented in the literature that a financially constrained economy is subject to pecuniary externalities both before and during a crisis. In the above model, negative endowment shock on $y_{2}^{T}$ creates downward pressure on the capital price, making the benefit of borrowing decrease. Since asset prices are aggregate variables, an atomistic agent fails to internalize the effect of its borrowing decision on asset prices, and thus the borrowing capacity of others. As a result, allocations of the competitive equilibrium are inefficient. The government's problem, however, can incorporate this effect. By choosing the right policy instruments (e.g. capital control tax, spending, etc.), the government can correct these externalities and move the equilibrium closer to the constrainedefficient outcome.

In this subsection, I first define the optimal policy, then restrict the problem to the case where only government spending policy is available. The problem also depends on whether the period 2 government is able to commit fiscal policy in period 3. So, I first consider the discretionary government's policy and then go to the optimal policy under commitment.

Generally, the discretionary optimal policy can be defined recursively. In each period, the government chooses all current allocations taking private equilibrium conditions and the future 
government's problem as given. In the example above, let $V_{t}\left(S_{t}\right)$ be the value function at the beginning of period $\mathrm{t}$, defined over the state-space $S_{t}=\left(B_{t}, y_{t}^{T}\right)$. Using curly letters to denote functionals on the state-space, we have the following definition:

DeFINITION 2. The discretionary optimal policy of the model is defined as value functions $\left\{V_{t}\right\}_{t=1}^{3}$, policy functions of allocations $\left\{\mathcal{C}_{t}^{N}\right\}_{t=2}^{3},\left\{\mathcal{C}_{t}^{T}\right\}_{t=1}^{3},\left\{\mathcal{G}_{t}^{N}\right\}_{t=2}^{3},\left\{\mathcal{G}_{t}^{T}\right\}_{t=2}^{3}, \mathcal{L}_{2},\left\{\mathcal{B}_{t+1}\right\}_{t=1}^{2}$ and prices $\mathcal{P}_{2}^{N}, \mathcal{P}_{3}^{N}, \mathcal{Q}_{2}^{K}, \mu_{2}^{D, S P}$ such that: for each $t=1,2$, given future policy and value functions, the current policies solve the following problem ${ }^{19}$

$$
V_{t}\left(S_{t}\right)=\max _{\left\{c_{t}^{T}, c_{t}^{N}, g_{t}^{T}, g_{t}^{N}, B_{t+1}, l_{t} q_{t}^{K}, \mu_{t}^{D, S P}, p_{t}^{N}\right\}}\left(\log \left(c_{t}\right)-\chi \frac{l_{t}^{1+\nu}}{1+\nu}+\eta_{G} \log \left(g_{t}\right)\right)+\beta \mathbb{E} V_{t+1}\left(S_{t+1}\right),
$$

subject to the resource constraints of equations (8)-(12) and the implementability constraints of equations (7) and (13)-(18). Variable $\mu_{t}^{D, S P}$ is the Lagrangian multiplier on collateral constraint for the discretionary optimal policy problem.

This formulation of optimal policy follows the "primal approach" with the government choosing allocations subject to implementability constraints and leaving asset prices market-determined. In the numerical solution below, I use the method of a time-consisitent social planner's problem in Mendoza \& Bianchi (2015). They show that the complete formulation of optimal policy defined by the "primal approach" is equivalent to the social planner's "recursive constrained-efficient equilibrium" where redundant constraints are dropped ${ }^{20}$.

The important implementability constraints here are asset pricing equations (15) and (16). In choosing comsumption and borrowing, the government internalizes the effect on $p^{N}$ and $q^{K}$, and thus the financial constraint, making the social marginal value of wealth different from private one. Mendoza \& Bianchi (2015) shows that whether the optimal allocations can be decentralized depends on policy instruments and with debt taxes available, the constrained-efficient outcome can be decentralized. Since I emphasize the net effect of government spending in this paper, I assume away the state-contingent tax from the second period. The marginal value of wealth is still evaluated at its social level from the government's perspective.

One thing to notice is that the capital price (in equation (15)) is defined in a recursive way: the capital price today depends on future prices and policies. In this simple economy, once the financial constraint is binding in period 2, the government wishes the period 3 government to increase real exchange rate, because this helps the period 2 government increase the capital price and relax the financial constraint. However, when period 3 arrives, the past benefit is sunk and the government does not consider the effect of its decisions on the period 2 problem. Therefore, a time-inconsistency problem arises. The optimal policy of the discretionary government is sub-optimal relative to the

\footnotetext{
${ }^{19}$ Since there is no financial constraint in period 1 and period 3, the problem could be reduced. But to save space, I set out the problem in general form here.

${ }^{20}$ Similarly, Biljanovska (2017) also shows the more and less restricted Ramsey plans are possibly equivalent depending on the set of policy instruments.
} 
solution under commitment. The government is willing to make commitment on future policies to alleviate the severity of financial crisis, only it cannot credibly do so since its incentives change once next period arrives. Now, I define the optimal policy under commitment as the following:

DEFINITION 3. The optimal policy under commitment is to choose all allocations $\left\{c_{t}^{N}\right\}_{t=2}^{3}$, $\left\{c_{t}^{T}\right\}_{t=1}^{3},\left\{g_{t}^{N}\right\}_{t=2}^{3},\left\{g_{t}^{T}\right\}_{t=2}^{3}, l_{2},\left\{b_{t+1}\right\}_{t=1}^{2}$ and prices $\left\{p_{2}^{N}, p_{3}^{N}, q_{2}^{K}, \mu_{2}^{C, S P}\right\}$ at time 1 to maximize the lifetime utility (1) subject to resource constraints of (8)-(12) and implementability constraints (7) and (13)-(18). Variable $\mu_{t}^{C, S P}$ is the Lagrangian multiplier on collateral constraint for the commitment problem.

\subsection{Analysis}

\subsubsection{Illustration of Periods 2 and 3}

The model described in the previous subsection is rich enough to display the non-linear feature of fiscal policy. Before going to the solution of optimal policies, I analyze the effect of government spending $\left\{g_{2}^{N}, g_{2}^{T}, g_{3}^{N}, g_{3}^{T}\right\}$ on period 2 and 3 . To get some intuition, consider the non-tradable good price

$$
p_{2}^{N} \uparrow=\frac{u_{c N}(2)}{u_{c T}(2)}=\frac{1-\omega}{\omega}\left(\frac{y_{2}^{T}-g_{2}^{T} \downarrow-b_{2}+\frac{1}{R^{*}} b_{3} \Uparrow}{y_{2}^{N}-g_{2}^{N} \uparrow}\right)^{\frac{1}{\theta}},
$$

where I plug-in the market clearing conditions. The government spending has a direct effect on the non-tradable good price, but this effect depends on its composition (or home-bias $\omega^{G}$ ). All else equal, a higher non-tradable spending (or lower tradable spending) increases $p_{2}^{N}$. The higher $p_{2}^{N}$ pushes up labor demand and increases the non-tradable good production.

In addition to the direct effect, the collateral constraint creates an induced effect through the capital price. It works through two channels. First, because a higher $p_{2}^{N}$ makes the tradable good relatively cheaper, the agent becomes wealthier and the level of final consumption increases, especially when the elasticity of substitution $\theta$ is low. The higher consumption lowers the rate at which households discount dividends, increasing the capital price (Wealth Channel). Second, because the debt is denominated in foreign currencies while the collateral is a domestic asset, the higher $p_{3}^{N}$ increases the value of dividends at time 3 and also boosts the period 2 capital price (Currency Mismatch Channel). Through these two channels, the increase (decrease) in nontradable (tradable) government purchase reverses the debt-deflation effect and relaxes the financial constraint when it binds.

Figure 5 illustrates the conditional effect of the increase in $g_{2}^{N}$ or $g_{3}^{N}$ on the period 2 borrowing. If the financial constraint does not bind (left panel), the borrowing level is determined by optimality condition (14). An increase in $g_{2}^{N}$ crowds-out $c_{2}^{N}$. Because tradable and non-tradable goods are complements, the marginal benefit of borrowing decreases. As a result, equilibrium borrowing $\left(b_{3}^{*}\right)$ is also reduced. However, if the constraint binds (right panel), the level of borrowing is restricted by the capital price, which in turn depends on the borrowing level itself. An increase in $g_{2}^{N}$ and 

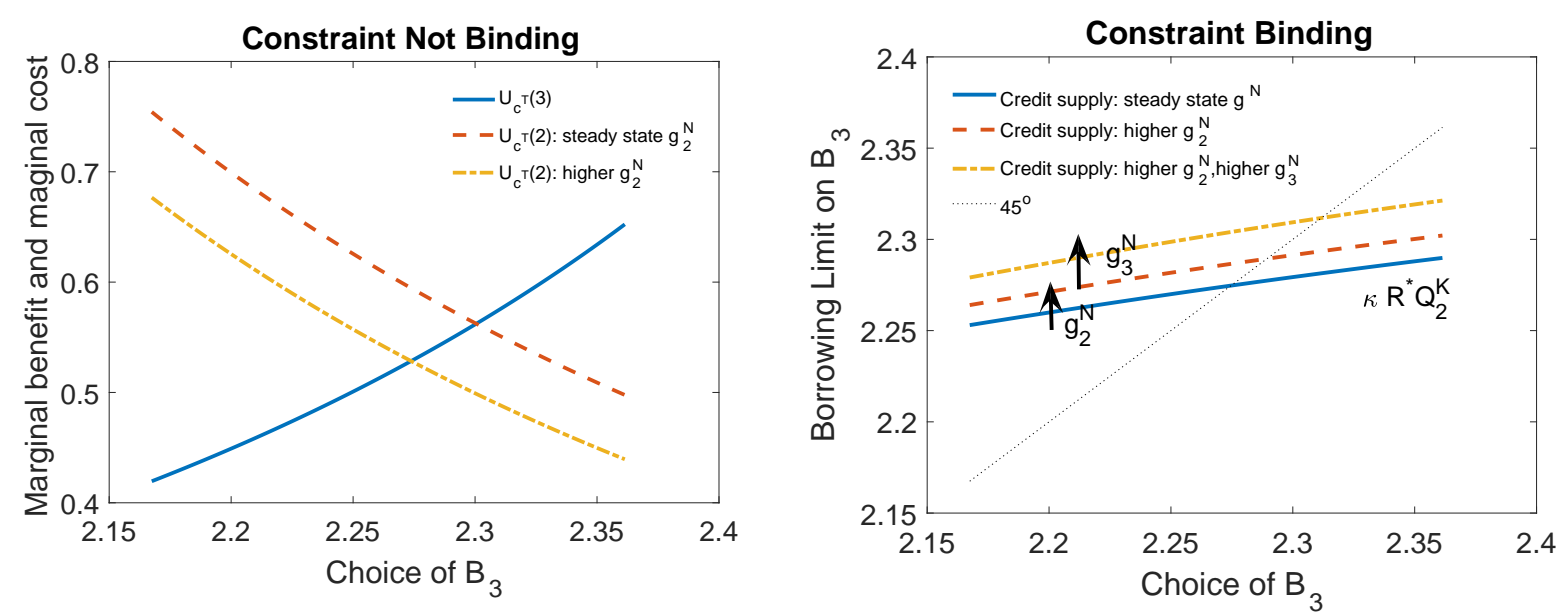

Figure 5: Conditional Effect of Government Spending on Private Borrowing

Note: The left panel shows the effect of $g_{2}^{N}$ on the marginal benefit and marginal cost of borrowing when the financial constraint does not bind. The right panel shows the effect of $g_{2}^{N}, g_{3}^{N}$ on capital price $q_{2}^{K}$ and borrowing capacity in the second period.

$g_{3}^{N}$ props up the capital price through the channels discussed above, enlarging agents' borrowing capacity. The endogenous feedback loop is also present. The higher borrowing and the associated real absorption in turn raise $p_{2}^{N}$ and $q_{2}^{K}$, which further relaxes the financial constraint. In the end, this turns the vicious cycle into a virtuous one.

\subsubsection{Result: Periods 2 and 3}

What does the optimal government spending look like? Firstly, in the problem of discretionary policy, the government chooses the current spending level, only considering its contemporary effect on capital price. The related first order conditions are:

$$
\begin{aligned}
& \lambda_{2}^{D, T}=u_{C T}(2)+\frac{\kappa \mu_{2}^{D, S P}}{1-\kappa \mu_{2}^{D, S P}} \frac{\partial \beta \Lambda_{2,3}\left[p_{3}^{N} F_{k}(3)\right]}{\partial c_{2}^{T}}=u_{G T}(2) \\
& \lambda_{2}^{D, N}=u_{C N}(2)+\frac{\kappa \mu_{2}^{D, S P}}{1-\kappa \mu_{2}^{D, S P}} \frac{\partial \beta \Lambda_{2,3}\left[p_{3}^{N} F_{k}(3)\right]}{\partial c_{2}^{N}}=u_{G N}(2)
\end{aligned}
$$

where $\Lambda_{2,3}=\frac{u_{C T}(3)}{u_{C T}(2)}$ is the consumption pricing kernel. Notice that the marginal values of wealth $\lambda_{2}^{D, T}, \lambda_{2}^{D, N}$ in both sectors are evaluated from the social perspective, incorporating the externalities of consumption on the financial constraint. This is different from the marginal utility when $\mu_{2}^{D, S P}>$ 0 . If two goods are complementary enough, $\sigma<\frac{1}{\theta}$, we have $\frac{\partial \Lambda_{2,3}}{\partial c_{2}^{T}}>0$ and $\frac{\partial \Lambda_{2,3}}{\partial c_{2}^{N}}<0$. This gives the period 2 government an incentive to increase (decrease) the non-tradable (tradable) spending when the financial constraint is binding.

Now, consider the optimal policy under commitment. Given that there is no financial constraint in period 1 , the period 2 problem under commitment is similar to the discretionary one. However, the period 3 government also internalizes the effect of its decisions on the past financial constraint. 
The related first order conditions are:

$$
\begin{aligned}
& \lambda_{3}^{C, T}=u_{C T}(3)+\frac{\kappa \mu_{2}^{C, S P}}{1-\kappa \mu_{2}^{C, S P}} \frac{\partial \beta \Lambda_{2,3}\left[p_{3}^{N} F_{k}(3)\right]}{\partial c_{3}^{T}}=u_{G T}(3) \\
& \lambda_{3}^{C, N}=u_{C N}(3)+\frac{\kappa \mu_{2}^{C, S P}}{1-\kappa \mu_{2}^{C, S P}} \frac{\partial \beta \Lambda_{2,3}\left[p_{3}^{N} F_{k}(3)\right]}{\partial c_{3}^{N}}=u_{G N}(3)
\end{aligned}
$$

where $\lambda_{3}^{C, T}, \lambda_{3}^{C, N}$ are the social marginal values of wealth at time 3 under commitment. The signs of these two externalities are ambiguous. However, with proper parameter values, I show that $\frac{\partial \Lambda_{2,3}}{\partial c_{3}^{N}}<0$, which means it is beneficial to commit to a higher level of non-tradable spending in period 3 whenever the constraint binds in period 2.
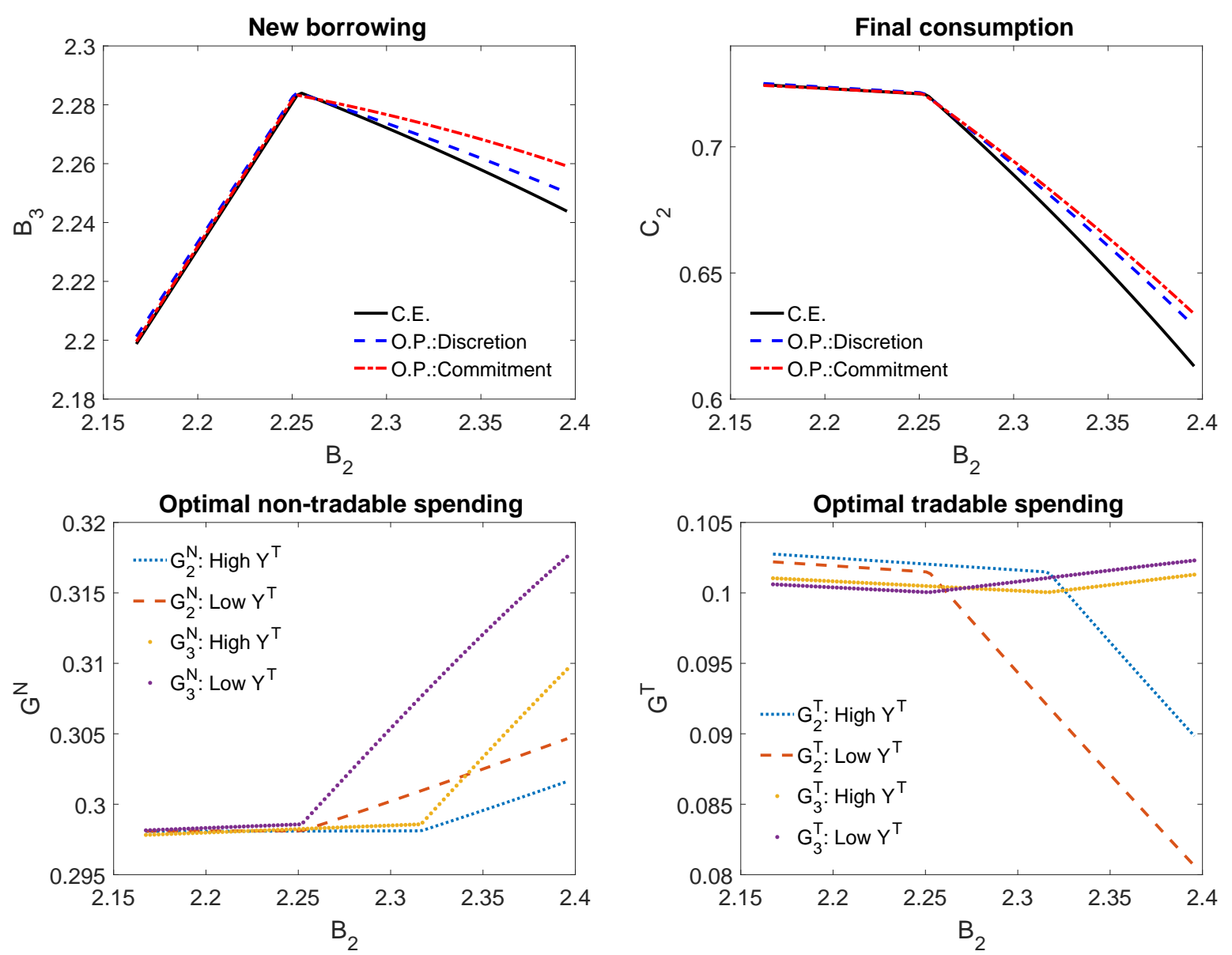

Figure 6: The Optimal Government Spending and Financial Constraint

Note: The upper panel shows the equilibrium borrowing and consumption decisions in the second period for the case of competitive equilibrium (black), discretionary optimal spending (blue), and the optimal spending under commitment (red). The lower panel shows the shape of the optimal government spending across debt state.

The policy functions are displayed in figure 6. First of all, consistent with the intuition provided, the optimal government spending displays non-linear features both during and after a financial crisis. In period 2, the government increases $g_{2}^{N}$ (decreases $g_{2}^{T}$ ) at high-debt states where the 
financial constraint is binding. The optimal policies enable the government to relax the financial constraint and increase borrowing (upper left panel). The upper right panel of figure 6 shows that even in this three-period model, the financial effect of government spending is strong enough that final consumption is crowded-in. Secondly, with a commitment measure, the government also increases $g_{3}^{N}$ at high-debt states, which further relaxes the financial constraint. The commitment effect of $g_{3}^{T}$ is quite small.

One thing to notice from the model is that the major role of government spending comes from its impact on asset prices. Whether an increase in asset prices has favorable effect on real activities depends on whether the financial constraint binds or not, which implies the state-dependence of fiscal stimulating effect.

\subsubsection{Result: Period 1}

How does the presence of optimal spending during crisis affect borrowing in the first period and the welfare? In the optimal policy problem, the period 1 borrowing is determined by the following Euler equation:

$$
\frac{1}{R^{*}} u_{C T}(1)=\beta \mathbb{E}[u_{C T}(2)+\underbrace{u_{C T}(2) \frac{\kappa \mu_{2}^{S P}}{1-\kappa \mu_{2}^{S P}} \frac{\partial \beta \Lambda_{2,3}\left[p_{3}^{N} F_{k}(3)\right.}{\partial c_{2}^{T}}}_{\text {Pecuniary Externality } \tau_{1}^{M P}}] .
$$

First, private agents fail to consider the social cost of borrowing in inviting greater likelihood of the financial crisis tomorrow, which is the emphasized over-borrowing phenomenon in the literature (e.g., Bianchi, 2011). Second, with the proper fiscal policy managing the crisis ex post, the financial crisis becomes less costly and the precautionary motive in the first period is even smaller compared to the case without ex post policy ${ }^{21}$. Moreover, with different policy instruments available ex post, the borrowing externality in period 1 is also different. These conflicting incentives are illustrated by comparing the marginal benefits and marginal costs of borrowing, as shown in appendix E.3.

Table 2 shows the equilibrium borrowing and welfare. Consistent with the intuition, the optimal government spending mitigates the pain of financial crisis, reducing the precautionary motives. As a result, the agents borrow more under optimal policies, followed with the higher probability of crisis. The macro-prudential tax is a measure to represent the pecuniary externality and it depends on both the probability and the severity of a crisis. From the table, even when the economy is more indebted under the optimal spending policies, the macro-prudential tax rate is still smaller. The optimal spending policies generally increase the welfare to private agents. The welfare benefit mainly comes from two reasons: the smaller precautionary saving motives make agents more able to front-load consumption, while the cost of crisis is also alleviated by ex post fiscal stimulus.

\footnotetext{
${ }^{21}$ Benigno et al. (2016) explains how the presence of different ex post policy can affect the role of ex ante policy.
} 


\begin{tabular}{|c|c|c|c|}
\hline & C.E. with $\tau_{1}^{M P}$ & Optimal $G_{2}$ & Optimal $G_{2}, G_{3}$ \\
\hline$B_{2}^{*}$ & 2.2713 & 2.2739 & 2.2744 \\
\hline Prob. of Crisis $\left(\mathbb{P}\left(\mu_{2}>0\right)\right)$ & 0.52 & $0 . \overline{5} 4$ & 0.54 \\
\hline Sev. of Crisis $\left(\mathbb{E} \mu_{2}\right)$ & 0.0519 & 0.0488 & 0.0484 \\
\hline$\tau_{1}^{M P}$ & 0.0237 & 0.0221 & 0.0216 \\
\hline$V_{1}$ & -1.2396 & -1.2366 & -1.2375 \\
\hline
\end{tabular}

a. C.E. means the competitive equilibrium with government spending fixed at its steady state. In order to explore the net welfare benefit of the optimal spending policy, I assume there is always an optimal capital control (state-contingent tax) on debt in the first period. So, the increase in equilibrium borrowing $\left(B_{3}^{*}\right)$ indicates the cost of crisis becomes smaller when government spending is used to manage crisis after it happens.

b. To be consistent with the full model where government spending is wasteful, here I consider the welfare implication of fiscal policy on private agents. $V_{1}$ means the life-time welfare from private utilities, which is

$$
V_{1}=\log \left(c_{1}^{T}\right)+\mathbb{E}_{1}\left[\beta\left(\log \left(c_{2}\right)-\chi \frac{l_{2}^{1+\nu}}{1+\nu}\right)+\beta^{2}\left(\log \left(c_{3}\right)\right)\right] .
$$

That explains why the welfare under commitment is smaller than the one under discretionary policy.

Table 2: Three-Period Model

\subsection{Quantifying the Static Multipliers}

Given the analysis above, it is natural to explore how the spending multiplier depends on the states of the economy. In this section, I treat the government spending as exogenous and in fixed proportion between the two sectors. I define the static multiplier at time 2 as: $\frac{\Delta x_{2}}{\Delta g_{2}}$, where $x_{2}$ is the variable of our interests. Figure 7 shows the multiplier on tradable consumption $c_{2}^{T}$ across different parameter spaces. The multipliers of other endogenous variables are shown in appendix E.3.

First, we know from the optimal policy analysis that a promised fiscal expansion in the future relaxes the current financial constraint and enhances the ability to borrow. Therefore, the higher shock persistence (larger $\rho_{G}$ ) implies a higher multiplier on $c_{2}^{T}$. Second, since the financial effect of government spending works through the non-tradable good price, parameter values making $p_{2}^{N}$, $p_{3}^{N}$ more sensitive to a government spending shock can potentially generate higher multipliers. The lower elasticity of substitution (smaller $\theta$ ) makes the wealth effect stronger under a positive shock, thus increasing fiscal multipliers during crisis. The larger degree of home-bias on government consumption (smaller $\omega_{G}$ ) creates a larger increase in $p_{2}^{N}$ for a positive shock of given size, increasing the multipliers. Lastly, the smaller size of the tradable sector (smaller $\omega$ ) also implies the higher multipliers when the constraint binds.

In summary, this section studies the state-dependent effect of government spending in an optimal policy environment. The model implies that with enough home-bias and a large degree of complementarity, the increase in government spending is more stimulative during a financial crisis than during normal times. Under policy commitment, the promised fiscal expansion has further expansionary effect on private activities. 

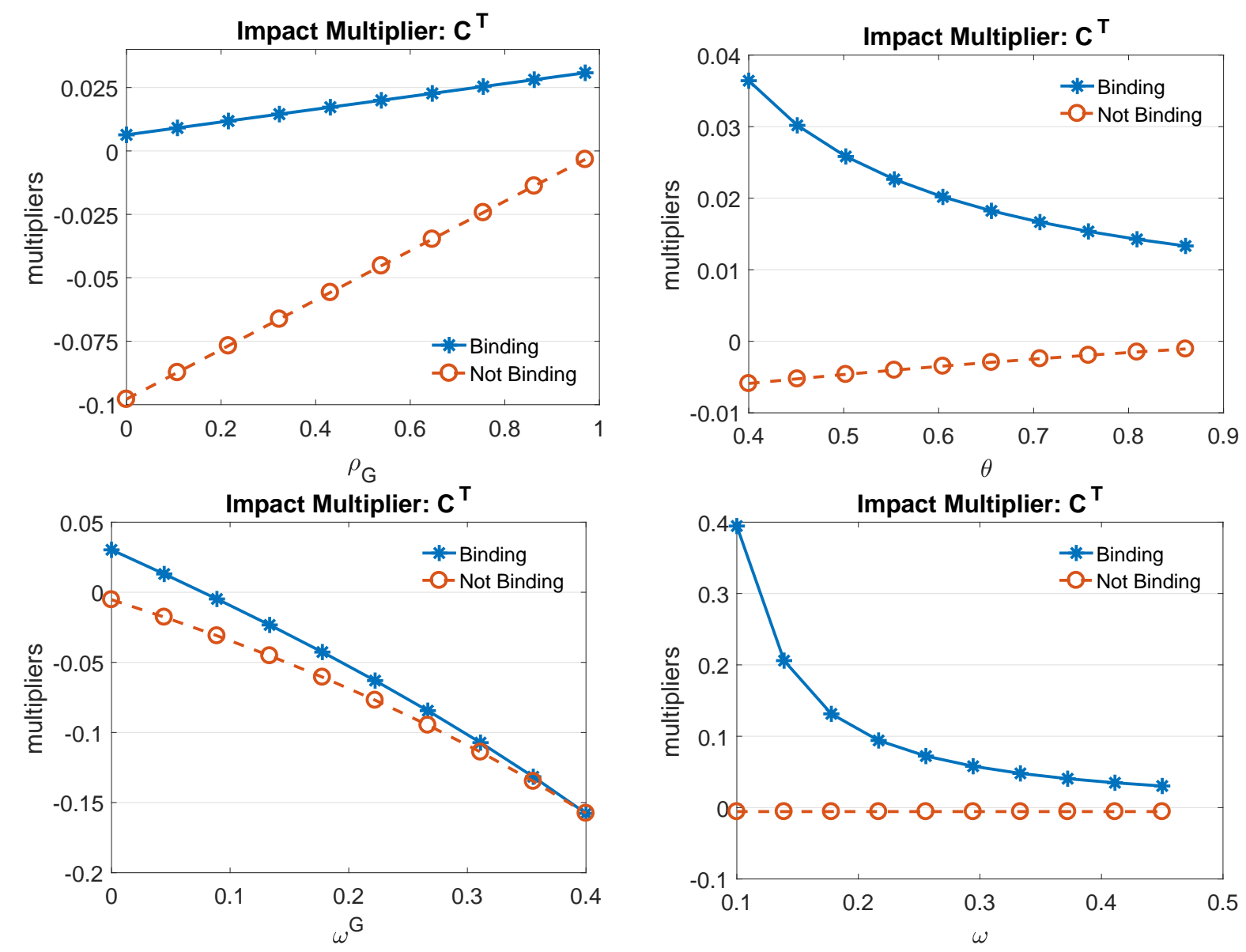

Figure 7: The Spending Multiplier and Financial Constraint

Note: The simulated multipliers $\frac{\Delta c_{2}^{T}}{\Delta g_{2}}$ here depend on the beginning state in period 2: $\left(b_{2}, y_{2}^{T}, g_{2}\right)$. Suppose the non-binding (binding) state is $y_{2}^{T}=1.01\left(y_{2}^{T}=0.99\right)$ while $b_{2}$ and $g_{2}$ are kept at their mean values. The benchmark parameter values are $\rho_{G}=0.95, \theta=0.45, \omega^{G}=0, \omega=0.35$ respectively, and I change one parameter at a time. I assume government purchases are allocated to tradable and non-tradable sectors in fixed proportion: $g_{t}=\min \left\{\frac{g_{t}^{T}}{\omega^{G}}, \frac{g_{t}^{N}}{1-\omega^{G}}\right\}$ for $t=2,3$, and they follow a persistent process: $g_{3}=\bar{g}^{1-\rho_{G}} g_{2}^{\rho_{G}}$ where $\bar{g}$ is the steady state.

\section{$4 \quad$ Full Model}

This section extends the three-period model to an infinite horizon envioronment. There are two differences: 1) I impose a working-capital constraint on the firms' problem as in Mendoza (2010) so that the financial condition has a direct impact on domestic production, and 2) the firms' labor demand is subject to DNWR in the spirit of Schmitt-Grohé \& Uribe (2016). This way to model the labor market friction captures the cyclical unemployment in SOE financial crises which I use to consider how my government spending channel behaves under different exchange rate systems ${ }^{22}$. In the quantitative analysis below, the demand channel and the financial friction are two important

\footnotetext{
${ }^{22}$ Many papers use this form of one-side rigidity to account for the asymmetry over the business cycle (e.g., Castro et al., 2013; Ottonello, 2012). The motivation lies in that crisis scenario usually embodies a temporary increase in the degree of both the financial frictions and nominal frictions.
} 
factors in explaining the business-cycle-dependent multipliers, and I study the interaction of these two channels and their relative importance. The government spending processes are exogenous. There are three agents in the economy: an infinitely lived firm-household makes consumption and production decisions, the government conducts fiscal policy, and the central bank makes exchange rate policy. The international debt market is incomplete, as in the previous model.

\subsection{Firm-Household}

The representative firm-households have life-time utility:

$$
\mathbb{E}_{0}\left[\sum_{t=0}^{\infty} \beta^{t} u\left(c_{t}, l_{t}\right)\right],
$$

where $c_{t}$ denotes the final consumption basket as in equation $(2) . \mathbb{E}_{t}$ is the expectation operator conditional on information available at time t. I assume the per-period utility function takes the separable form

$$
u\left(c_{t}, l_{t}\right)=\frac{c_{t}^{1-\sigma}-1}{1-\sigma}-\chi \frac{l_{t}^{1+\nu}}{1+\nu} .
$$

Parameter $\sigma$ is the relative risk aversion, while $\chi$ is the weight on labor disutility and $\nu$ denotes the labor elasticity.

The firm-households are consolidated agents with separable decision-making incentives based on their social status. One one hand, the households earn wage income, get tradable endowment, and consume tradable and non-tradable goods. They issue debt in the international market to smooth consumption. On the other hand, the firms hire labor, make production and investment, and borrow working-capital loans. The non-tradable good production follows

$$
y_{t}^{N}=z_{t} F\left(k_{t}, l_{t}^{d}\right)
$$

where the T.F.P. process $z_{t}$ is an exogenous $\mathrm{AR}(1)$ process

$$
\log \left(z_{t}\right)=\rho_{z} \log \left(z_{t-1}\right)+\epsilon_{z, t}
$$

with i.i.d. shock $\epsilon_{z, t} \sim \mathbb{N}\left(-\frac{1}{2} \sigma_{z}^{2}, \sigma_{z}^{2}\right)$. To account for disequilibrium in the labor market, I use $l_{t}^{d}$ to denote the labor demand of firms, which could be different from the labor supply $l_{t}$, as specified below. The production function has non-increasing returns to scale: $F\left(k_{t}, l_{t}^{d}\right)=k_{t}^{\alpha_{K}} l_{t}^{d, \alpha_{L}}$, with $\alpha_{K} \geq 0, \alpha_{L} \geq 0$ and $\alpha_{K}+\alpha_{L} \leq 1$.

Labor and capital are owned by the households. The households borrow from foreign investors by issuing short-term bonds, denominated in foreign currency units. The gross interest rate is $R^{*}$. The budget constraint denominated in the local currency is given by

$$
E_{t} c_{t}^{T}+P_{t}^{N} c_{t}^{N}+Q_{t}^{K}\left(k_{t+1}-k_{t}\right)+E_{t} b_{t}+=E_{t} y_{t}^{T}+W_{t} l_{t}+R_{t}^{K} k_{t}+\frac{1}{R^{*}} E_{t} b_{t+1}-E_{t} T_{t}+E_{t} \pi_{t} .
$$


The nominal exchange rate is denoted by $E_{t} . P_{t}^{N}$ is the nominal non-trdable good price. $Q_{t}^{K}$ is the nominal price of capital. $W_{t}$ and $R_{t}^{K}$ are nominal wage rate and rent of capital. $T_{t}$ is the lump-sum tax/subsidy collected by the government. I assume firm's profit $\pi_{t}$ is rebated back to households in a lump-sum fashion. The tradable endowment $y_{t}^{T}$ follows an $\operatorname{AR}(1)$ process

$$
\log \left(y_{t}^{T}\right)=\left(1-\rho_{y^{T}}\right) \bar{y}^{T}+\rho_{y^{T}} \log \left(y_{t-1}^{T}\right)+\epsilon_{y^{T}, t},
$$

with i.i.d. shock $\epsilon_{y^{T}, t} \sim \mathbb{N}\left(-\frac{1}{2} \sigma_{y^{T}}^{2}, \sigma_{y^{T}}^{2}\right)$. The domestic average price level is defined as

$$
P_{t}=\left(\omega^{\theta} E_{t}^{1-\theta}+(1-\omega)^{\theta} P_{t}^{N(1-\theta)}\right)^{\frac{1}{1-\theta}}
$$

Here, I assume the foreign price level is constant, $P_{t}^{*} \equiv 1$. Define the real exchange rate as the price of the final consumption good in terms of tradables ${ }^{23}$. Then the real exchange rate equals the nominal exchange rate adjusted by the relative price levels

$$
r e x_{t}=\frac{1}{E_{t}} \frac{P_{t}}{P_{t}^{*}}=\left(\omega^{\theta}+(1-\omega)^{\theta} p_{t}^{N(1-\theta)}\right)^{\frac{1}{1-\theta}}
$$

where $p_{t}^{N}=\frac{P_{t}^{N}}{E_{t}}$ is the real price of the non-tradable good. Note that the real exchange index $r e x_{t}$ is proportional to $p_{t}^{N}$. This makes it convenient to use the tradable good as the numeraire and re-express the budget constraint as

$$
c_{t}^{T}+p_{t}^{N} c_{t}^{N}+q_{t}^{K}\left(k_{t+1}-k_{t}\right)+b_{t}+=y_{t}^{T}+w_{t} l_{t}+r_{t}^{K} k_{t}+\frac{1}{R^{*}} b_{t+1}-T_{t}+\pi_{t}
$$

where I use the lower case to denote the relative prices with respect to tradable units, i.e. $w_{t}=\frac{W_{t}}{E_{t}}$, $r_{t}^{K}=\frac{R_{t}^{K}}{E_{t}}, q_{t}^{K}=\frac{Q_{t}^{K}}{E_{t}}$.

The financial market is incomplete and the total credit available is restricted by the value of collateral. There are two types of credit: bond issuance and a working capital loan. The bond is due after one period; the working-capital loan is an intra-period contract and does not bear any interest $^{24}$. The form of the collateral constraint is

$$
\frac{1}{R^{*}} b_{t+1}+\phi w_{t} l_{t} \leq \kappa q_{t}^{K} k_{t+1}
$$

The parameter $\kappa$ governs the maximum leverage of the economy. In the solution part below, I use this parameter to target the country's indebtedness. Before production, the firms are supposed to prepay a fraction $\phi$ of the wage bill out of the pocket.

\footnotetext{
${ }^{23}$ This is different from the common practice in the literature where the real exchange rate is the relative price of the foreign numeraire in terms of local consumption goods. In my definition, the higher value of rex $_{t}$ means local currency appreciation.

${ }^{24}$ In the working capital constraint of Neumeyer \& Perri (2005), hiring factor inputs carries a financing cost determined by $R^{*}$ and thus the decision responds to interest rate shocks. I abstract from that part to simply the problem and to isolate the direct effect of asset price fluctuation on production.
} 
Similar constraints have been used by many papers in the small open economy enviornment, such as in Mendoza (2010) and Fornaro (2015). In this paper, I do not explicitly derive the credit constraint as the outcome of an optimal contract between lenders and borrowers. Instead, this collateral constraint represents the reduced form of an environment in which informational and institutional frictions affect the credit relationship between domestic and foreign agents. In economic downturns, the depreciating capital price restricts internatinal borrowing and makes the private agents reduce their consumption level. The lower aggregate consumption further reduces the capital price and sets-in the Fisher's debt-deflation channel, the same as before. From the quantitative side, the severe economic recession driven by asset price deflation is a favorable feature of this model which provides a good laboratory to study sudden stop behavior of small open economies. From the theory side, this environment incorporates two types of pecuniary externalities emphasized by Dávila \& Korinek (2017), since the agents take aggregate prices (such as $w_{t}, p_{t}^{N}$ and $q_{t}^{K}$ ) in the budget and collateral constraint as given, but ignore the effect of their individual decisions on these prices and how that changes the feasibility set of others.

Given prices and shocks, the household's problem is to choose $\left\{c_{t}^{T}, c_{t}^{N}, l_{t}, k_{t+1}, b_{t+1}\right\}_{t=0}^{\infty}$, maximizing the life-time utility (24) subject to (31) and (32). The firm's problem is to maximize its profits:

$$
\pi_{t}=\max _{\left\{k_{t}, l_{t}^{d}\right\}}\left\{p_{t}^{N} z_{t} F\left(k_{t}, l_{t}^{d}\right)-w_{t} l_{t}^{d}-r_{t}^{K} k_{t}\right\}
$$

The model is solved by taking first order conditions. The relative consumption demand is determined by

$$
p_{t}^{N}=\frac{1-\omega}{\omega}\left(\frac{c_{t}^{T}}{c_{t}^{N}}\right)^{\frac{1}{\theta}} .
$$

The bond Euler equation is given by

$$
\frac{1}{R^{*}} u_{C T}(t)\left(1-\mu_{t}\right)=\beta \mathbb{E}\left[u_{C T}(t+1)\right]
$$

where $\mu_{t}$ is the Lagrangian multiplier on the collateral constraint. The left-hand side denotes the marginal utility of borrowing one unit of tradable good in increasing current consumption. If the collateral constraint does not bind $\left(\mu_{t}=0\right)$, this is equated to the expected utility of repaying foreign currency bonds and sacrificing consumption in period $t+1$. When the financial constraint binds $\left(\mu_{t}>0\right)$, the household is not free to borrow as much as it would like to and the marginal benefit of borrowing falls short of the marginal cost. Also note that this term can distort the household' decisions at time $t$ even if the constraint is not binding at time $t$ but there is a positive probability that it binds in $t+1$. That results in lower tradable consumption (i.e., more precautionary savings) than in an economy without a borrowing constraint.

The capital Euler equation is

$$
u_{C T}(t)\left(1-\kappa \mu_{t}\right) q_{t}^{K}=\beta \mathbb{E}\left\{u_{C T}(t+1)\left[q_{t+1}^{K}+p_{t+1}^{N} z_{t+1} F_{k}\left(k_{t+1}, l_{t+1}^{d}\right)\right]\right\} .
$$


The capital price is determined by future values of dividends, discounted by a subjective discounting factor. The right-hand side shows the return on capital depends on the value of marginal product of capital and its re-selling price, which in turn relies on future prices $p_{t+1}^{N}$ and $q_{t+1}^{K}$. First, under the occasionally binding financial constraint, capital serves as collateral, increasing the marginal benefit of buying the asset. Second, due to the currency mismatch, the fluctuation of future non-tradable good prices, not the current price, affects the current capital price. But since the current non-tradable good price is determined by supply and demand, it is also influenced by the current capital price. This creates the time-inconsistency problem, as discussed in the three-period model. Committing to a fiscal policy that appreciates the local currency in the future can help the government earn more financial flexibility today.

The relation between the financial constraint and asset prices can be examined by further exploring these equations. Define the rate of return on capital as $R_{t+1}^{q}=\frac{q_{t+1}^{K}+p_{t+1}^{N} z_{t+1} F_{k}\left(k_{t+1}, l_{t+1}\right)}{q_{t}^{K}}$. Using equation (35) and (36), the expected excess return (i.e. equity premium) on capital can be written as

$$
R_{t}^{E P}=\mathbb{E}_{t}\left[R_{t+1}^{q}-R^{*}\right]=\frac{(1-\kappa) \mu_{t}-\operatorname{cov}\left(\Lambda_{t, t+1}, R_{t+1}^{q}\right)}{\mathbb{E}_{t} \Lambda_{t, t+1}} .
$$

$\Lambda_{t, t+j}=\beta^{j} \frac{u_{C T}(t+j)}{u_{C T}(t)}$ is the j-period stochastic discount factor. In the right hand side, the first term increases when the current financial constraint becomes more binding. For the second term, the expectation of a binding collateral constraint suppresses the rate of return on capital and pushes up the discounting factor. This means the covariance is more negative in economic downturns. Since $R_{t}^{E P}$ is a good proxy for the financial status of the economy, in the numerical exercise below, I will compare that to its counterpart in the data.

Combining labor demand and labor supply, we have

$$
w_{t}^{f}=\frac{u_{L}\left(c_{t}, l_{t}\right)}{u_{C T}\left(c_{t}, l_{t}\right)}=\frac{p_{t}^{N} F_{l}\left(k_{t}, l_{t}^{d}\right)}{1+\phi \mu_{t}}
$$

where $w_{t}^{f}$ is the effective wage earned by households. The financial constraint has both a direct and an indirect effect on labor hiring, and thus on output production. When the financial constraint binds, $\mu_{t}$ goes up and this makes it more costly for the firms to pledge working capital. As a result, the effective wage earned by the households goes down. The indirect effect comes from the endogenous change of $p_{t}^{N}$. Upon a sudden stop of capital inflows, the reduction of real absorption $\left(c_{t}^{T}\right)$ depreciates local currency $\left(p_{t}^{N}\right)$, suppressing labor demand and production.

\subsection{Downward Nominal Wage Rigidity}

Following Schmitt-Grohé \& Uribe (2016), I allow the nominal wage to be potentially downward rigid. Formally, nominal wages are required to satisfy the following condition:

$$
W_{t} \geq \gamma W_{t-1}
$$


where $\gamma$ controls the degree of wage rigidity. Simple manipulation implies that real wage satisfies

$$
w_{t} \geq \gamma \frac{w_{t-1}}{\epsilon_{t}}
$$

where $\epsilon_{t}=\frac{E_{t}}{E_{t-1}}$ is the growth rate of the nominal exchange rate. The current real wage depends on previous-period wage state and exchange rate policy if this constraint binds, or the labor market optimality condition otherwise. The presence of downward wage rigidity implies that a negative international shock depresses labor demand and could lead to involuntary unemployment $\left(U_{t}\right)$. In the model, the shocks driving the economy into unemployment crisis are almost the same ones causing financial crisis. So, in the downturn, these two types of crises usually happen at the same time and interact with each other, as I will illustrate below. Moreover, the mere possibility that the wage constraint is binding tomorrow can change the effect of spending policy today. In normal times, higher government spending pushes up wage state and increases the probability of an unemployment crisis in the next period. Since the capital price is defined recursively, the expected decline in production will make the collateral constraint more binding today. When $\gamma=0$, the model has a flexible real wage.

\subsection{The Government Spending and Exchange Rate Policy}

The government spending policy follows a Taylor-type of feedback rule:

$$
\log \frac{g_{t}}{\bar{g}}=\rho^{G} \frac{g_{t-1}}{\bar{g}}+\gamma^{Y} \log \frac{g d p_{t-1}}{\overline{g d p}}+\gamma^{B} \log \frac{b_{t-1} / g d p_{t-1}}{\bar{b} / \overline{g d p}}+\epsilon_{t}^{G} .
$$

The real value of GDP in the model is $g d p_{t}=y_{t}^{T}+p_{t}^{N} y_{t}^{N}$. The fiscal shock $\epsilon_{t}^{G} \sim \mathbb{N}\left(-\frac{1}{2} \sigma_{G}^{2}, \sigma_{G}^{2}\right)$. The parameter $\rho^{G}$ indicates the persistence of spending policy. I will investigate the fiscal multiplier for different levels of $\rho^{G}$ below.

For simplicity, I assume government consumption is allocated to the tradable and non-tradable sectors in fixed proportion,

$$
g_{t}=\min \left\{\frac{g_{t}^{T}}{\omega^{G}}, \frac{g_{t}^{N}}{1-\omega_{G}}\right\},
$$

where $\omega^{G}$ is the weight on tradable goods. Then, the relative price of government consumption is $p_{t}^{G}=\omega^{G}+\left(1-\omega^{G}\right) p_{t}^{N}$.

The feedback rule includes past GDP and external debt to account for systematic changes of fiscal policy. For example, the counter-cyclical stabilizers $\left(\gamma^{Y}<0\right)$ in advanced economies indicate that the government systematically reacts to low GDP by providing stimulus. On the other hand, the fiscal policy in emerging economies is found to be pro-cyclical. More recently, many advanced economies are required to adopt austerity measures in order to keep their fiscal budget sustainable. $\gamma^{B}<0$ captures the government spending cuts during external debt overhang periods. For the countries I study in this paper, these two concerns coexist and I calibrate the government spending rule using Mexican data. 
To examine whether the mechanisms apply for countries under different exchange rate regimes, I extend the model to include the flexible exchange rate policies as the following:

$$
\epsilon_{t}=\max \left\{\frac{\gamma w_{t-1}}{w_{t}^{f}}, 1\right\}^{\gamma^{E}},
$$

with $\gamma^{E} \in[0,1] . w_{t}^{f}$ is the potential wage rate at the full-employment status from equation (37). The coefficient $\gamma^{E}=0$ implies a strict nominal peg (as "peg" below), while $\gamma^{E}=1$ is the fullemployment exchange rate policy (as "flex" below). In practice, the exchange rate policy in most countries lies between these two extremes and varies over time. In the baseline analysis, I compare the multiplier effects in the two extreme cases, and I check for other intermediate values of $\gamma^{E}$ in the sensitivity analysis.

\subsection{Competitive Equilibrium}

In the baseline model, I assume the aggregate stock of capital is fixed: $K_{t}=1$. The labor market is in disequilibrium: $l_{t}=l_{t}^{d}+U_{t}$, which is labor supply equals to labor demand plus involuntary unemployment. Using the firm's profits (33) and the household's budget constraint (31), I get the resource constraints:

$$
\begin{aligned}
& c_{t}^{T}+g_{t}^{T}+b_{t}=\frac{1}{R^{*}} b_{t+1}+y_{t}^{T}, \\
& c_{t}^{N}+g_{t}^{N}=y_{t}^{N} .
\end{aligned}
$$

Then, I define the competitive equilibrium as the following:

Definition 4. Given initial conditions $\left\{K_{0}, B_{0}, y_{0}^{T}, z_{0}, g_{0}\right\}$, exogenous processes $\left\{y_{t}^{T}, z_{t}, g_{t}\right\}_{t=0}^{\infty}$, the competitive equilibrium of the full model consists of sequences of allocations $\left\{C_{t}^{T}, C_{t}^{N}, Y_{t}^{N}, L_{t}, L_{t}^{d}, U_{t}, B_{t+1}, K_{t+1}\right\}_{t=0}^{\infty}$ and prices $\left\{w_{t}, q_{t}^{K}, p_{t}^{N}, \epsilon_{t}\right\}_{t=0}^{\infty}$, such that (a) The household maximizes (24) subject to constraints (31) and (32) taking prices and policies as given, (b) The firm maximizes profits (33) taking prices and policies as given, (c) The DNWR constraint (39) holds, (d) The government sets fiscal policy based on (40), (e) The central bank sets exchange rate policy based on (42), (f) The labor and capital market satisfy: $L_{t}=L_{t}^{d}+U_{t}$ and $K_{t}=1$, and (g) The tradable and non-tradable goods market clear.

The solution of the model is characterized by the first order conditions, resources constraints, exogenous process of shocks, and two inequality constraints. The full description of all model equations is in appendix A. 


\subsection{Analysis: The Fisherian Deflation and Unemployment Crisis}

Before proceeding to the numerical results, it is useful to understand the interaction between the financial constraint and DNWR, and to build some intuition on the effect of government spending in this environment. How does the financial constraint affect involuntary unemployment? Is the government spending effect larger or smaller under DNWR?

As before, a negative shock on $y_{t}^{T}$ makes the households' borrowing constrained and tradable consumption declines. The return to capital is discounted at a higher rate, depressing the capital price and making the financial constraint even tighter. The amplification mechanism creates a cycle of falling capital prices, lower borrowing, and a more-binding collateral constraint. At the same time, the declining real absorption also pushes down the exchange rate $p_{t}^{N}$. This means that the financial crisis is usually accompanied by local currency depreciation.
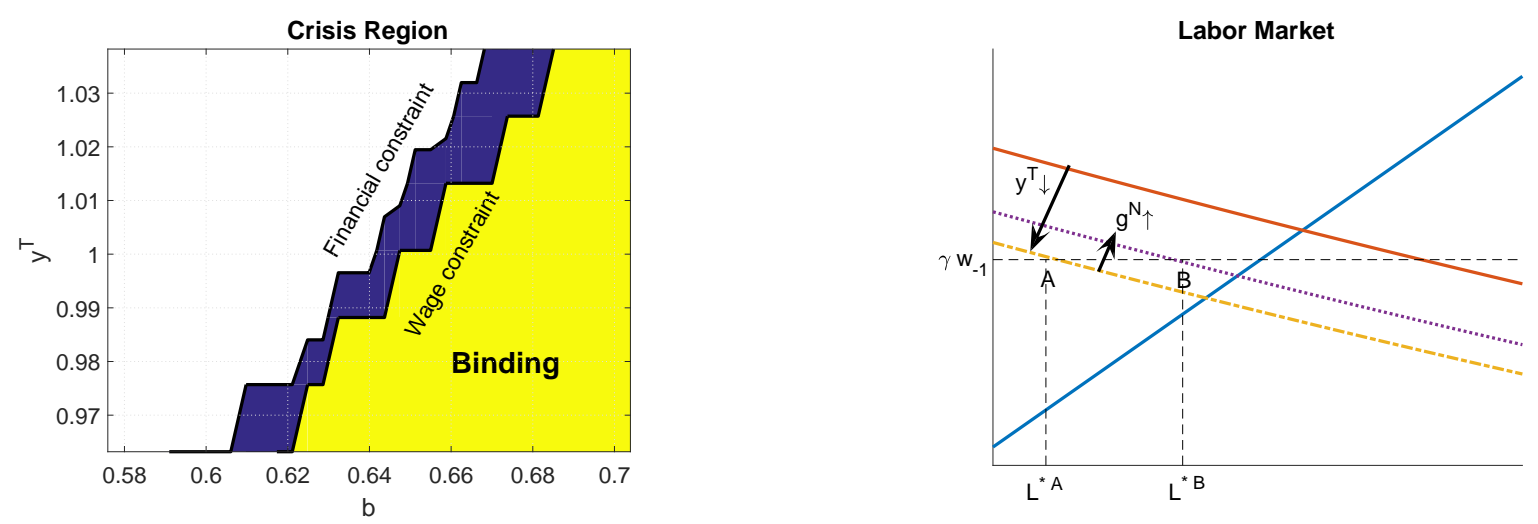

Figure 8: Occasionally Binding Constraints and Involuntary Unemployment

How is the production determined under DNWR? To see this, combine equation (39) and (37) to write the labor market equilibrium as 25

$$
\frac{p_{t}^{N} \downarrow F_{l}\left(k_{t}, l_{t}^{d} \Downarrow\right)}{1+\phi \mu_{t} \uparrow} \geq \gamma w_{t-1}
$$

The binding financial constraint makes $\mu_{t}$ increase and $p_{t}^{N}$ decrease. When the real wage is rigid from downward, the labor is demand-determined and the higher-than-market-clearing effective wage induces firms to reduce hiring. As a consequence, labor demand falls short of labor supply and the economy is driven into involuntary unemployment. The mechanism is illustrated in the right panel of figure 8. The choice is made at point A after a negative shock on $y_{t}^{T}$. The left panel describes the binding areas of the financial constraint and wage constraint across the relevant state spaces. Notice that both constraints bind more often in bad states when debt levels are high or tradable endowments are low.

What is the effect of government spending during the "twin crises"? Rewrite the non-tradable

\footnotetext{
${ }^{25} \uparrow$ means direct effect, and $\Uparrow$ means induced effect.
} 
good price as

$$
p_{t}^{N} \Uparrow \Downarrow=\frac{\omega}{1-\omega}\left(\frac{y_{t}^{T}-b_{t}+\frac{1}{R^{*}} b_{t+1} \Uparrow}{y_{t}^{N} \Uparrow-g_{t}^{N} \uparrow}\right)^{\frac{1}{\theta}} .
$$

The same as before, an increase in $g_{t}^{N}$ has both direct and indirect effects (through $b_{t+1}$ ) on $p_{t}^{N}$, relaxing the financial constraint. The difference here is with DNWR in place, government spending has a stronger stimulative effect on $y_{t}^{N}$ production, lifting the labor choice from point A to point B in the right panel of figure 8 . The expansionary effect on $y_{t}^{N}$ is large enough so that the increase in $p_{t}^{N}$ is partially offset by the overproduction. Notice that this offsetting channel is even stronger with the higher degree of complementarity (lower $\theta$ ). Therefore, the presence of wage rigidity weakens the financial channel of government spending when the two constraints bind at the same time. Overall, as we can see in the quantitative analysis below, fiscal expansions can always mitigate the financial crisis by appreciating the real exchange rate and capital price, but its effectiveness depends on the exchange rate policy and whether DNWR is binding.

\section{Calibration and Model Fit}

Since there are two occasionally-binding constraints in the model, I use the global solution method. More specifically, I use a collocation method with time iteration on Euler equations. A set of decision rules is defined and approximated by functions on the discretized state-space $\mathcal{S}_{t}=$ $\left(b_{t}, w_{t-1} ; y_{t}^{T}, z_{t}, g_{t}\right)$. For each iteration and at each grid point, I find the solution to a system of Euler equations and the decision rules are updated accordingly. I iterate on these policies until the difference between successive iterations is small enough. The computational details can be found in appendix B.

The calibration strategy follows Mendoza (2010) and Mendoza \& Bianchi (2011). The model is calibrated to a two-sector production economy using Mexico 1993Q1 - 2015Q4 data. On the production side, I use the labor share in their paper so that $\alpha^{L}=0.64$. The output elasticity of capital $\alpha^{K}=0.05$ is taken from Mendoza \& Bianchi $(2011)^{26}$. On the preference side, relative risk aversion is set to a standard value of $\sigma=1$. The elasticity of substitution $\theta$ is an important parameter since it governs the fluctuation of the real exchange rate. Mendoza (2005) reports a wide range of estimates from 0.4 to 0.83 , and I use the middle value of 0.65 . The share of tradable goods in the consumption basket $\omega$ is set to match the average output ratio between the two sectors, $\frac{y^{T}}{p^{N} y^{N}}=0.614$, using the value-added data at annual frequency from World Development Indicator $^{27}$. The Frisch elasticity parameter $\nu$ is given a standard value of 1 and $\chi$ is to chosen to normalize the steady state labor.

The interest rate is set to the historical average of the government bond rate $R^{*}=1.02 . \phi=0.15$

\footnotetext{
${ }^{26}$ Since capital in the model is in fixed supply, I cannot set the capital share to the standard value of $1 / 3$, which is based on capital income accrued to the entire capital stock. Instead, Mendoza \& Bianchi (2011) sets $\alpha^{K}$ so that the model matches an estimate of fixed capital to GDP ratio based on the value of the housing stock.

${ }^{27}$ Generally consistent with the existing papers, the tradable sector is defined as manufacturing industry, agricultural products and natural resources. I define the rest of GDP as the non-tradable sector.
} 
so that the average working capital-GDP ratio equals to 9\%, as in Mendoza \& Bianchi (2011). The historical average of government spending to GDP ratio is $11.7 \%$. The home-bias $\omega_{G}$ is an important parameter but difficult to find from data. Mendoza (2002) uses a shorter sample of sectoral data to get the tradable share of government purchase as 7.2\% while other papers (e.g., Anzoategui, 2016; Bianchi et al., 2016) simply assume $\omega^{G}=0$. I follow the later assumption. The degree of wage rigidity $\gamma=(0.99)^{1 / 4}$ follows Schmitt-Grohé \& Uribe (2016). The remaining six parameters - the subjective discounting parameter $\beta$, the collateral rate $\kappa$, and the structural shock parameters $\sigma_{z}$, $\sigma_{y^{T}}, \rho_{z}, \rho_{y^{T}}$ - are jointly calibrated to match data moments: the average debt service-GDP ratio, the average equity premium (or sudden stop probability), and the standard deviations and the first order auto-correlations of GDP and real exchange rate ${ }^{28}$. Table 3 summarizes the calibrated parameters and the ones used to target data moments.

Because most of the Mexican external debt has long maturities, and my model only has short term debt, I use the debt service rather than the total external debt balance in the calibration. In a debt-constrained economy, the debt service ratio better reflects the overall financial burden. The average debt-service to GDP ratio for Mexico is 5.19\%. Many related papers (e.g., Schmitt-Grohé \& Uribe, 2017) calibrate the process of sectoral shocks by directly running regressions on the sectoral outputs. Given that I have a production economy and this paper mainly focuses on the sudden stop crisis that is closely related to the behavior of real exchange rate, I calibrate the exogenous process to match the statistics of real GDP and the real exchange rate instead.

The fiscal rule of the government is estimated using a longer data sample from 1981 to 2016. The estimation result is

$$
\log \left(g_{t}\right)=0.96^{* * *} \log \left(g_{t-1}\right)-0.02 \log \left(g d p_{t-1}\right)+0.02 b_{t-1} / g d p_{t-1}+\epsilon_{t}^{g}
$$

We can see that government spending process is highly persistent and both the lagged GDP and debt-GDP ratio are statistically insignificant. For this reason, in the numerical exercise below I assume $g_{t}$ process is exogenous.

Model Fit Table 4 shows the data moments and their model counterparts when I simulate the economy for 1,000,000 periods, discarding the first 10,000 periods. The baseline economy assumes the flexible exchange rate policy, but I also report the result of pegged exchange rate for comparison. The model does a decent job fitting the selected moments, especially for the average debt-service ratio and auto-correlations. Moreover, the shock of this size is able to generate sudden stops crises with the correct frequency. As for other statistics, notice that the model is able to capture some distinctive features of small open economies: private consumption is more volatile than output, trade balance is counter-cyclical and consumption is highly correlated with output.

\footnotetext{
${ }^{28}$ There is no ageement in the literature about what proportion of real exchange rate volatility is due to changes in the non-tradable good price. Mendoza (2005) reports that when Mexico was under a managed exchange rate regime, the fluctuations of its non-tradable good price account for between $50 \%$ and $70 \%$ of the fluctuations in the CPI-adjusted Mexico-US real exchange rate. Here I use the lower bound of $50 \%$.
} 


\begin{tabular}{lcc}
\hline Parameters & Value & Description \\
\hline \hline From literature or simple moment match: & Standard \\
$\sigma$ & 1 & Standard \\
$\nu$ & 1 & Normalize steady state labor to 1 \\
$\chi$ & 1.35 & Mendoza $(2005)$ \\
$\theta$ & 0.65 & Relative sector size \\
$\omega$ & 0.46 & Mendoza (2002) \\
$\omega^{G}$ & 0 & Mendoza \& Bianchi $(2011)$ \\
$\alpha_{k}$ & 0.05 & Mendoza \& Bianchi $(2011)$ \\
$\alpha_{l}$ & 0.64 & Schmitt-Grohé \& Uribe $(2016)$ \\
$\gamma$ & $0.99^{1 / 4}$ & Historical average \\
$R^{*}$ & 1.02 & Historical average \\
$G / G D P$ & 0.117 & Working capital-GDP ratio \\
$\phi$ & 0.15 & Debt service-GDP ratio \\
\hline Calibrated to fit targets: & & Equity Premium or Crisis probability \\
$\beta$ & 0.963 & GDP standard deviation \\
$\kappa$ & 0.285 & GDP auto-correlation \\
$\sigma_{z}$ & 0.016 & REX standard deviation \\
$\rho_{z}$ & 0.75 & REX auto-correlation \\
$\sigma_{y^{T}}$ & 0.023 &
\end{tabular}

Table 3: Parameter Values

Aside from that, my model also reproduces a counter-cyclical spread and a pro-cyclical real exchange rate $^{29}$ that are widely observed among emerging market economies with sudden stop risk. When the economy is hit by a negative shock, the indebted agents deleverage and decrease consumption, depressing the capital price. If the shock is large enough, the financial constraint becomes binding. The risk premium rises to compensate for the loss of capital investment. At the same time, the decrease in tradable consumption suppresses the effective wage rate. If the real wage is downward-rigid, large wage deflation creates involuntary unemployment. In general, the model shows important features of economies prone to sudden stops : deleveraging, currency depreciation, rising risk premia, and current account reversals ${ }^{30}$.

\section{Quantitative Analysis}

This section quantifies the state-dependent effect of a government spending shock. First, I consider the definition of the fiscal multiplier in the model environment.

\footnotetext{
${ }^{29}$ The unemployment rate is also counter-cyclical in the model under a pegged exchange rate with $\rho(U, y)=-0.80$.

${ }^{30}$ In order to show the model can account for similar sudden stop characteristics as in the data, in appendix E.4, I compare the 9-periods event window of sudden stop episodes from the data and the model. Similar to the data, sudden stop in the model is characterized by large real depreciations and consumption drops. However, the model can not match the pre-crisis expansion seen in the data and also displays less persistence during the recession. Both of these features are considered as drawbacks of sudden stop models with only transitory shocks, as in Aguiar \& Gopinath (2006).
} 


\begin{tabular}{lccc}
\hline & Mexico & Baseline Model & \multirow{2}{*}{ Peg } \\
\hline Targeted Moments: & & Flex & \\
$\sigma(y)$ & 2.34 & 2.27 & 3.12 \\
$\rho\left(y, y_{-1}\right)$ & 0.77 & 0.79 & 0.70 \\
$\sigma($ rex $) \times 50 \%$ & 3.93 & 4.12 & 2.53 \\
$\rho($ rex, rex -1$)$ & 0.70 & 0.69 & 0.82 \\
Debt service-GDP $(\%)$ & $5.19 \%$ & $5.16 \%$ & $5.25 \%$ \\
Average spread $(\%)$ & $6.04 \%$ & $5.73 \%$ & $5.65 \%$ \\
Prob. of Crisis $(\%)$ & $3 \%-5 \%$ & $4.1 \%$ & $3.2 \%$ \\
\hline Other Statistics: & & & \\
$\sigma(c) / \sigma(y)$ & 1.18 & 1.13 & 1.18 \\
$\sigma(t b) / \sigma(y)$ & 0.53 & 0.19 & 0.14 \\
$\rho(c, y)$ & 0.82 & 0.95 & 0.97 \\
$\rho\left(\frac{t b}{y}, y\right)$ & -0.51 & -0.23 & -0.39 \\
$\rho($ rex,$y)$ & 0.58 & 0.44 & 0.31 \\
$\rho($ spread,$y)$ & -0.22 & -0.55 & -0.72 \\
\hline
\end{tabular}

a. For the data, when calculating the second moment, the logarithms of GDP, private consumption, government consumption, and the trade-balance ratio were detrended by HP filter with a smoothing parameter of 1600 . I report deviations from trend. The interest rate spread is the difference between the domestic lending rate and the saving rate. The spread is in annual terms. b. Consistent with the empirical analysis before, the Sudden Stop in the simulation is defined as the state where the financial constraint is binding, GDP is one standard deviation below its long-run trend, and the current account reversal is greater than two standard deviations.

c. The pegged exchange rate regime is the case with $\gamma^{E}=0$, while the flexible one is with $\gamma^{E}=1$.

\section{Table 4: Model Fit}

\subsection{Definition}

The non-linear nature of this model and the state-dependence make it conceptually difficult to define the fiscal multipliers. Here, I use the procedure similar to that used to compute generalized impulse response functions (GIRF). In the model, the fiscal multiplier is a function of the state of the economy, $\mathcal{S}=\left(b, w ; y^{T}, z, g\right)$. Starting from $\mathcal{S}_{0}$, I simulate the economy for a large number of paths of shocks and take this as the benchmark. In the second time, I simulate it again with the same set of shocks but increase the government spending shock in the first period by a certain amount ${ }^{31}$. At each time horizon, the spending multiplier is the median difference of the outcomes between the paths with and without the fiscal shock. Specifically, the cumulative multiplier of horizon $T$ is defined as,

$$
F M^{T}\left(\mathcal{S}_{0}\right)=\frac{\sum_{t=1}^{T}\left[\prod_{j=1}^{t} 1 / R_{j}^{*}\right]\left(X_{t}^{\text {Shock }}-X_{t}^{\text {No Shock }}\right)}{\sum_{t=1}^{T}\left[\prod_{j=1}^{t} 1 / R_{j}^{*}\right]\left(\text { Spending } t_{t}^{\text {Shock }}-\text { Spending } \text { So Shock }_{t}\right)},
$$

where $X$ is the variable of our interests. Because the model is in an open economy environment, I consider the multiplier on variables denominated in both values or volumes. When $X$ is measured

\footnotetext{
${ }^{31}$ Given that in a nonlinear environment, the effect of shocks is not additive, both the sign and size of shocks matter for the value of fiscal multiplier. To control this, for each simulation I use $50 \%$ of negative shocks and $50 \%$ of positive shocks. The size of the shock is fixed at $0.25 \%$ of GDP unless otherwise noted.
} 
in tradable values (i.e. GDP-value, C-value), the denumerator is also adjusted for the change of real exchange rate. When $X$ is measured in final good volumes (i.e. GDP-volume, C-volume), the real exchange rate is kept constant at its steady state. For example, to define the value-multiplier of GDP, I use $X_{t}=y_{t}^{T}+y_{t}^{N} p_{t}^{N}$ and Spending $g_{t}=p_{t}^{G} g_{t}$. To define the volume-multiplier of output, I use $X_{t}=y_{t}^{T}+y_{t}^{N} \overline{p^{N}}$ and Spending $g_{t}=\overline{p^{G}} g_{t}$.

The multiplier in equation (48) is called the cumulative multiplier in Ramey \& Zubairy (2014), and it nests the impact multiplier when $T=1$. Because my baseline model does not have the components needed to create a cumulative effect of government spending and the sudden stop event is featured with the sudden collapse of financial activities in either one or two periods, the discussion below mainly focuses on impact multipliers.

\subsection{State-Dependent Effect of Government Spending}

Government purchases are the canonical instrument of macroeconomic stabilization. For models in the literature, the stimulus channels of counter-cyclical fiscal policy are mostly due to NewKeynesian nominal rigidity, consumption habit-persistence, search friction in the labor market, or unresponsive monetary policy. In this paper, these traditional channels are shut down and I focus on the novel effect of government spending during the financial crisis of small open economies.
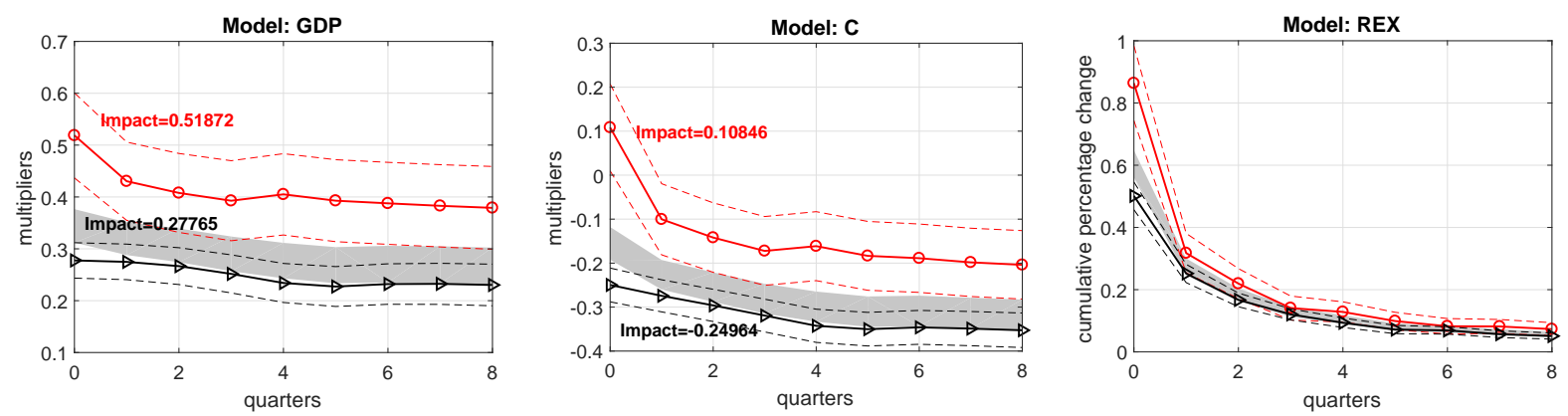

Figure 9: Model Simulation

Note: The figures report the predicted fiscal multipliers from the model-simulated data. The red (black) series are multipliers during sudden stop periods (normal times). In estimating the fiscal multiplier, I use the same econometric strategy as in the empirical analysis. I simulate a panel of 30 countries with the same sample length for each country. 15 countries are classified as pegging exchange rate regime $\gamma^{E}=0$, while the others have $\gamma^{E}=1$. The "sudden stop" period is defined as GDP at least one standard deviation below the average and current account reversals at least two standard deviations higher than the average.

Figure 9 plots the predicted multipliers from the model-simulated data, where I apply the same estimation method as before. We can see the model is successful in producing the financial-cycledependent fiscal multiplier effect. The multipliers on output and consumption are higher during sudden stop crises than that during normal times. The real exchange rate also appreciates more during crises. Although my model predictions generally line up with the key channels of financial crisis, they do not necessarily match the quantitative features of the data. First of all, while in the data an increase in government spending generates a consumption multiplier close to 0 in normal times and significantly crowds-in consumption during sudden stops, the model generally predicts 
crowding-out, except on impact during sudden stop periods ${ }^{32}$. Second, the model fails to generate the hump-shaped fiscal multiplier effect on output and consumption seen in the data ${ }^{33}$. These shortfalls are mainly due to using a parsimonious model to understand the financial channels of government spending while abstracting from the traditional channels mentioned above that can generate sizable and empirically-relevant fiscal multipliers.

From figure 10, we find the same channel applies to both exchange rate regimes, and the difference of multipliers between financial states is even larger for the case of pegged exchange rate. Under a flexible exchange rate, the average impact multiplier on consumption is -0.31 in normal times and -0.12 in the identified sudden stop periods. Under a pegged exchange rate, it increases further, from -0.18 in normal times to 0.37 in sudden stops. In the later case, consumption is crowded-in on impact when the shock hits. In contrast, the model predicts sudden stop has a larger impact on real exchange rate appreciation under the flexible exchange rate policy.
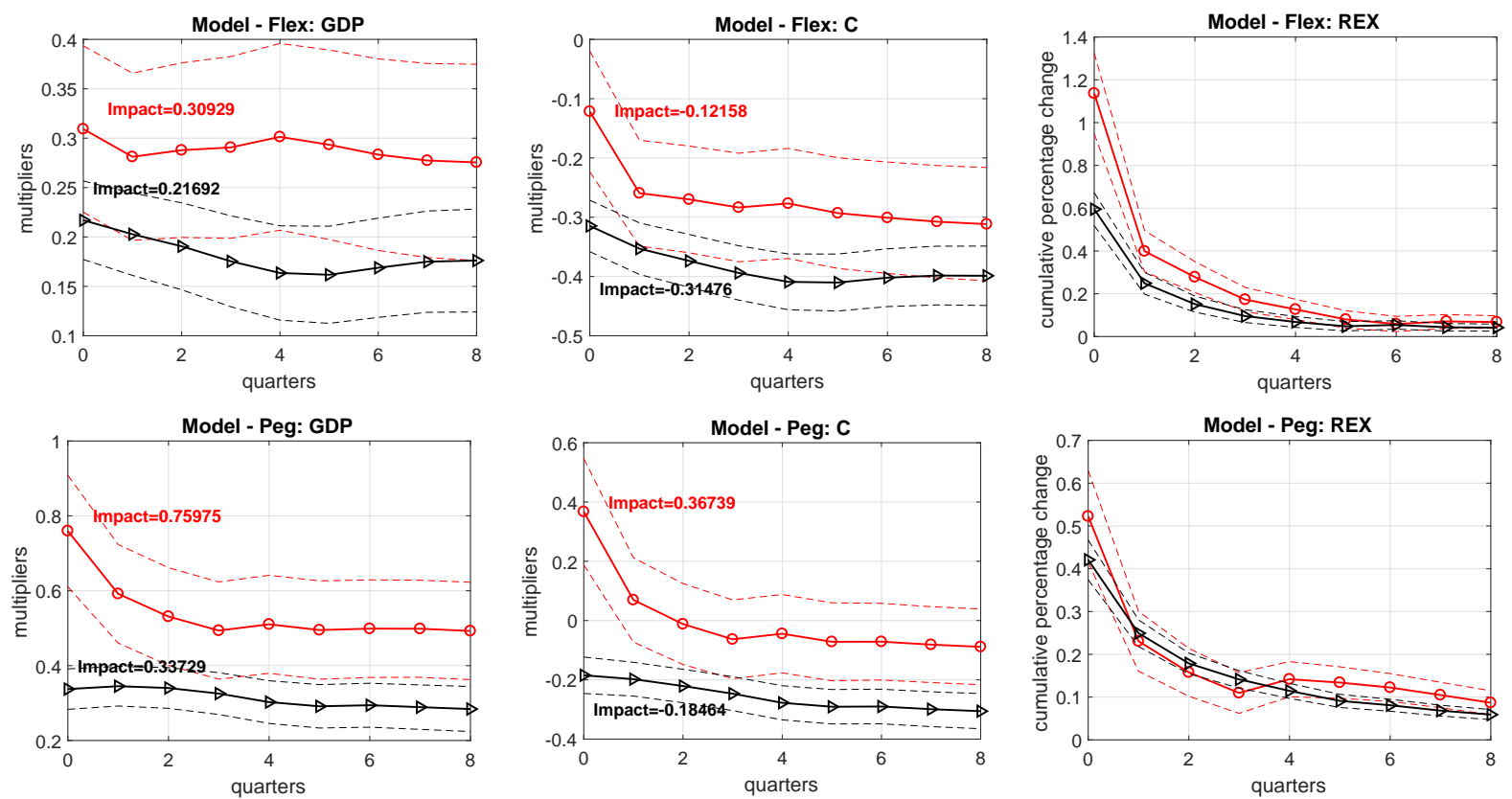

Figure 10: Model Simulation for Different ERR

Note: The figures report the predicted fiscal multipliers from the model-simulated data under different exchange rate regimes. The flexible exchange rate is the case of $\gamma^{E}=1$, while the pegged exchange rate is $\gamma^{E}=0$. See the note in figure 9 for details.

In order to contrast fiscal multipliers between distinct states of nature more clearly, I define the economic "boom" and "bust" states, and then compare the theoretical impulse responses starting from different states $^{34}$. I start the economy from the stochastic steady state and hit it with a

\footnotetext{
${ }^{32}$ Due to the strong RBC flavor of my model, the consumption is crowded out after a positive expenditure shock, especially without DNWR. This is consisitent with Lewis \& Winkler (2017). They find even with endogenous firm entry, the model fails to generate consumption crowding-in for a variety of model specifications, except with strong compementarity between public and private consumption in utility or assuming public spending is productivityaugmenting. In this paper, I emphasize the dependence of multipliers on financial states.

${ }^{33}$ From the event analysis in appendix E.4, we can see the simulated sudden stop does not show much persistence as well.

${ }^{34}$ Different authors define the "boom-bust cycle" in different way. Schmitt-Grohé \& Uribe (2016)'s definition is
} 
sequence of four positive $y_{t}^{T}$ shocks of 1 standard deviation. At the end of the fourth quarter, the economy is highly leveraged with consumption and output above the trend. The ever-increasing production also drives up the wage state. This state is defined as the boom. Next, I get the bust by imposing large "sudden stop shocks" on the economy, which are extracted from longrun simulations ${ }^{35}$. This empirical strategy to generate "boom-bust cycles" is motivated by the observation that sudden stop crises are usually the periods when a highly leveraged economy is hit by large international shocks. Notice that this is different than simply starting the economy at the stochastic steady state and hitting it with a positive (negative) international shock, with the reason being that my procedure accounts for the evolution of endogenous states. This is particularly important for my purpose, as a leverage boom increases consumption today but potentially makes the economy more exposed to financial and unemployment crisis tomorrow.

Baseline: Flexible Exchange Rate

\begin{tabular}{|c|c|c|c|c|c|c|}
\hline & Boom-impact & Bust-impact & Boom-1 year & Bust-1 year & Boom 4-years & Bust 4-years \\
\hline$c^{T}$ & 0.02 & 0.22 & 0.02 & 0.03 & 0.01 & 0.01 \\
\hline$c^{N}$ & -0.58 & -0.53 & -0.58 & -0.57 & -0.58 & -0.58 \\
\hline REX & 0.24 & 0.27 & 0.24 & 0.21 & 0.23 & 0.21 \\
\hline$\overline{\mathrm{C}}-\overline{\text {-volume }}-{ }^{--}$ & $-0.6 \overline{0}$ & $-\overline{-0.2 \overline{8}}$ & $-\overline{0.59}$ & $-\overline{0.53}$ & $-\overline{-0.5 \overline{9}}$ & $-\overline{-0.56}$ \\
\hline GDP-volume & 0.42 & 0.47 & 0.42 & 0.43 & 0.42 & 0.42 \\
\hline C-value & 0.29 & 0.77 & 0.30 & 0.33 & 0.29 & 0.29 \\
\hline \multirow[t]{2}{*}{$\begin{array}{l}\text { GDP-value } \\
\frac{1}{\%} \text { of c.e. }\end{array}$} & $--\frac{1.28}{-0.17 \%}-$ & $--\frac{1.59}{-0 . \frac{13}{\%}}--$ & $--\frac{1.29}{-0 . \overline{16 \%}}-$ & $--\frac{1.30}{-0.15 \%}-$ & $--\frac{1.28}{-0.14 \%}-$ & $--\frac{1.28}{-0 . \overline{1} \frac{1}{4} \%}-$ \\
\hline & \multicolumn{6}{|c|}{ Baseline: Pegged Exchange Rate } \\
\hline & Boom-impact & Bust-impact & Boom-1 year & Bust-1 year & Boom 4-years & Bust 4-years \\
\hline$c^{T}$ & 0.04 & 0.17 & 0.03 & 0.03 & 0.01 & 0.01 \\
\hline$c^{N}$ & -0.33 & 0.03 & -0.41 & -0.20 & -0.46 & -0.21 \\
\hline REX & 0.15 & 0.11 & 0.18 & 0.10 & 0.19 & 0.10 \\
\hline$\overline{\mathrm{C}}-\overline{\text {-volume }}{ }^{-}$ & $-0.3 \overline{1}$ & $0 . \overline{1} \overline{-}^{-}$ & $-0 . \overline{4}$ & $-0 . \overline{18}$ & $-0.4 \overline{7}$ & $-0.2 \overline{1}$ \\
\hline GDP-volume & 0.67 & 0.97 & 0.59 & 0.80 & 0.54 & 0.79 \\
\hline C-value & 0.24 & 0.47 & 0.25 & 0.16 & 0.24 & 0.14 \\
\hline $\begin{array}{l}\text { GDP-value } \\
\overline{\%}-\overline{\text { of c.e. }}\end{array}$ & $--\frac{1.22}{-0 . \overline{0} 9 \overline{\%}}-$ & $-\frac{1.32}{0.09 \%}-$ & $-\frac{1.23}{-0.09 \%}$ & $-\frac{1.14}{0.00 \%}-$ & $--\frac{1.23}{-0.10 \%}-$ & $--\frac{1.13}{-0.02 \%}$ \\
\hline
\end{tabular}

a. Given initial states, I simulate the economy for 10,000 times with and without the government spending shock and take the difference. The numbers in the table are the median paths of cumulative multipliers starting from the "boom" and the "bust" states (except for REX and c.e.). The real exchange rate is in term of cumulative percentage differences between the path with a government spending shock and the path without the shock.

b. c.e. is the certainty equivalence moving from an economy without shock to an economy with one unit government spending shock. The c.e. is the amount of final consumption goods that households are willing to pay so that the finite-periods utility sums of the two economies are equalized. This is a way to measure the state-dependent welfare effect of government spending shock, similar to the "welfare multiplier" in Rendahl (2016).

Table 5: State-Dependent Multipliers

based on exogenous processes. The way I define the boom-bust leverage cycle is consistent with the empirical finding that the leverage and real activities usually go above the trend during the periods prior to sudden stop crises.

${ }^{35}$ I simulate the economy for 100,000 periods and identify the sudden stop events by the standard described before. Event window analysis shows that the sudden stop is usually accompanied by a large negative shock on $y^{T}$ and a small positive shock on domestic TFP $z$. The combinations of exogenous processes are averaged across the crisis events and I call that "sudden stop shocks". 
The state-dependent effect of government spending is evident from table 5 , which compares the median value of simulated multipliers between the financial states ${ }^{36}$. Generally, the fiscal multipliers on GDP and consumption are higher in the credit bust than in the credit boom, especially on impact. Moreover, due to DNWR, the difference in the volume-multipliers (C-volume or GDP-volume) is even more pronounced for an economy with a pegged exchange rate. Lastly, model's prediction about the real exchange rate is different from the data. The real exchange rate always appreciates after the shock but the difference between the bust and the boom depends on which exchange rate regime it lives in.

The financial channel is the same as that in the three-period model. At the bust states where the financial constraint binds, a fiscal expansion increases the capital price and relaxes the constraint, thus promoting borrowing. Greater ability to borrow increases tradable consumption and relaxes the financial constraint by even more. The increase in government spending also has larger stimulative effect on production in recessions than in expansions. This comes from two reasons. From the working-capital requirement, the relaxed financial constraint reduces the firm's laborhiring cost. When the real wage is rigid, the higher government spending also reduces involuntary unemployment, further stimulating non-tradable good production.

It is interesting to know how much of the state-dependence comes from DNWR and how much comes from the financial constraint. This is easy to tell by comparing GDP-volume multipliers between the two exchange rate regimes. Notice that the difference between financial states is relatively small under a flexible exchange rate (0.42 in the boom and 0.47 in the bust), which means the working-capital constraint only contributes marginally to the stimulative effect of government spending on the production. On the other hand, under a pegged exchange rate, the multipliers increase from 0.67 in the boom to 0.97 in the bust. This bigger difference is due to DNWR.

However, we know from the discussion above that under a pegged exchange rate, overproduction of $y^{N}$ exerts a counteractive force on the financial constraint and may worsen the real activities. This is evident by considering the multiplier effects of government spending on either REX, $c^{T}$ or GDP-values. First, we find in the lower panel of the table that, due to the large increase of non-tradable good production, the real exchange rate appreciates less in the bust than it does in the boom. That limits the financial channel of government spending. So, the difference in $c^{T}$ multipliers between the financial states also gets smaller. The GDP-value can be written as,

$$
\text { GDP-value }=y^{T}+\frac{1-\omega}{\omega}\left(\frac{c^{T}}{y^{N}-g^{N}}\right)^{\frac{1}{\theta}} y^{N} .
$$

When the financial constraint binds, $c^{T}$ depends on the credit available from foreign investors and thus the price of capital. It increases because the fiscal expansion relaxes the financial constraint. However, when $\frac{1}{\theta}>1$, overproduction of $y^{N}$ has an offsetting effect on the non-tradable good price and makes the difference of GDP-value multipliers also relatively small.

\footnotetext{
${ }^{36}$ In appendix E.4, I plot the median path of simulated multipliers from the impulse response for the economy under two distinct exchange rate systems
} 
c.e. denotes the certainty equivalence households are willing to pay for moving from a no-policy economy to an economy with a unit government spending shock. Here, it measures the net welfare effect of a policy shock in finite periods of time. Notice that c.e. is larger when the shock hits the economy at the bust state. This is consistent with the implication from the three-period model. The higher government spending increases capital price and mitigates the severity of crises at bust states. When the wage is rigid, part of the benefit also comes from the stimulative effect on output. Therefore, the welfare multipliers are generally larger in the economic bust than in the economic boom, and a wasteful government spending shock can even produce an instant net welfare gain under a pegged exchange rate.

Overall, the model can capture the empirical findings of this paper: the spending multiplier is higher when the shock hits during financial recessions than during financial expansions, and the financial-state-dependence is stronger for an economy under the pegged exchange rate. My model contains this non-linear feature due to the occasionally-binding constraints and the mechanisms described before. The result is different from Ilzetzki et al. (2013)'s finding that fiscal stimulus in highly indebted countries may be counter-productive. Ilzetzki et al. (2013) also concludes that the fiscal multiplier is larger in economies under predetermined exchange rates than in economies under flexible exchange rates. On the other hand, this paper emphasizes how it depends on the financial states.

\subsubsection{Multipliers across Different Levels of Indebtedness}

To illustrate the debt-deflation mechanism more clearly, figure 11 displays the landscape of fiscal multipliers across the debt ratios. It is evident from this figure that the fiscal multiplier effect is highly non-linear and is characterized by the two thresholds where financial constraint and wage constraint start to bind, respectively. When the financial constraint binds, government spending increases borrowing and consumption (upper left panel), but its effect on production is relatively small (lower left panel). If the wage constraint also binds, the multipliers on consumption and GDP volumes (left panels) rise up further. However, this strong effect from the wage rigidity in turn reduces real exchange rate and dampens the multipliers on consumption and GDP values (right panels). As a result, even though the multiplier effect on GDP volumes is monotone across the debt ratios, the net effect on equilibrium GDP values may not be.

Using U.S. data, Bernardini \& Peersman (2015) finds that in private debt over-hang periods, the crowding-in effect drives multipliers to be higher than one (1.45), whereas significant crowding-out of personal consumption and investment in low debt states produces multipliers below one. Based on different mechanisms, my model indicates external indebtedness is another important factor in determining fiscal multipliers for small open economies. 

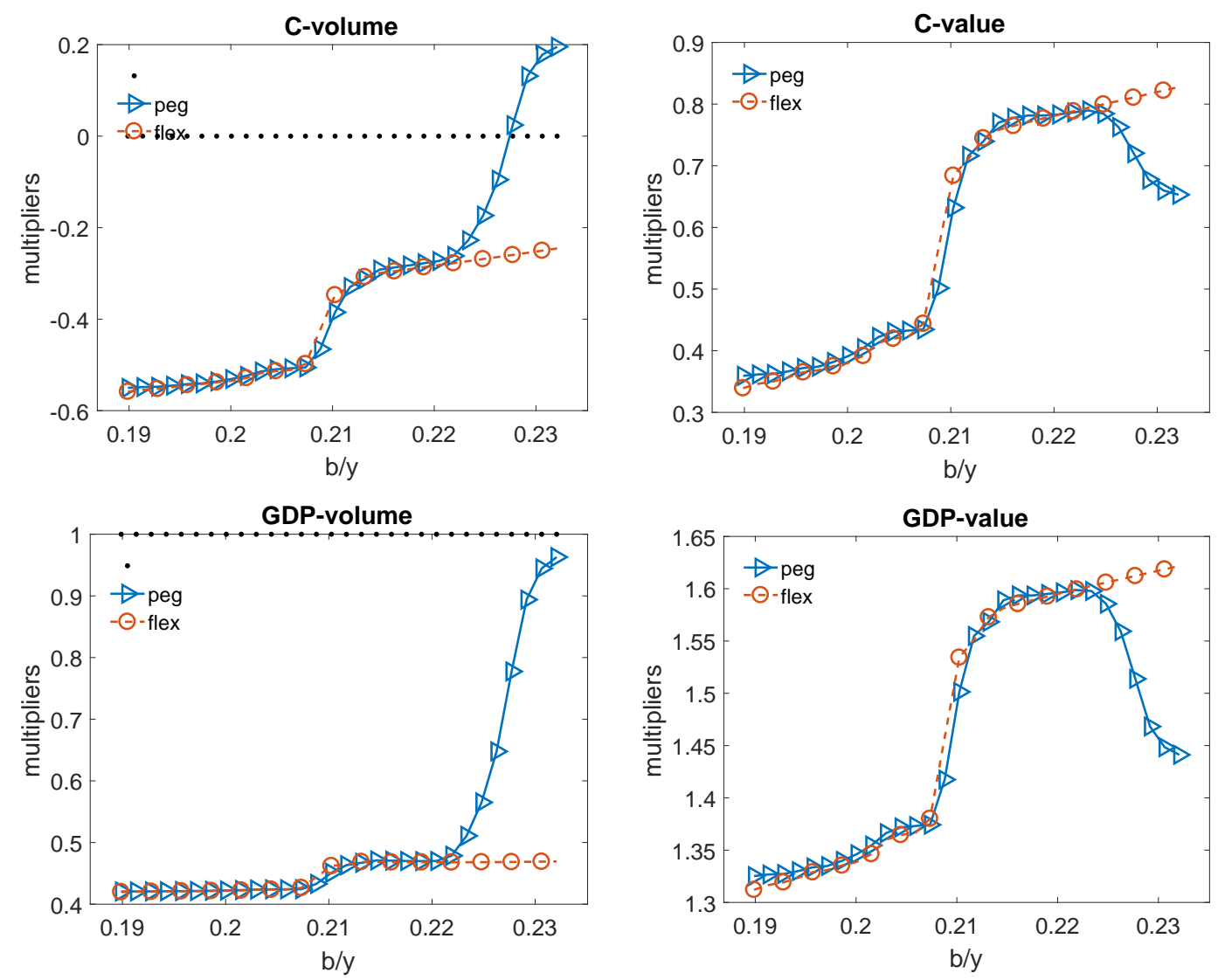

Figure 11: Multipliers across the State-Space

Note: The figures plot the median values of impact multipliers at different debt-GDP ratios. The wage state is fixed at $95 \%$ of its mean because that allows me to separate out effects of the two constraints in the figures. The exogenous states are kept at their steady states.

\subsection{Asymmetric Multipliers}

Since I have a non-linear model, the marginal multiplier (for a small government spending shock) should be different from the average multiplier (for a sizable government spending shock) ${ }^{37}$. The intuition is that large government spending shocks can potentially put the economy in different financial regimes or change the probability of regime-shifting. Moreover, given the two inequality constraints, positive shocks are supposed to have different impacts on the economy from negative shocks, especially when the shocks are sizable. To understand this result, we return to the asset price channel discussed before. A positive government spending shock generates wealth effect through real appreciation and boosts the capital price. But the capital price plays a smaller role if the financial constraint is less likely to bind. On the other hand, a negative spending shock initially reduces tradable consumption and, simultaneously, tightens the financial constraint. This accelerates the decline of private activities resulting in a larger fiscal multiplier in size.

Table 6 shows that both the size and sign of government spending shocks matter. Generally,

\footnotetext{
${ }^{37}$ The size effect of government spending shock is also explored in the non-linear model of Fernández-Villaverde et al. (2015)
} 
positive shocks have smaller multiplier effects than negative shocks. From the middle column to the right, notice that the average multipliers on consumption and output become smaller when the positive shock is larger. On the other hand, from the middle to the left, a more sizable negative shock generates a bigger multiplier effect on average. Comparing the upper and lower panels, we can see the DNWR amplifies the multiplier effect of a large negative shock on production (GDPvolume, C-volume), but weakens its effect on the financial constraint (see multipliers on $c^{T}$ ). Notice that in the model with a flexible exchange rate, the decrease in production after a negative shock is due to the working-capital constraint, which is relatively small.

\begin{tabular}{|c|c|c|c|c|c|c|}
\hline & $-2 \%$ & $-1 \%$ & $-0.25 \%$ & $+0.25 \%$ & $+1 \%+$ & $2 \%$ \\
\hline$c^{T}$ & 0.170 & 0.148 & 0.123 & 0.118 & 0.108 & 0.098 \\
\hline $\mathrm{C}$-volume & -0.376 & -0.404 & -0.437 & -0.444 & -0.457 & -0.470 \\
\hline \multirow[t]{3}{*}{ GDP-volume } & 0.451 & 0.446 & 0.439 & 0.439 & 0.437 & 0.436 \\
\hline & \multicolumn{6}{|c|}{ Baseline: Pegged Exchange Rate } \\
\hline & $-2 \%$ & $-1 \%$ & $-0.25 \%$ & $+0.25 \%$ & $+1 \%$ & $+2 \%$ \\
\hline$c^{T}$ & 0.200 & 0.191 & 0.188 & 0.160 & 0.132 & 0.118 \\
\hline $\mathrm{C}$-volume & -0.036 & -0.111 & -0.187 & -0.230 & -0.288 & -0.288 \\
\hline GDP-volume & 0.759 & 0.693 & 0.627 & 0.613 & 0.581 & 0.548 \\
\hline
\end{tabular}

Note: "+ $0.25 \%$ " means government spending increases by 0.25 percent of GDP; a negative number means government spending decrease. The numbers in the table are the median of impact multipliers. For comparison, the multipliers of positive and negative shocks have the same meaning. The simulation starts from the model's long-run stochastic steady state.

Table 6: Sign and Size Effect of Government Spending Shock

It is well known that many emerging economies conduct pro-cyclical fiscal policies, which indicates spending cuts during recessions. My model predicts the asymmetric multiplier effects, especially during sudden stop periods. This calls for the necessity to understand and explore the asymmetric effect of government spending in fiscal policy research. It also casts doubt on empirical estimation that uses linear VAR to identify the effect of government spending shock. Using the threshold VAR approach, Pragidis et al. (2017) claims that the multiplier of a negative spending shock is higher than that of a positive shock during financially stressful periods and the asymmetry is absent in financially tranquil periods. Failure to account for the asymmetric multiplier effects may result in biased estimation, and could be a potential explanation for the wide range of fiscal multiplier estimates in the literature.

\subsection{Shock Persistence}

As implied by the three-period model, if the government is able to commit to certain paths of fiscal policies in the future, the current financial constraint can be relaxed. This motivates me to investigate the effect of government spending at different levels of shock persistence. In this section, I solve the model for different values of $\rho^{G}$, and for each $\rho^{G}$ I calculate the impact multipliers at both the boom and bust states. 
From figure 12, we can see that the government spending is more expansionary with the higher level of shock persistence, especially during a crisis. At the relatively low persistence, the financial channel is weak so that the median multipliers on output (lower left panel) in the economic bust are smaller than those in the boom. Only when the shock persistence is greater than a threshold (around 0.73), can output multipliers in the bust exceed the ones in the boom. The intuition comes from the currency mismatch channel. Promised fiscal expansions create an expectation of real appreciation which helps in relaxing the current financial constraint and in increasing real activities. At the same time, more persistent fiscal expansions also impose a stronger negative wealth effect through higher taxes. The result occurs because the financial channel dominates.
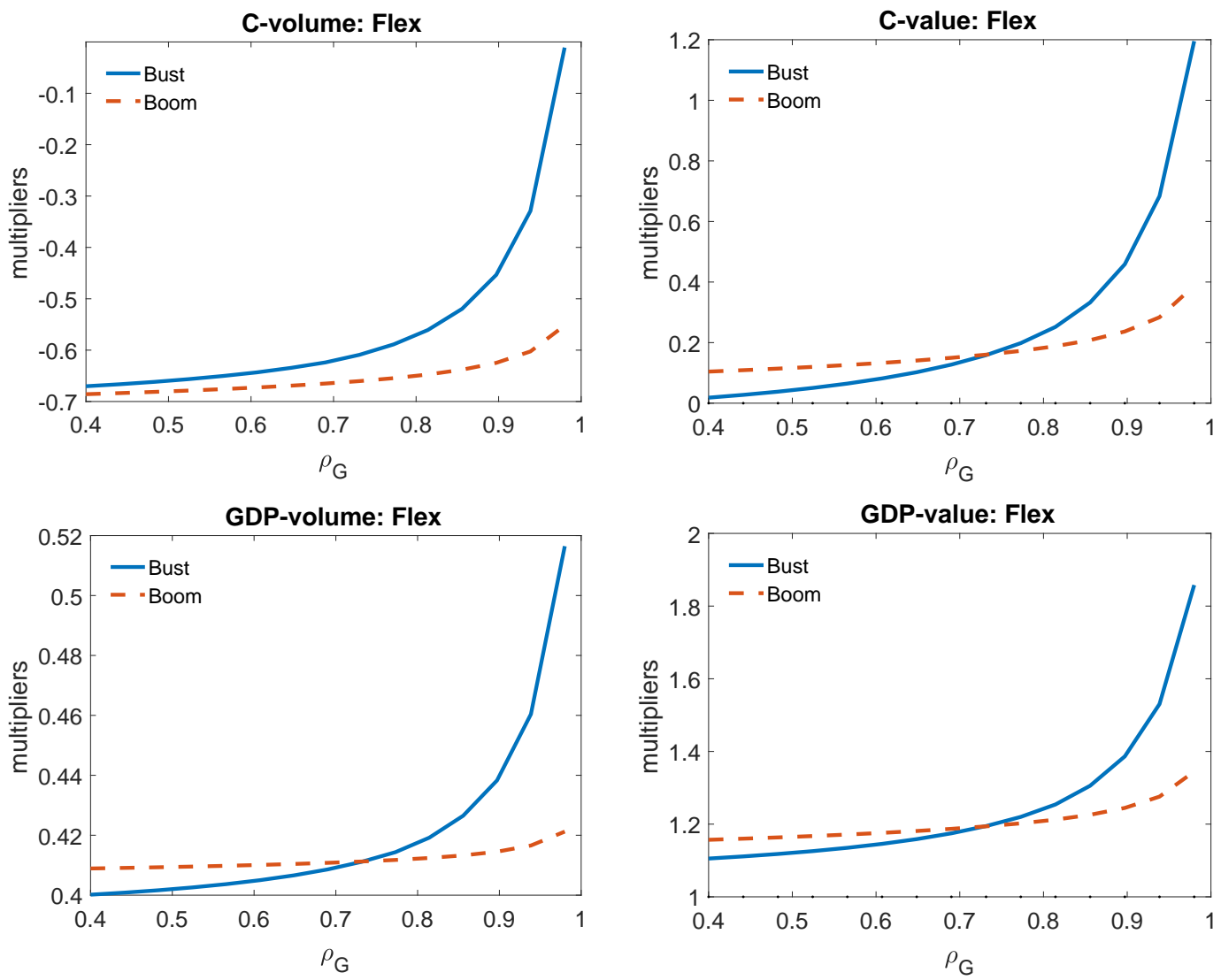

Figure 12: Multipliers for Different Shock Persistence

Note: The figures plot the median value of impact multipliers for different degree of shock persistence. Here, I use the baseline model with a flexible exchange rate. The simulation of the boom and the bust states are the same as before. The figures for the model of a pegged exchange rate is in appendix E.4.

\subsection{Investment Economy}

The baseline model does not have investment and assume the aggregate amount of capital always equals to one. Capital accumulation heavily affects the value of spending multipliers in a standard RBC model, and here it also influences the financial accelerator channel emphasized in this paper. So, it is useful to see how the above mechanism works in an investment economy. 
Suppose there is a capital good producer with investment technology,

$$
k_{t+1}-(1-\delta) k_{t}=k_{t} \Phi\left(\frac{i_{t}}{k_{t}}\right),
$$

where $i_{t}$ is the same composite good as the final consumption ${ }^{38}$,

$$
i_{t}=\left(\omega i_{t}^{T \frac{\theta-1}{\theta}}+(1-\omega) i_{t}^{N \frac{\theta-1}{\theta}}\right)^{\frac{\theta}{1-\theta}} .
$$

The capital good producer purchases the used capital from the firm-households, decorates them and resells them in the financial market. It solves the following static problem

$$
\max _{\left\{i_{t}^{T}, i_{t}^{N}\right\}}\left\{q_{t}^{K}\left[k_{t+1}-(1-\delta) k_{t}\right]-r e x_{t} i_{t}\right\}
$$

subject to (50) and (51). Parameter $\delta$ is the depreciation rate of physical capitals. The equilibrium conditions are listed in appendix A.

Following Bocola (2016), the functional form of investment adjustment is $\Phi\left(\frac{i_{t}}{k_{t}}\right)=a_{1}+a_{2}\left(\frac{i_{t}}{k_{t}}\right)^{1-\xi}$, where $\xi$ is the captial price elsticity of investment demand. Three parameters need to be recalibrated in this environment: $\xi=0.46$ is used to match the relative standard deviation of investment $\sigma(i) / \sigma(y)=3.04$ in the data; $\delta$ is set to 0.88 following Mendoza $(2010)^{39}$; and different

\begin{tabular}{|c|c|c|c|c|c|c|}
\hline & Boom-impact & Bust-impact & Boom-1 year & Bust-1 year & Boom 4-years & Bust 4-years \\
\hline C-volume & -0.58 & -0.23 & -0.56 & -0.51 & -0.54 & -0.52 \\
\hline I-volume & 0.15 & 0.27 & 0.16 & 0.17 & 0.17 & 0.17 \\
\hline \multirow[t]{3}{*}{ GDP-volume } & 0.44 & 0.52 & 0.46 & 0.48 & 0.51 & 0.52 \\
\hline & \multicolumn{6}{|c|}{ Pegged Exchange Rate } \\
\hline & Boom-impact & Bust-impact & Boom-1 year & Bust-1 year & Boom 4-years & Bust 4-years \\
\hline C-volume & -0.53 & -0.03 & -0.50 & -0.32 & -0.51 & -0.39 \\
\hline I-volume & 0.17 & 0.38 & 0.19 & 0.23 & 0.19 & 0.23 \\
\hline GDP-volume & 0.50 & 0.98 & 0.55 & 0.75 & 0.56 & 0.71 \\
\hline
\end{tabular}
from the baseline model, $\alpha^{K}$ here is set to the standard value of 0.3 as the capital share.

Flexible Exchange Rate

Note: Given initial states, I simulate the economy for 10,000 times with and without the government spending shock and take the difference. The numbers are the median cumulative multipliers from the simulation.

\section{Table 7: Investment Economy}

\footnotetext{
${ }^{38}$ Another extreme assumption used in the literature is that investment goods are sector-specific. In my model, that implies: $i_{t}=i_{t}^{N}$. Given that the non-tradable sector mainly consists of the service industry, this assumption is not realistic. I indeed find that the investment multiplier depends on the sectoral weight parameter $\omega$ in the investment good aggregator. But the conclusion about its state-dependence here remains.

${ }^{39}$ Mendoza (2010) uses the perpetual inventory method to back out a series of capital stock and a depreciation rate. Although our data sample extends the one he used, I believe the depreciation rate doesn't vary too much over time. Investment to GDP ratio is set to the sample average of $20.3 \%$.
} 
As can be seen from the Euler equation of capital price (as shown in appendix A), the fluctuation of Tobin's Q, and therefore the strength of the financial channel, highly depends on elasticity $\xi$. In this environment, an increase in government spending has two competing effects in play. On one hand, similar to a closed economy RBC model, the higher government spending increases the domestic interest rate (that is the interest rate in non-tradable sector: $1 /\left[\beta \mathbb{E}_{t} \frac{u_{C N}(t+1)}{u_{C N}(t)}\right]$ ) and crowds-out investment through the traditional inter-temporal substitution effect. On the other hand, once the financial constraint is binding, the Fisher's debt-deflation mechanism is in place. The higher government spending appreciates the real exchange rate and capital price, and thus increases the investment good purchases. Here, both effects exist and the value of investment multiplier depends on model calibrations ${ }^{40}$.

The upper panel of table 7 shows the multiplier effect under a flexible exchange rate and the lower panel shows the case of a pegged exchange rate. I find with the chosen parameter values, government spending increases the capital price and crowds-in investment. For the same reasons discussed above, the crowding-in is even stronger at states where the financial constraint is binding. The baseline results about consumption and GDP multipliers still hold here. The multipliers are larger during credit contractions than during credit expansions, and the presence of wage rigidity enlarges the multiplier effect on outputs. Compared to the baseline model, the difference in consumption multipliers between financial states becomes smaller due to the investment crowding-in. Even with a pegged exchange rate, consumption is always crowded-out by government spending.

\section{Sensitivity Analysis}

This section checks whether the baseline results can be extended to other model specifications. Firstly, the baseline model has a separable utility function that is popular in the two-sector environment. Another commonly used preference is the GHH preference (Greenwood et al., 1988), which eliminates the wealth effect on labor ${ }^{41}$. The utility function is modified as

$$
u\left(c_{t}, l_{t}\right)=\frac{\left[c_{t}-\chi_{t}^{l_{t}^{1+\nu}}\right]^{1-\sigma}-1}{1-\sigma} .
$$

Frisch elasticity parameter $\nu$ is the same as in the baseline model and I re-calibrate $\chi$ to normalize the steady state of labor. The first order condition with respect to labor becomes

$$
\frac{\chi l_{t}^{\nu}}{\omega c_{t}^{\frac{1}{\theta}} c_{t}^{T-\frac{1}{\theta}}}=\frac{p_{t}^{N} F_{l}\left(k_{t}, l_{t}^{d}\right)}{1+\phi \mu_{t}}=w_{t}^{f} \geq \gamma w_{t-1},
$$

\footnotetext{
${ }^{40}$ The impulse responses of the domestic interest rate and the capital price after a government spending shock are show in appendix E.4.

${ }^{41}$ Under the GHH preference, the consumption's wealth effect on labor supply equals to 0 in the one-good environment. In this two-goods set up, the wealth effect on labor is actually still present.
} 
where $w_{t}^{f}$ is the full-employment wage. In the upper panel of table 8 , we can see that due to the smaller wealth effect, the multipliers on GDP-volume are smaller than those in the baseline case. Due to the complementarity between consumption and labor in GHH utility, consumption multipliers are also smaller. Sudden stop crises still increase the multiplier effect of government spending, but for the same reason, the financial channel is weakened. With a flexible exchange rate, consumption multipliers only increase from -0.72 in the boom to -0.49 in the bust with GHH preferences (compared to -0.60 and -0.28 for the baseline economy). In the lower panel, when the economy is also subject to DNWR, the strong increases of non-tradable good production depreciates the real exchange rate and hurts the borrowing constraint. Therefore, the consumption multipliers in the boom and the bust get even closer.

Flexible Exchange Rate

\begin{tabular}{|c|c|c|c|c|c|c|c|c|}
\hline \multirow[b]{3}{*}{ Baseline } & \multicolumn{2}{|c|}{ C-volume } & \multicolumn{2}{|c|}{$\mathrm{C}$-value } & \multicolumn{2}{|c|}{ GDP-volume } & \multicolumn{2}{|c|}{ GDP-value } \\
\hline & Boom & Bust & Boom & Bust & Boom & Bust & Boom & Bust \\
\hline & -0.60 & -0.28 & 0.29 & 0.77 & 0.42 & 0.47 & 1.28 & 1.59 \\
\hline GHH & -0.72 & -0.49 & 0.36 & 0.59 & 0.28 & 0.35 & 1.34 & 1.48 \\
\hline \multirow[t]{4}{*}{$Y^{T}$ Production } & -0.65 & -0.58 & -0.22 & -0.18 & 0.33 & 0.36 & 0.76 & 0.76 \\
\hline & \multicolumn{8}{|c|}{ Pegged Exchange Rate } \\
\hline & \multicolumn{2}{|c|}{ C-volume } & \multicolumn{2}{|c|}{$\mathrm{C}$-value } & \multicolumn{2}{|c|}{ GDP-volume } & \multicolumn{2}{|c|}{ GDP-value } \\
\hline & Boom & Bust & Boom & Bust & Boom & Bust & Boom & Bust \\
\hline Baseline & -0.31 & 0.13 & 0.24 & 0.47 & 0.67 & 0.97 & 1.22 & 1.32 \\
\hline GHH & -0.33 & -0.26 & 0.31 & 0.08 & 0.66 & 0.76 & 1.26 & 1.09 \\
\hline$\gamma^{E}=0.3$ & -0.42 & -0.23 & 0.26 & 0.32 & 0.58 & 0.71 & 1.24 & 1.26 \\
\hline
\end{tabular}

Note: The numbers in the table are the median of impact multipliers for each variable. The simulations of the boom and the bust states are the same as before.

Table 8: Sensitivity Analysis

My analysis so far assume the tradable good follows an exogenous process. Next, I extend the model to include a tradable good production as

$$
y_{t}^{T}=z_{t}^{T} l_{t}^{T \alpha^{T}}
$$

and the non-tradable good production is re-written as

$$
y_{t}^{N}=z_{t}^{N} k_{t}^{\alpha^{K}} l_{t}^{N \alpha^{N}}
$$

Here, I assume the labor shares are the same between sectors $\left(\alpha^{T}=\alpha^{N}=0.64\right)$ and the labor services are flexible to move. As in the literature, there are reasons to believe the tradable sector, which mainly refers to manufacturing industry, is less labor-intensive than the non-tradable sector, which mainly consists of services. That means $\alpha^{T}<\alpha^{N}$ and implies a smaller sector reallocation effect after an increase in non-tradable government spending. Besides, existing papers (e.g., Shen et al., 2015) also use the model with labor market segmentation and hold the view that labor 
services are not perfectly substitutable between sectors. This provides another friction on labor adjustment. In that sense, the modeling choice here provides a lower bound to consider the impact of financial crisis on fiscal multiplier. As can be imagined, either a smaller labor share in the tradable sector or assuming an adjustment cost of labor movement between sectors would make the result closer to the baseline case. The result is shown in the upper panel of table 8 . We see the tradable production indeed weakens the financial channel of government spending. An increase in non-tradable government spending attracts more labor to non-tradable sector, reducing the proportion supplied to the tradable sector. The multipliers on output only increase marginally from 0.33 in the boom to 0.36 in the bust. The decrease of tradable goods in turn deteriorates the value of collateral and tightens the financial constraint. As a result, the borrowing condition is only slightly improved by the fiscal stimulus. Compared to the baseline case, the difference of consumption multipliers also become smaller which is -0.65 in the boom and -0.58 in the bust.

Lastly, given the fact that most countries operate under the managed-float exchange rate system and their exchange rate policies vary across time, I check the intermediate value of exchange rate coefficient $\gamma^{E}=0.3$. A higher value of $\gamma^{E}$ implies a more accommodating exchange rate policy following the government spending shock ${ }^{42}$. Consistent with the intuition, table 8 shows that the values of fiscal multiplier with $\gamma^{E}=0.3$ lie between the baseline economies with perfectly pegged exchange rate and perfectly flexible one. Fiscal expansions still stimulate production more in the financial bust (0.71) than in the boom (0.58), but since the real wage rigidity is partly offset by nominal depreciation, the stimulating effect is smaller compared to the perfectly pegged case $(0.67$ in the boom and 0.97 in the bust). The financial channel is still present here and consumption multipliers increase from -0.42 in the boom to -0.23 in the bust. In appendix E.4, I show the multiplier effects for a continuum of exchange rate coefficients $\gamma^{E} \in[0,1]$, where we can see the exchange rate policy is an important factor determining the state-dependent multipliers in a small open economy. It governs the relative strength of the two channels studied in this paper: the demand channel and the financial channel.

\section{Conclusion}

In this paper, I provide the empirical evidence and a theoretical framework to explain that the financial channel plays an important role in the transmission of government spending shock for small open economies. Using the cross-country data, I find that the fiscal stimulus has a stronger expansionary effect on private consumption during sudden stop crises than during normal times, and the dependence of the fiscal multiplier on financial states is more significant for countries with pegged exchange rates.

To understand the mechanism, I build a two-sector three-period small open economy model with a collateral constraint. In the model, the debt is denominated in foreign currency units while the domestic capital is used for collateral. When the constraint binds, a higher government

\footnotetext{
${ }^{42}$ That means the nominal exchange rate is depreciated at the time of the fiscal expansion if the wage constraint is binding.
} 
purchase of non-tradable goods appreciates the real exchange rate, increases the price of collateral, and promotes real absorption. Since the value of collateral today depends on the expectation of the future real exchange rate, the government's commitment to future stimulus can further relax the current financial constraint and stimulate real activities. Optimal policy analysis shows that the fiscal expansion ameliorates the severity of financial crises when the constraint binds. The mitigated crises in turn encourage private borrowing in normal times. Next, I extend the analysis to an infinite-horizon environment and show that the model can account for the empirical features established. The simulation result shows that under a flexible (pegged) exchange rate, the consumption multiplier on impact is -0.31 (-0.18) during normal times and is -0.12 (0.37) during sudden stop episodes. I also show how this result is sensitive to a variety of model specifications.

To keep the non-linear solution manageable, my model abstracts from several important aspects that can be important to quantify the effects of government spending, such as rule-of-thumb consumers, domestic real and nominal rigidities, or unresponsive monetary policy. Incorporating these components can help generate empirically-relevant multipliers, at the cost of making the key mechanism less clear. Despite the limitation, the result of this paper suggests that external debtdeflation is an important channel to consider when we study the fiscal multiplier in small open economies that are subject to sudden stop risks. For the future, it is interesting to incorporate it into a quantitative environment with the above components and examine how it interacts with traditional channels. 


\section{References}

Aguiar, M., \& Gopinath, G. (2006). Defaultable debt, interest rates and the current account. Journal of international Economics, 69(1), 64-83.

Anzoategui, D. (2016). Sovereign debt and the effects of fiscal austerity.

Auerbach, A. J., \& Gorodnichenko, Y. (2012a). Fiscal multipliers in recession and expansion. In Fiscal policy after the financial crisis (pp. 63-98). University of Chicago press.

Auerbach, A. J., \& Gorodnichenko, Y. (2012b). Measuring the output responses to fiscal policy. American Economic Journal: Economic Policy, 4(2), 1-27.

Benigno, G., Chen, H., Otrok, C., Rebucci, A., \& Young, E. R. (2013). Financial crises and macro-prudential policies. Journal of International Economics, 89(2), 453-470.

Benigno, G., Chen, H., Otrok, C., Rebucci, A., \& Young, E. R. (2016). Optimal capital controls and real exchange rate policies: A pecuniary externality perspective. Journal of Monetary Economics, $84,147-165$.

Bernardini, M., \& Peersman, G. (2015). Private debt overhang and the government spending multiplier: Evidence for the united states.

Bianchi, J. (2011). Overborrowing and systemic externalities in the business cycle. American Economic Review, 101 (7), 3400-3426.

Bianchi, J., Ottonello, P., \& Presno, I. (2016). Fiscal policy, sovereign risk, and unemployment.

Biljanovska, N. (2017). Optimal policy in collateral constrained economies. Macroeconomic Dynamics, 1-39.

Blanchard, O., \& Perotti, R. (2002). An empirical characterization of the dynamic effects of changes in government spending and taxes on output. the Quarterly Journal of economics, 117(4), 13291368.

Bocola, L. (2016). The pass-through of sovereign risk. Journal of Political Economy, 124(4), 879-926.

Calvo, G. A., Izquierdo, A., \& Mejia, L.-F. (2004). On the empirics of sudden stops: the relevance of balance-sheet effects (Tech. Rep.). National Bureau of Economic Research.

Carrillo, J. A., \& Poilly, C. (2013). How do financial frictions affect the spending multiplier during a liquidity trap? Review of Economic Dynamics, 16(2), 296-311.

Castro, G., Felix, R. M., Julio, P., Maria, J. R., et al. (2013). Fiscal multipliers in a small euro area economy: How big can they get in crisis times? Banco de Portugal. 
Cuadra, G., Sanchez, J. M., \& Sapriza, H. (2010). Fiscal policy and default risk in emerging markets. Review of Economic Dynamics, 13(2), 452-469.

Dávila, E., \& Korinek, A. (2017). Pecuniary externalities in economies with financial frictions. The Review of Economic Studies, rdx010.

Devereux, M. B., Young, E. R., \& Yu, C. (2015). A new dilemma: Capital controls and monetary policy in sudden stop economies (Tech. Rep.). National Bureau of Economic Research.

Dupor, B., \& Li, R. (2015). The expected inflation channel of government spending in the postwar us. European Economic Review, 74, 36-56.

Fernández-Villaverde, J., Gordon, G., Guerrón-Quintana, P., \& Rubio-Ramirez, J. F. (2015). Nonlinear adventures at the zero lower bound. Journal of Economic Dynamics and Control, 57, $182-204$.

Fornaro, L. (2015). Financial crises and exchange rate policy. Journal of International Economics, $95(2), 202-215$.

Greenwood, J., Hercowitz, Z., \& Huffman, G. W. (1988). Investment, capacity utilization, and the real business cycle. The American Economic Review, 402-417.

Ilzetzki, E., Mendoza, E. G., \& Végh, C. A. (2013). How big (small?) are fiscal multipliers? Journal of monetary economics, 60(2), 239-254.

Ilzetzki, E., Reinhart, C. M., \& Rogoff, K. S. (2017). Exchange arrangements entering the 21st century: Which anchor will hold? (Tech. Rep.). National Bureau of Economic Research.

Jordà, Ò., et al. (2005). Estimation and inference of impulse responses local projections. American economic review, 95(1), 161-182.

Kim, S., \& Roubini, N. (2008). Twin deficit or twin divergence? fiscal policy, current account, and real exchange rate in the us. Journal of International Economics, $74(2), 362-383$.

Kiyotaki, N., \& Moore, J. (1997). Credit cycles. Journal of political economy, 105(2), 211-248.

Lewis, V., \& Winkler, R. (2017). Government spending, entry, and the consumption crowding-in puzzle. International Economic Review, 58(3), 943-972.

Mendoza, E. G. (2002). Credit, prices, and crashes: Business cycles with a sudden stop. In preventing currency crises in emerging markets (pp. 335-392). University of Chicago Press.

Mendoza, E. G. (2005). Real exchange rate volatility and the price of nontradables in sudden-stopprone economies (Tech. Rep.). National Bureau of Economic Research.

Mendoza, E. G. (2010). Sudden stops, financial crises, and leverage. The American Economic Review, $100(5)$, 1941-1966. 
Mendoza, E. G., \& Bianchi, J. (2011). Overborrowing, financial crises and 'macro-prudential'policy? (No. 11-24). International Monetary Fund.

Mendoza, E. G., \& Bianchi, J. (2015). Optimal, time-consistent macroprudential policy.

Miyamoto, W., Nguyen, T. L., \& Sheremirov, V. (2016). The effects of government spending on real exchange rates: evidence from military spending panel data.

Monacelli, T., \& Perotti, R. (2010). Fiscal policy, the real exchange rate and traded goods. The Economic Journal, 120(544), 437-461.

Neumeyer, P. A., \& Perri, F. (2005). Business cycles in emerging economies: the role of interest rates. Journal of monetary Economics, 52(2), 345-380.

Ottonello, P. (2012). Optimal exchange rate policy under collateral constraints and wage rigidity. manuscript, Columbia University.

Pragidis, I., Tsintzos, P., \& Plakandaras, B. (2017). Asymmetric effects of government spending shocks during the financial cycle. Economic Modelling.

Pröbsting, C., House, C. L., \& Tesar, L. L. (2017). Austerity in the aftermath of the great recession (Tech. Rep.). NBER.

Ramey, V. A. (2011). Identifying government spending shocks: it's all in the timing. The Quarterly Journal of Economics, 126(1), 1-50.

Ramey, V. A., \& Zubairy, S. (2014). Government spending multipliers in good times and in bad: evidence from us historical data (Tech. Rep.). National Bureau of Economic Research.

Ravn, M. O., Schmitt-Grohé, S., \& Uribe, M. (2012). Consumption, government spending, and the real exchange rate. Journal of Monetary Economics, 59(3), 215-234.

Rendahl, P. (2016). Fiscal policy in an unemployment crisis. The Review of Economic Studies, $83(3), 1189-1224$.

Schmitt-Grohé, S., \& Uribe, M. (2016). Downward nominal wage rigidity, currency pegs, and involuntary unemployment. Journal of Political Economy, 124(5), 1466-1514.

Schmitt-Grohé, S., \& Uribe, M. (2017). Is optimal capital control policy countercyclical in open economy models with collateral constraints? IMF Economic Review, 65 (3), 498-527.

Shen, W., Yang, S., \& Zanna, L.-F. (2015). Government spending effects in low-income countries.

Sin, J. (2016). The fiscal multiplier in small open economy: The role of liquidity frictions. 


\section{Appendices}

\section{A Equilibrium Conditions}

The first order conditions of the baseline model are listed as follows,

$$
\begin{aligned}
& p_{t}^{N}=\frac{1-\omega}{\omega}\left(\frac{c_{t}^{T}}{c_{t}^{N}}\right)^{\frac{1}{\theta}} \\
& \left(1-\mu_{t}\right)=\beta \mathbb{E}_{t} \Lambda_{t, t+1} R^{*} \\
& \left(1-\kappa \mu_{t}\right) q_{t}^{K}=\beta \mathbb{E}_{t}\left\{\Lambda_{t, t+1}\left[q_{t+1}^{K}+r_{t+1}^{K}\right]\right\} \\
& \Lambda_{t, t+1}=\frac{u_{C T}\left(c_{t+1}, l_{t+1}\right)}{u_{C T}\left(c_{t+1}, l_{t}\right)} \\
& \frac{1}{R^{*}} b_{t+1}+\phi w_{t} l_{t} \leq \kappa q_{t}^{K} k_{t+1} \\
& w_{t}=\frac{u_{L}\left(c_{t}, l_{t}\right)}{u_{C T}\left(c_{t}, l_{t}\right)}=\frac{p_{t}^{N} z_{t} F_{L}\left(k_{t}, l_{t}^{d}\right)}{1+\phi \mu_{t}} \\
& r_{t}^{K}=p_{t}^{N} z_{t} F_{K}\left(k_{t}, l_{t}^{d}\right) \\
& y_{t}^{N}=z_{t} F\left(k_{t}, l_{t}^{d}\right) \\
& w_{t} \geq \gamma \frac{w_{t-1}}{\epsilon_{t}} \\
& c_{t}=\left(\omega c_{t}^{T \frac{\theta-1}{\theta}}+(1-\omega) c_{t}^{N \frac{\theta-1}{\theta}}\right)^{\frac{\theta}{1-\theta}} \\
& k_{t}=1 \\
& c_{t}^{T}+\omega^{G} g_{t}+b_{t}=\frac{1}{R^{*}} b_{t+1}+y_{t}^{T} \\
& c_{t}^{N}+\left(1-\omega^{G}\right) g_{t}=y_{t}^{N} \\
& \log \left(z_{t}\right)=\rho^{z} \log \left(z_{t-1}\right)+\epsilon_{t}^{z} \\
& \log \left(y_{t}^{T}\right)=\rho^{Y T} \log \left(y_{t-1}^{T}\right)+\epsilon_{t}^{Y T} \\
& \text { Spending policy: } \quad \log \frac{g_{t}}{\bar{g}}=\rho^{G} \frac{g_{t-1}}{\bar{g}}+\gamma^{Y} \log \frac{g d p_{t-1}}{\overline{g d p}}+\gamma^{B} \log \frac{b_{t-1} / g d p_{t-1}}{\bar{b} / \overline{g d p}}+\epsilon_{t}^{G} \\
& \text { Exchange rate policy: } \epsilon_{t}=\max \left\{\frac{\gamma w_{t-1}}{w_{t}^{f}}, 1\right\}^{\gamma^{E}}
\end{aligned}
$$


In the model with investment technology, we also have the following equations:

$$
\begin{aligned}
& k_{t+1}-(1-\delta) k_{t}=k_{t} \Phi\left(\frac{i_{t}}{k_{t}}\right) \\
& i_{t}=\left(\omega i_{t}^{T \frac{\theta-1}{\theta}}+(1-\omega) i_{t}^{N \frac{\theta-1}{\theta}}\right)^{\frac{\theta}{1-\theta}} \\
& q_{t}^{K} \Phi^{\prime}\left(\frac{i_{t}}{k_{t}}\right) \omega i_{t}^{\frac{1}{\theta}} i_{t}^{T-\frac{1}{\theta}}=1 \\
& q_{t}^{K} \Phi^{\prime}\left(\frac{i_{t}}{k_{t}}\right)(1-\omega) i_{t}^{\frac{1}{\theta}} i_{t}^{N-\frac{1}{\theta}}=p_{t}^{N}
\end{aligned}
$$

\section{B Computational Method}

The model is solved using global method. I use time iteration and linear interpolation. The high dimensional expectation is evaluated using monomial quadrature. The state space of the baseline economy is:

$$
\mathbb{S}_{t}=\left[b_{t}, w_{t-1} ; y_{t}^{T}, z_{t}, g_{t}\right]
$$

Firstly, I discretize the state space and approximating a list of control variables (policy functions) $\mathbb{C}_{t}$ by multi-linear functions on $\mathbb{S}_{t}{ }^{43}$. Taking these functions as initial guess, I can back out other model variables at time $t$ and the state vector at the beginning of next period $\mathbb{S}_{t+1}$. Then, I evaluate the control variables at time $t+1\left(\mathbb{C}_{t+1}\right)$ using the guessed policy functions and linear interpolation. The conditional expectations are calculated. Next, at each state point, a system of equations is solved simultaneously by a Newton-type solver and the policy functions are updated accordingly. In the next iteration, I use these new policy functions to evaluate the variables at $t+1$. I iterate on these policies until the difference between successive iteration is small enough.

In my model environment, the algorithm proceeds as follows,

1. Use piece-wise linear functions to approximate a set of policies on the state space $\mathbb{C}^{0}=$ $\left\{c_{t}^{T, 0}, l_{t}^{0}, \eta_{t}^{w, 0}, q_{t}^{K, 0}\right\}$. As the initial guess, I use the model's non-stochastic steady state. $\left(\eta_{t}^{w, 0}\right.$ is an auxiliary variable to deal with the wage constraint. See below.)

2. Given the initial guess $\mathbb{C}^{0}$, back out other variables in the current period $\left\{y_{t}^{N}, w_{t}, r_{t}^{K}, c_{t}^{N}, b_{t+1}, p_{t}^{N}\right\}$ using static equilibrium conditions. Notice that $b_{t+1}$ and $w_{t}$ are the endogenous state of the next period' problem.

3. Use the law of motion for the exogenous process to iterate the state vector. On each quadrature point, the next period state is $\mathbb{S}_{t+1}=\left[b_{t+1}, w_{t} ; y_{t+1}^{T}, z_{t+1}, g_{t+1}\right]$. Then, I use the guessed policy functions to evaluate control variables at time $\mathrm{t}+1:\left\{c_{t+1}^{T}, l_{t+1}, \eta_{t+1}^{w}, q_{t+1}^{K}\right\}$, and back out other variables at time $\mathrm{t}+1:\left\{p_{t+1}^{N}, c_{t+1}^{N}, l_{t+1}\right\}$.

4. For each point on the grid, jointly solve a system of equations (58), (59), (61), (62), (65) and

\footnotetext{
${ }^{43}$ Linear interpolation is good to deal with kinks near the constraint region.
} 
update the value of policies: $\mathbb{C}^{1}=\left\{c_{t}^{T, 1}, l_{t}^{1}, \eta_{t}^{w, 1}, q_{t}^{K, 1}\right\}$ (also the financial multiplier $\mu_{t}^{1}$. See below.).

5. Compute the distance between the new policy functions and the original ones, stop if

$$
\max \left|\mathbb{C}^{0}-\mathbb{C}^{1}\right|<1 e-7
$$

Otherwise, take the new policy functions as the guess and start from the second step.

There are two occationally binding constraints and I use different methods to deal with them. For the wage constraint, I apply the auxiliary vairable mehod in Benigno et al. (2013). Suppose $\eta_{t}^{w}$ is an auxiliary variable and it is positive if and only if the wage constraint is binding. In that case, there is involuntary unemployment in equilibrium and I define,

$$
l_{t}^{s}-l_{t}^{d}=U_{t}=\max \left(\eta_{t}^{w}, 0\right)^{3}
$$

If the wage constraint is not binding, $\eta_{t}^{w}$ is negative and its absolute value is the difference between full-employment wage and wage state from the last period,

$$
w_{t}-\frac{\gamma w_{t-1}}{\epsilon_{t}}=\max \left(-\eta_{t}^{w}, 0\right)^{3}
$$

The method allows me to transform the inequality constraint into equality when I can apply Newton-type solver to get the solutions.

To deal with the fianncial constraint, I use the "guess and verify" procedure as in Mendoza \& Bianchi (2015). In each iteration, I first solve the model without the financial constraint, and then check whether the financial constraint is violated. If it is not, go to the next grid point. Otherwise, solve the model again assuming the financial constraint is binding.

\section{Empirical Appendix}

This paper collects quarterly data on GDP components, real exchange rate and current account for a set of small open economies. The use of quarterly data is crucial to define sudden stop crisis episodes and is also essential for the identifying assumption.

Most of the data comes from IMF's International Financial Statistics, except for the missing values of current account balance for several countries where I interpolate the World Development Index's annual data to quarterly frequency. The real variables are the nominal variables deflated by GDP deflators if they exist or CPI index if they do not. The variables measured in US dollars are converted using period average exchange rate. For most of the countries, I use the CPI-adjusted real effective exchange rate index to represent the real exchange rate level. For those countries these indexes do not exist, I construct real exchange rate using nominal exchange rate adjusted by relative CPI levels. 
Sudden stops: I define the sudden stop as a big current account reversal happening amid of deep economic recession. This definition of sudden stop is similar to that in Calvo et al. (2004). Specifically, I count the sample-episodes that satisfying the following two criterion as sudden stop periods:

1. Year-To-Year current account reversal is larger that 1.5 standard deviations of the current account to GDP ratio;

2. The real GDP is at least 1.5 standard deviations below its long-run trend.

To compare the fiscal policy effect during the fixed sudden stop episodes, for each identified sudden stop period, I create a 6 -quarters event window with 2 periods before and 4 periods after it. This clear-cut way to define sudden stop event generally captures the spirit of "big and sudden" capital flow stop as in Calvo et al. (2004) and at the same time makes it suitable to do serious empirical analysis. Different from Calvo et al. (2004)'s definition, my sudden stop definition is also based on economic cycle of GDP, which makes our identified sudden stop dates not necessarily overlap. But I find most of the identified sudden stop episodes in their paper also belong to my sample.

Exchange rate regime: The way I define exchange rate regime follows Ilzetzki et al. (2013) and Ilzetzki et al. (2017). More specifically, I include the country with no legal tender, hard pegs, crawling pegs, and de facto or pre-announced bands or crawling bands with margins no larger than $\pm 2 \%$ as pegged exchange rate regime. While all other countries are classified as flexible regime.

Based on the above definitions, I construct a sample dataset of 30 small open economies with each country having at least one sudden stop event in the history. The sample covers a wide range of countries having the financially distressful periods that are frequently studied in the literature. I successfully identifies most of the well-known sudden stop events in the last two decades. These include the Tequila crisis in Latin American countries, Asian financial crisis, Russian financial crisis and European debt crisis, etc. Overall, I find 38 sudden stop episodes, and 15 countries are classified as pegged exchange change rate while the rest is believed to take flexible exchange rate regime.

\section{C.1 Econometric Methodology}

A key issue in fiscal multiplier research is the identification of fiscal shocks. In this paper, I combine the identification assumption of Ilzetzki et al. (2013) with Jordà et al. (2005)'s local projection method to generate impulse responses. Ilzetzki et al. (2013) applies the SVAR approach in Blanchard \& Perotti (2002) to a panel-data environment. The restriction behind this method is that fiscal policy requires at least one period to respond to innovations to economic states. To account for the non-linearity in my model, the econometric techique in this paper follows Jordà et al. (2005)'s local projection method, modified by Ramey \& Zubairy (2014). Compared with an SVAR, the local projection method has two advantages: 1 . it is more robust to misspecification because it does not impose implicit dynamic restrictions on the shape of the impulse responses; 2 . it is easy to accommodate state-dependence and to study non-linear objects. 
Ramey \& Zubairy (2014) modifies the "three steps method" in Jordà et al. (2005) to create impulse response and calculate multipliers into the "one step method", and they argue that these two methods gives the same result if there is no data loss. I mainly use the "one step method" in my paper but I also confirmed that the other way gives similar result for the baseline case. The methodology can be summarized as the following steps:

- Data transformation: Before running the regression, I convert each quantity variables as proportion of trend GDP.

$$
x_{i, t}=\frac{X_{i, t}}{\bar{Y}_{i, t}}
$$

where $X_{i, t}$ is respectively GDP or one of its component and $\bar{Y}_{i, t}$ is hp-filtered trend of GDP. After this transformation, all economic variables are in the same unit. That makes it convenient to get fiscal multipliers directly from the regression.

- SVAR regression: In order to identify the government spending shock and use that as an instrument in the multiplier estimation, I extract the residuals from the SVAR regression for each country and call that "BP shock". More specifically, I estimate a system of recursivelyidentified vector auto-regression equations:

$$
A Z_{i, t}=\sum_{k=1}^{4} C_{k} Z_{i, t-k}+B u_{i, t}
$$

where $Z_{i, t}=\left[g_{i, t-1}, G D P_{i, t-1}, d r e x_{i, t-1}, C A_{i, t-1} / G D P_{i, t-1}\right]^{\prime}$ is the vetor of economic variables. drex $_{i, t-1}$ is the difference of $\log$ real exchange rate. $A$ and $C_{k}$ are the estimated coefficent matrics featuring contemporous and dynamic effects. $B$ is an orthogonal matrix with the diagnal elements showing the variance of structrual shocks. Following Blanchard \& Perotti (2002), I assume that changes in government consumption require at least one quarter to respond to innovations in other macroeconomic variables. The remaining identifying assumptions include a Cholesky decomposition ordering current account ratio after GDP but before the real exchange rate.

- One-step estimation: For each variable and each horizon, I estimate the following panel IV regression with fixed effect:

$$
\sum_{j=0}^{h} x_{i, t+j}=c+\alpha_{i}+m^{x, h} \sum_{j=0}^{h} g_{i, t+j}+\Phi_{h}(L) z_{i, t-1}+u_{i, t+h}
$$

where $x$ is the variable of our interest, in this context, GDP, consumption, investment and real exchange rate change. $z_{i, t-1}$ controls for lagged economic fundamentals and fiscal variables $Y_{i, t-1}$. The endogenous regressor is instrumented by the estimated SVAR residual from the second step: shock $_{i, t}=u^{g}\left(g_{i, t}\right)$, which is the orthogonalized part of current government spending observations. The benefit of this one step method comes from the fact that the 
estimates of $m^{x, h}$ directly represents the spending multiplier on variable $x$ in horizon h. To study the state-dependent spending multiplier during sudden stop crisis, I run the following non-linear regression:

$$
\begin{aligned}
\sum_{j=0}^{h} x_{i, t+j}= & I_{i, t-1} \times\left[c_{A}+\alpha_{A, i}+m_{A}^{x, h} \sum_{j=0}^{h} g_{i, t+j}+\Phi_{A, h}(L) z_{i, t-1}\right] \\
& +\left(1-I_{i, t-1}\right) \times\left[c_{B}+\alpha_{B, i}+m_{B}^{x, h} \sum_{j=0}^{h} g_{i, t+j}+\Phi_{B, h}(L) z_{i, t-1}\right]+u_{i, t+h}
\end{aligned}
$$

"A" denotes sudden stop episodes and "B" denotes normal times. $I_{i, t-1}$ is a dummy variable that indicates whether the economy is in sudden stop recession or not. In this regression, the government spending is instrumented by $I_{i, t-1} \times$ shock $_{i, t}$ and $\left(1-I_{i, t-1}\right) \times$ shock $_{i, t}$ in respective regimes. The estimates of $m_{A}^{x, h}$ and $m_{B}^{x, h}$ are spending multipliers during sudden stop crisis and normal times.

In order to account for the interaction of sudden stop with exchange rate regime and the sign effect of fiscal shocks, I further extend the baseline regression. I divide my sample into the countryepisodes of pegged exchange rate "P" or flexible exchange rate "F", and fiscal expansion "+" or fiscal contraction "-". First, let $1_{i, t-1}^{P}\left(1_{i, t-1}^{F}\right)$ denote the economy is under predetermined (flexible) exchange rate regime, then I run the four-regime regression,

$$
\begin{aligned}
\sum_{j=0}^{h} x_{i, t+j}= & I_{i, t-1} \times 1_{i, t-1}^{P} \times\left[c_{P, A}+\alpha_{P, A, i}+m_{P, A}^{x, h} \sum_{j=0}^{h} g_{i, t+j}+\Phi_{P, A, h}(L) z_{i, t-1}\right] \\
& +\left(1-I_{i, t-1}\right) \times 1_{i, t-1}^{P} \times\left[c_{P, B}+\alpha_{P, B, i}+m_{P, B}^{x, h} \sum_{j=0}^{h} g_{i, t+j}+\Phi_{P, B, h}(L) z_{i, t-1}\right] \\
& +I_{i, t-1} \times 1_{i, t-1}^{F} \times\left[c_{F, A}+\alpha_{F, A, i}+m_{F, A}^{x, h} \sum_{j=0}^{h} g_{i, t+j}+\Phi_{F, A, h}(L) z_{i, t-1}\right] \\
& +\left(1-I_{i, t-1}\right) \times 1_{i, t-1}^{F} \times\left[c_{F, B}+\alpha_{F, B, i}+m_{F, B}^{x, h} \sum_{j=0}^{h} g_{i, t+j}+\Phi_{F, B, h}(L) z_{i, t-1}\right]+u_{i, t+h}
\end{aligned}
$$

The comparison between $m_{P, A}^{x, h}$ and $m_{P, B}^{x, h}\left(m_{F, A}^{x, h}\right.$ and $\left.m_{F, B}^{x, h}\right)$ shows the relative effectiveness of fiscal policy during sudden stops or normal times for the countries under pegged (flexible) exchange rate. Second, when I explore the asymmetric effect on fiscal multiplier, I define the indicator for a positive shock $1_{i, t-1}^{+}=\left[u^{g}\left(g_{i, t-1}\right) \geq 0\right]$, where $u^{g}(\cdot)$ is the estimated SVAR residual. Similarly, the indicator 
of a negative shock is $1_{i, t-1}^{-}=\left[u^{g}\left(g_{i, t-1}\right)<0\right]$. Then I run the regression,

$$
\begin{aligned}
\sum_{j=0}^{h} x_{i, t+j}= & I_{i, t-1} \times 1_{i, t-1}^{+} \times\left[c_{+, A}+\alpha_{+, A, i}+m_{+, A}^{x, h} \sum_{j=0}^{h} g_{i, t+j}+\Phi_{+, A, h}(L) z_{i, t-1}\right] \\
& +I_{i, t-1} \times 1_{i, t-1}^{-} \times\left[c_{-, A}+\alpha_{-, A, i}+m_{-, A}^{x, h} \sum_{j=0}^{h} g_{i, t+j}+\Phi_{-, A, h}(L) z_{i, t-1}\right] \\
& +\left(1-I_{i, t-1}\right) \times 1_{i, t-1}^{+} \times\left[c_{+, B}+\alpha_{+, B, i}+m_{+, B}^{x, h} \sum_{j=0}^{h} g_{i, t+j}+\Phi_{+, B, h}(L) z_{i, t-1}\right] \\
& +\left(1-I_{i, t-1}\right) \times 1_{i, t-1}^{-} \times\left[c_{-, B}+\alpha_{-, B, i}+m_{-, B}^{x, h} \sum_{j=0}^{h} g_{i, t+j}+\Phi_{-, B, h}(L) z_{i, t-1}\right]+u_{i, t+h}
\end{aligned}
$$

The difference between $m_{+, A}^{x, h}$ and $m_{-, A}^{x, h}$ (between $m_{+, B}^{x, h}$ and $m_{-, B}^{x, h}$ ) shows the asymmetric effect of fiscal policy during sudden stop episodes (normal times).

\section{C.2 Robustness Check}

\section{C.2.1 Testing instrument relevance}

I test the relevance of the BP shock as the instrument in the baseline linear and non-linear model. The Kleinpergan-Paap rk F statistic is used to test whether we have a weak instrument. Following Ramey \& Zubairy (2014), a statistic greater than 23 leads us to reject the null hypothesis and conclude the instrument in relevant. The result is shown in appendix E.

\section{C.2.2 Sensitivity to the "three steps method"}

Following Jordà et al. (2005)'s seminal paper, most of empirical studies using local projection method adopt the "three steps method" to estimate fiscal multipliers. They estimate the impulse responses from a series of forecasting regressions and then bootstrap fiscal multipliers using simulations. In order to see whether our baseline result is sensitive to this alternative, I also estimate the state-contingent multipliers using the "three steps method". The process is that, for each horizon $h=1,2, \ldots, H$, I estimate the regression model,

$$
\begin{aligned}
x_{i, t+h}= & I_{i, t-1} \times\left[c_{A}+\alpha_{A, i}+\beta_{A}^{x, h} \operatorname{shock}_{i, t}+\Phi_{A, h}(L) z_{i, t-1}\right] \\
& +\left(1-I_{i, t-1}\right) \times\left[c_{B}+\alpha_{B, i}+\beta_{B}^{x, h} \operatorname{shock}_{i, t}+\Phi_{B, h}(L) z_{i, t-1}\right]+u_{i, t+h}
\end{aligned}
$$

$x_{i, t+h}$ include both the variables of the interest and government spending. The collection of the coefficient $\beta_{A}^{x, h}\left(\beta_{B}^{x, h}\right)$ provides the dynamic response of variable $x$ at time $t+h$ after the shock hit the economy at time $t$ supposing the economy stays in the same financial regime A (B). The cumulative multipliers of horizon $H$ that is measured as the cumulative change of $x$ per cumulative 
change in government spending is calculated as,

$$
m_{A}^{x, H}=\frac{\sum_{h=0}^{H} \beta_{A}^{x, h}}{\sum_{h=0}^{H} \beta_{A}^{g, h}}, \quad m_{B}^{x, H}=\frac{\sum_{h=0}^{H} \beta_{B}^{x, h}}{\sum_{h=0}^{H} \beta_{B}^{g, h}}
$$

The confidence bands can be get by Monte Carlos simulations based on the Newey-West variancecovariance matrix from the impulse response estimation. The result is in appendix E.

\section{C.2.3 Sensitivity to alternative instruments}

Instead of taking SVAR residuals as fiscal instrument in the panel data regression, Ramey \& Zubairy (2014) directly uses the current government spending observations (after the transformation). They argue that controlling for past economic variables in the right hand side, the BP shocks are already embedded as a part of spending observations. However, SVAR imposes extra restrictions on the residuals in addition to the timing of fiscal response. These restrictions could provide additional information in identifying the effect of government spending shock. In appendix E, I also compare the baseline result with the one directly taking spending observations as the instruments.

\section{Additional tables}

\begin{tabular}{ll}
\hline \hline GDP: & Definition: real GDP over trend GDP \\
& Data sources: IFS: Nominal GDP adjusted by GDP deflator or CPI (NGDP_XDC) \\
\hline Government spending: & Definition: real government consumption over trend GDP \\
& Data sources: IFS: Public Final Consumption Expenditure, General Government \\
& (NCGG_XDC) \\
\hline Private consumption: & Definition: real private consumption over trend GDP \\
& Data sources: IFS: Household Consumption Expenditure, incl. NPISHs (NCP_XDC) \\
\hline Private investment: & Definition: real fixed capital formation over trend GDP \\
& Data sources: IFS: Gross Capital Formation, Gross Fixed Capital Formation, Corporations, \\
& Households, and Non-profit Institutions Serving Households (NFI_XDC) \\
\hline Current account-GDP ratio: & Definition: Current account balance divided by GDP \\
& Data sources: IFS: Balance of Payments, Supplementary Items, Current Account, Net \\
& (excluding exceptional financing) (BCAXF_BP6_USD) or WDI: Current account balance \\
& (BN.CAB.XOKA.CD) \\
\hline Real exchange rate: & Definition: CPI-based real effective exchange rate or nominal exchange rate divided by con- \\
& sumer price index \\
& Data sources: IFS: Real Effective Exchange Rate, based on Consumer Price In- \\
& dex (EREER_IX) or IFS: Domestic Currency Per US Dollar, Period Average \\
& (ENDA_XDC_USD_RATE) \\
\hline
\end{tabular}

Table 9: Data Sources 


\section{E Additional Figures}

\section{E.1 Data Coverage}
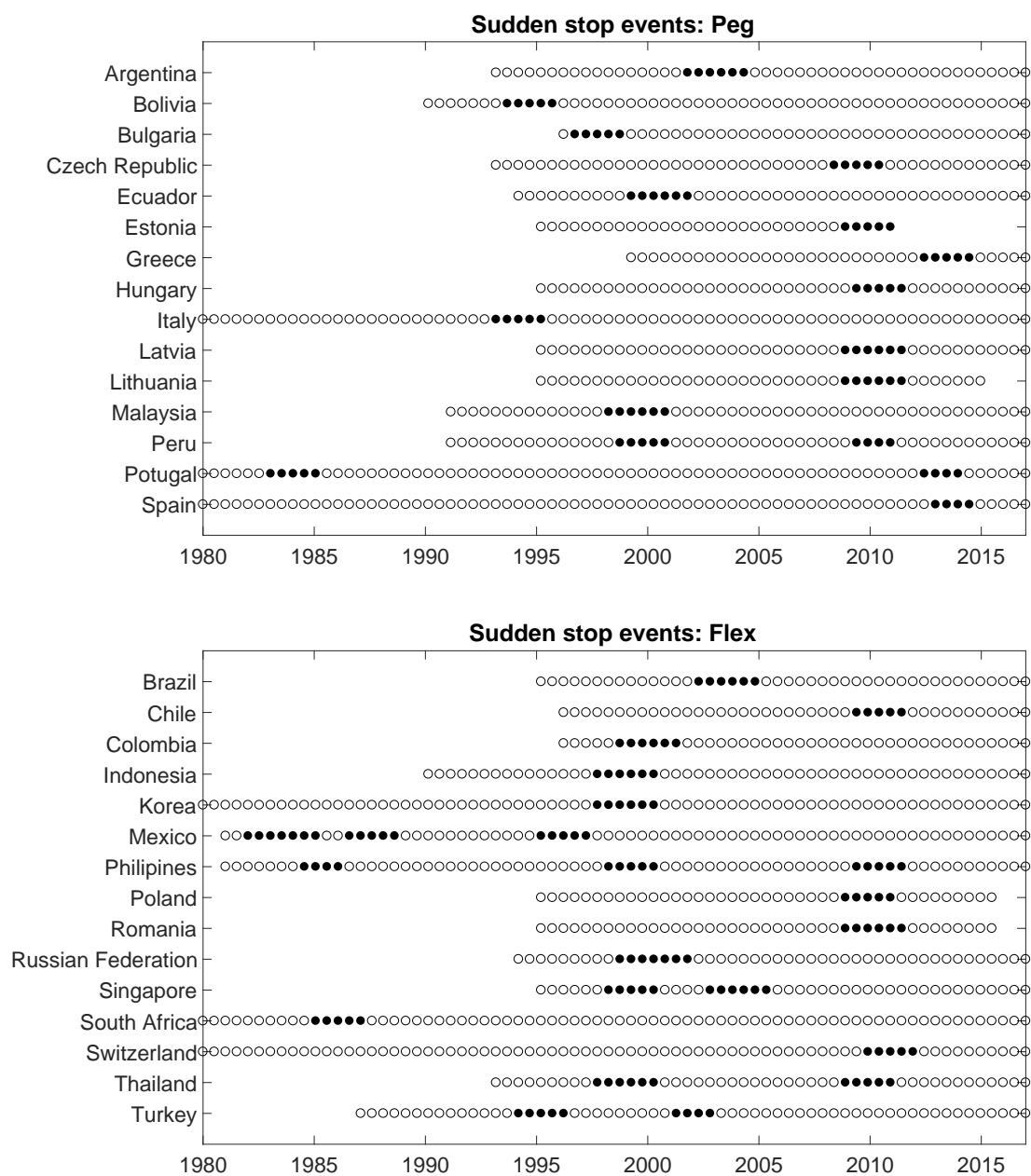

Figure 13: Peg and Flex Sample 


\section{E.2 Empirical Regression}

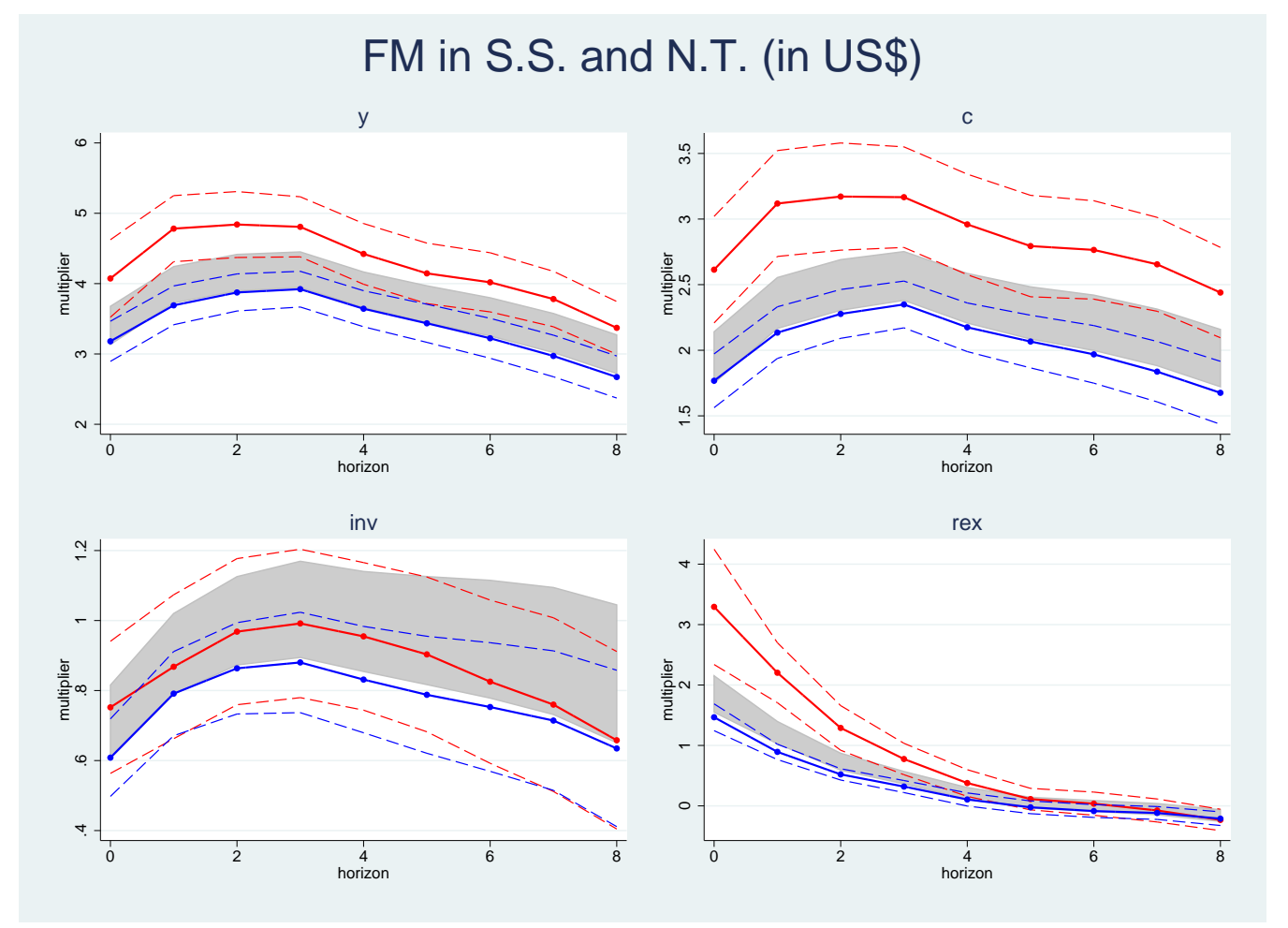

Figure 14: Fiscal Multiplier of S.S. and N.T. (in US\$)

Note: The variables in the regression are denominated in US\$, except real change rate as indexed numbers and current account ratio as percentage. Red curves are cumulative multipliers during sudden stop episodes; blue curves are cumulative multipliers in normal times. Dashed curves represent $80 \%$ confidence bands based on HAC standard deviations. 


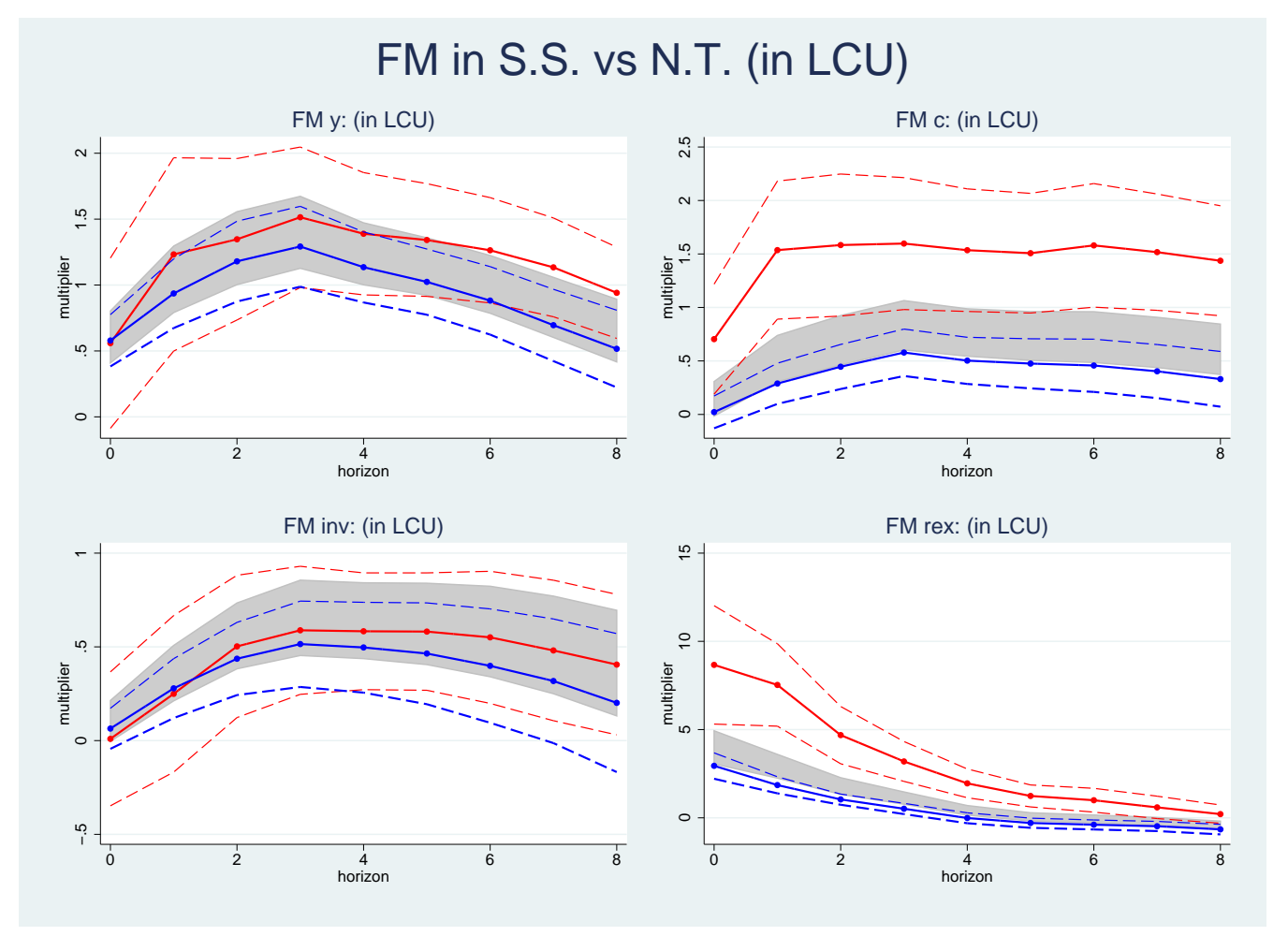

Figure 15: Fiscal Multiplier of S.S. and N.T. (in LCU)

Note: The variables in the regression are denominated in Local Currency Units (LCU), except real change rate as indexed numbers and current account ratio as percentage. Red curves are cumulative multipliers during sudden stop episodes; blue curves are cumulative multipliers in normal times. Dashed curves represent $80 \%$ confidence bands based on $H A C$ standard deviations. 


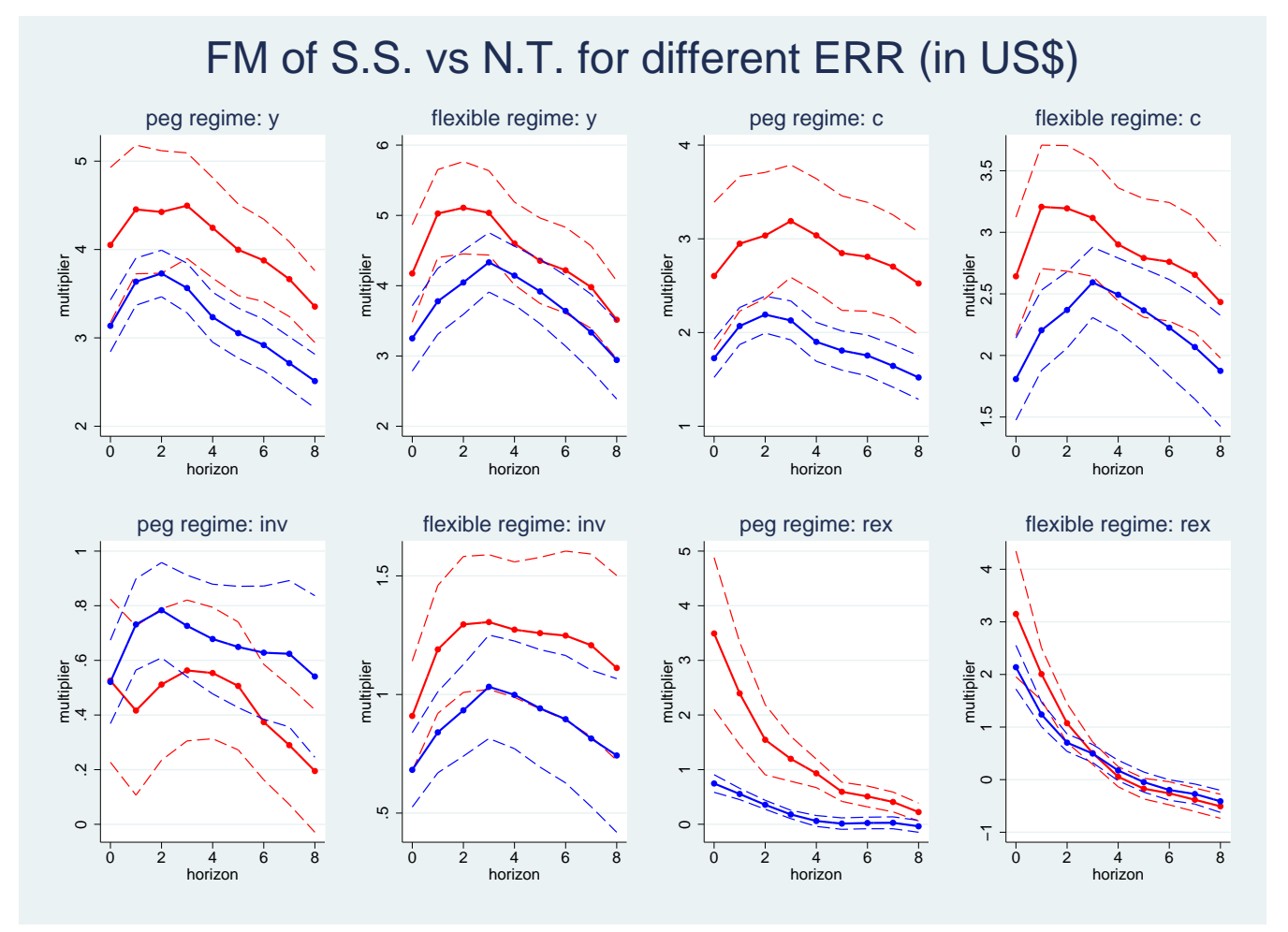

Figure 16: Fiscal Multiplier of S.S. and N.T. in different ERR (in US\$)

Note: The variables in the regression are denominated in US\$, except real change rate as indexed numbers and current account ratio as percentage. Red curves are cumulative multipliers during sudden stop episodes; blue curves are cumulative multipliers in normal times. Dashed curves represent $80 \%$ confidence bands based on HAC standard deviations. The definition of exchange rate regime follows Ilzetzki et al. (2017). 


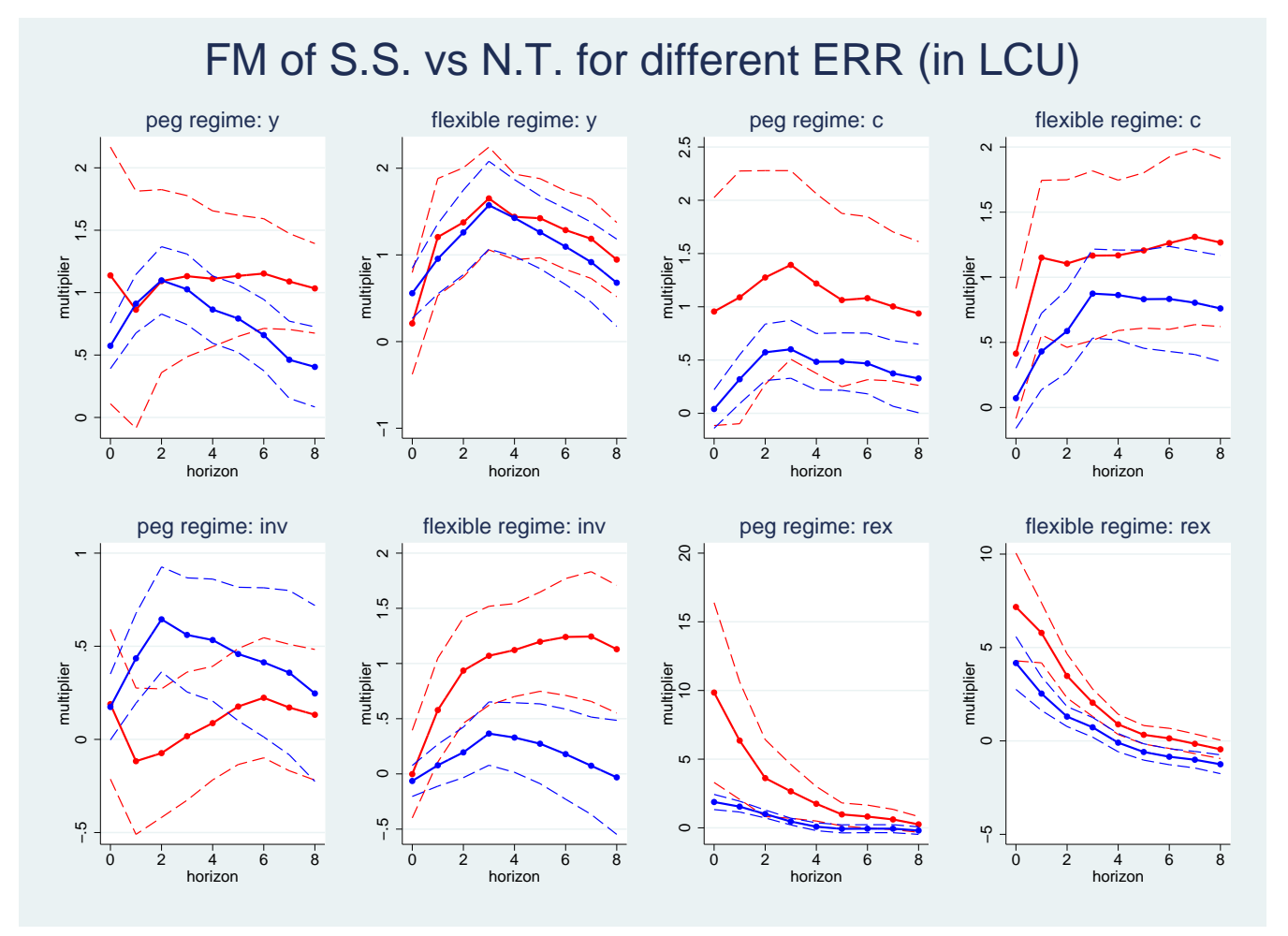

Figure 17: Fiscal Multiplier of S.S. and N.T. in different ERR (in LCU)

Note: The variables in the regression are denominated in $L C U$, except real change rate as indexed numbers and current account ratio as percentage. Red curves are cumulative multipliers during sudden stop episodes; blue curves are cumulative multipliers in normal times. Dashed curves represent $80 \%$ HAC confidence bands based on HAC standard deviations. The definition of exchange rate regime follows Ilzetzki et al. (2017). 


\section{FM under positive and negative shocks (in US\$)}
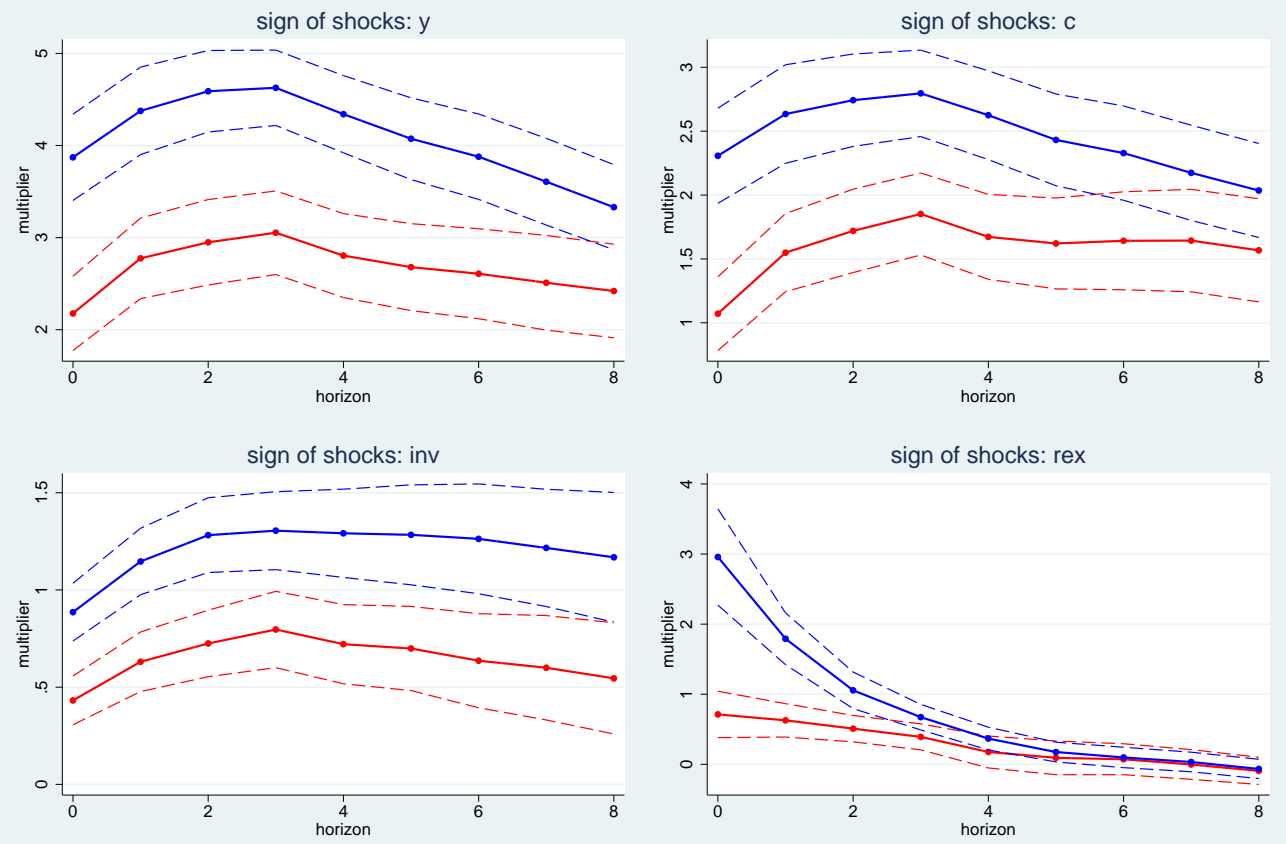

Figure 18: Fiscal Multiplier of positive and negative shocks (in US\$)

Note: The variables in the regression are denominated in US\$, except real change rate as indexed numbers and current account ratio as percentage. Red curves are cumulative multipliers associated with positive shocks; blue curves are cumulative multipliers associated with negative shocks. The sign of shocks comes from the SVAR residuals for each country. Dashed curves represent $80 \%$ confidence bands based on HAC standard deviations. 


\section{FM under positive and negative shocks for S.S. vs N.T. (in US\$)}
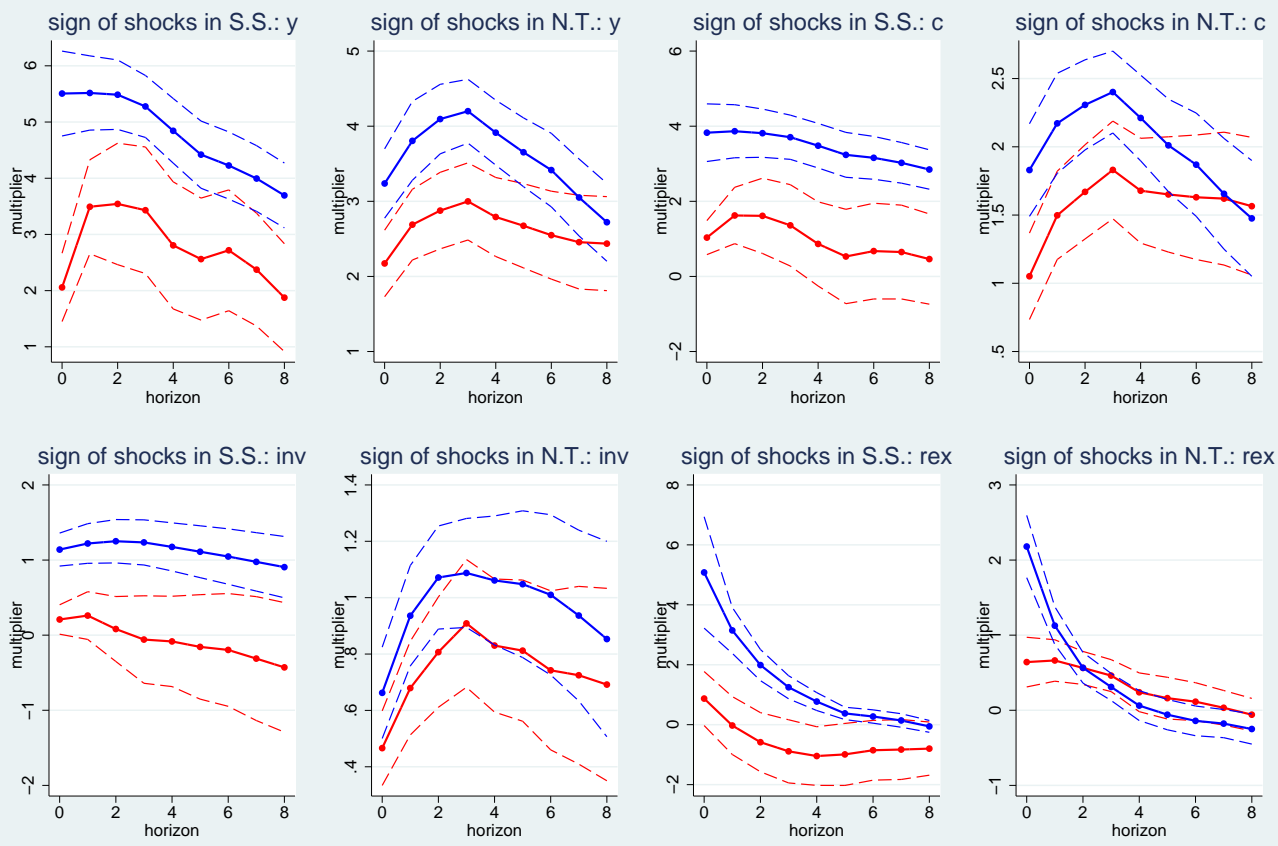

Figure 19: Fiscal Multiplier of positive and negative shocks in S.S. and N.T. (in US\$)

Note: The variables in the regression are denominated in US\$, except real change rate as indexed numbers and current account ratio as percentage. Red curves are cumulative multipliers associated with positive shocks; blue curves are cumulative multipliers associated with negative shocks. The sign of shocks comes from the SVAR residuals for each country. Dashed curves represent $80 \%$ confidence bands based on HAC standard deviations. 


\section{FM under positive and negative shocks (in LCU)}
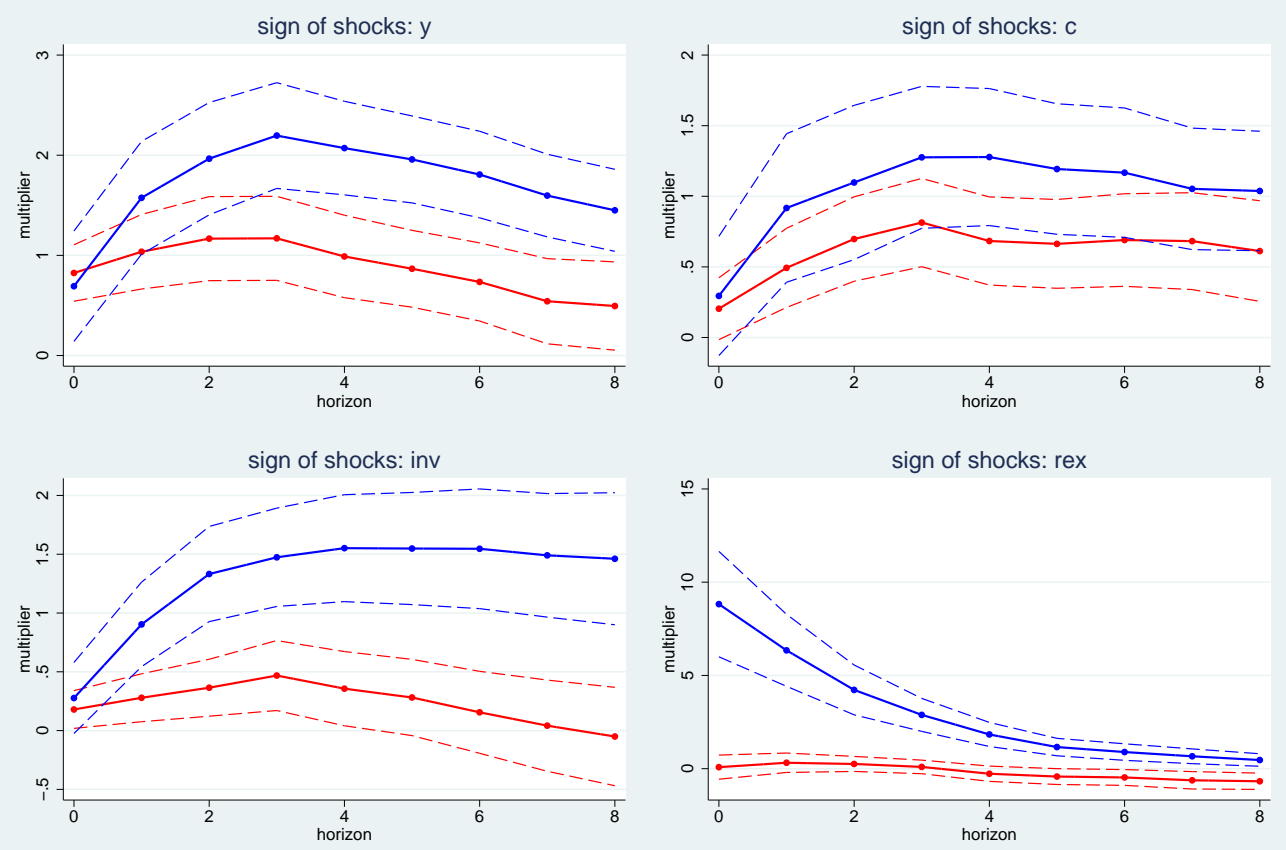

Figure 20: Fiscal Multiplier of positive and negative shocks (in LCU)

Note: The variables in the regression are denominated in $L C U$, except real change rate as indexed numbers and current account ratio as percentage. Red curves are cumulative multipliers associated with positive shocks; blue curves are cumulative multipliers associated with negative shocks. The sign of shocks comes from the SVAR residuals for each country. Dashed curves represent $80 \%$ confidence bands based on HAC standard deviations. 


\section{FM under positive and negative shocks for S.S. vs N.T. (in LCU)}
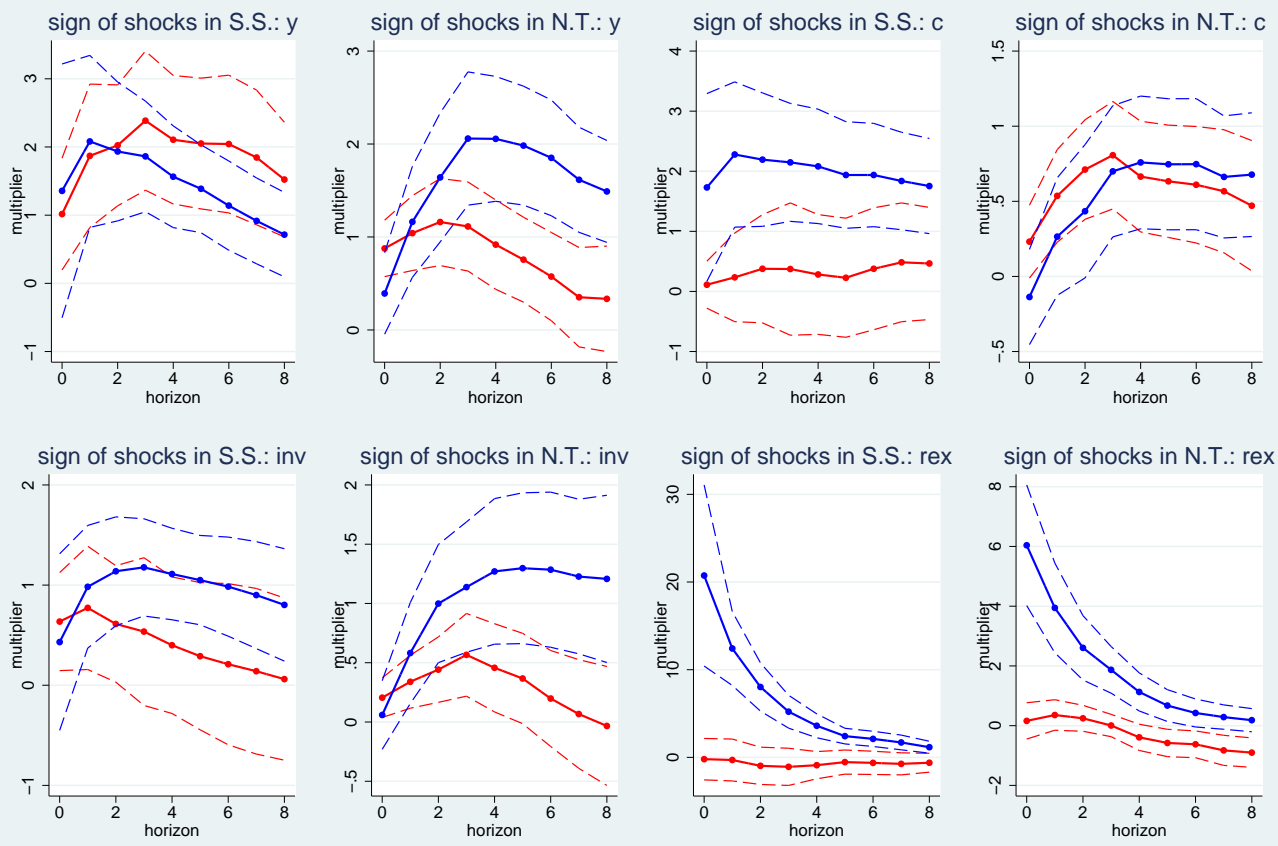

Figure 21: Fiscal Multiplier of positive and negative shocks in S.S. and N.T. (in LCU)

Note: The variables in the regression are denominated in $L C U$, except real change rate as indexed numbers and current account ratio as percentage. Red curves are cumulative multipliers associated with positive shocks; blue curves are cumulative multipliers associated with negative shocks. The sign of shocks comes from the SVAR residuals for each country. Dashed curves represent $80 \%$ confidence bands based on HAC standard deviations. 


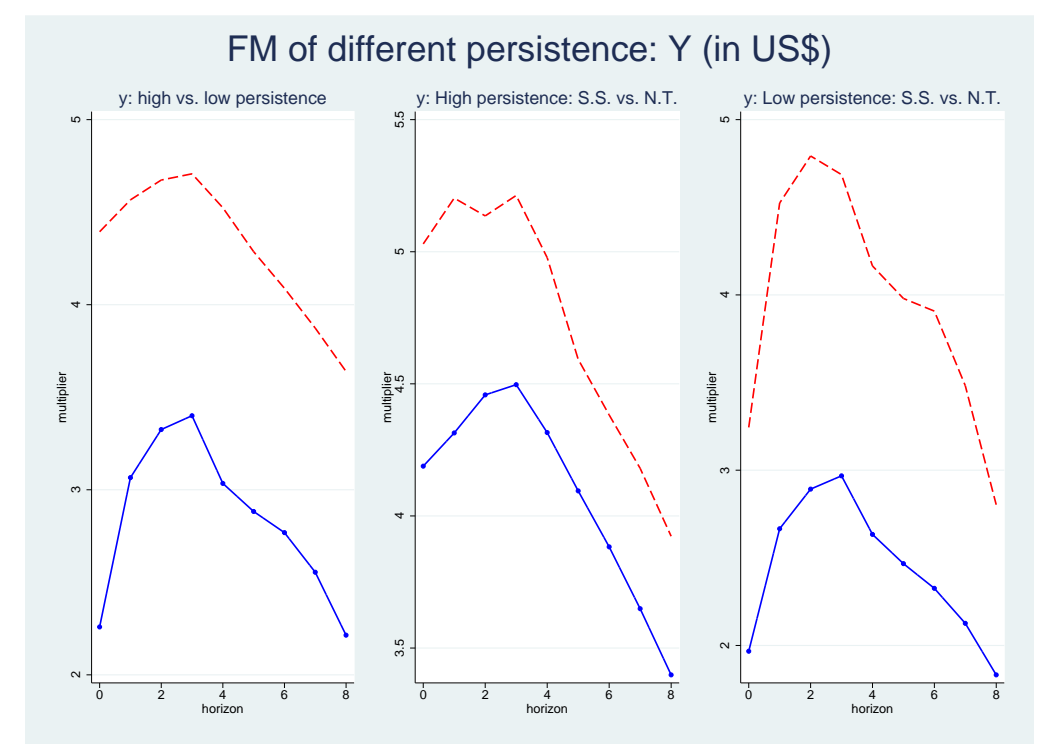

FM of different persistence: C (in US\$)

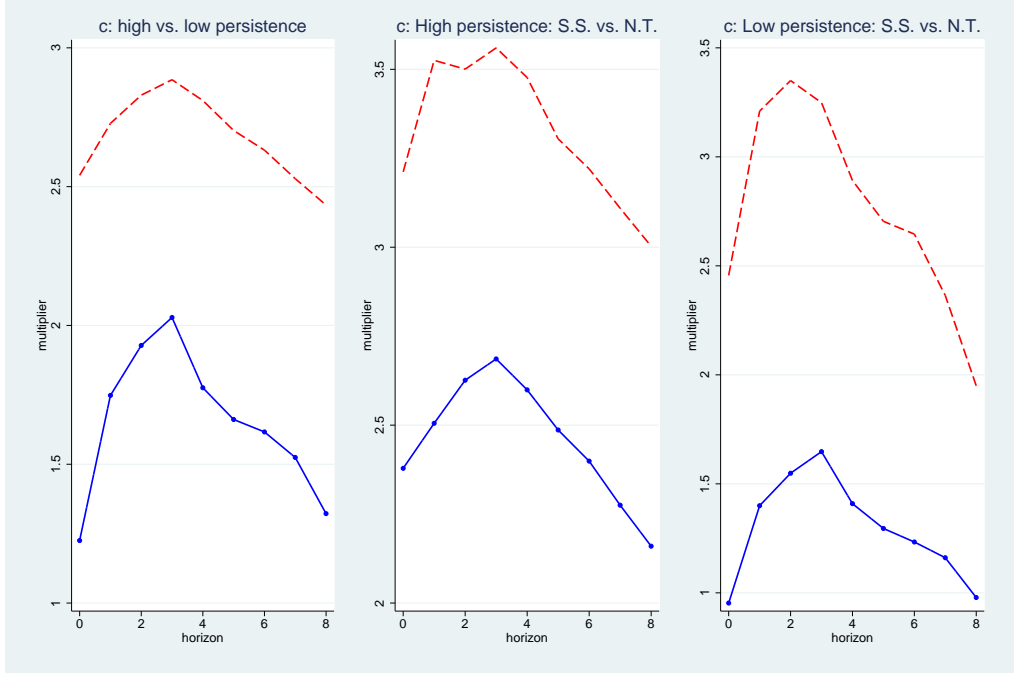

Figure 22: The effect of shock persistence (in US\$)

Note: The figures in the left compare fiscal multipliers for the countries with high (red) and low (blue) shock persistence. The middle and right panel shows respectively within certain persistence group, the fiscal multipliers during N.T. and S.S. episodes. All variables in the regression are denominated in US\$. The countries with auto-correlation higher than 0.7 are classified as high persistence group. 


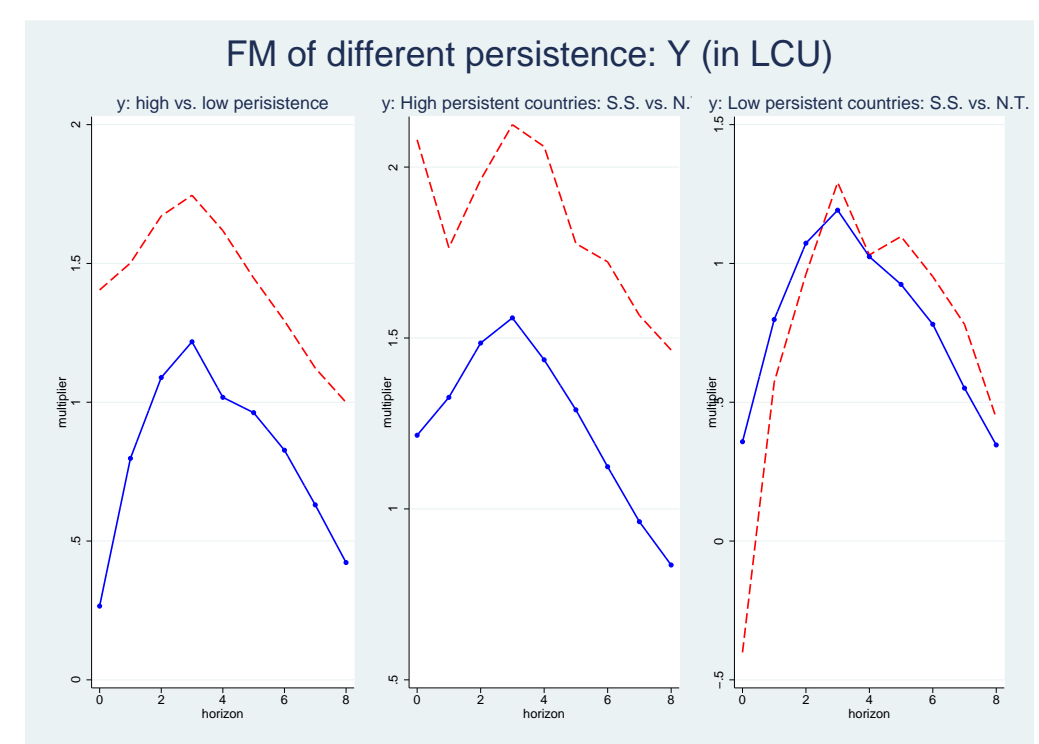

FM of different persistence: C (in LCU)

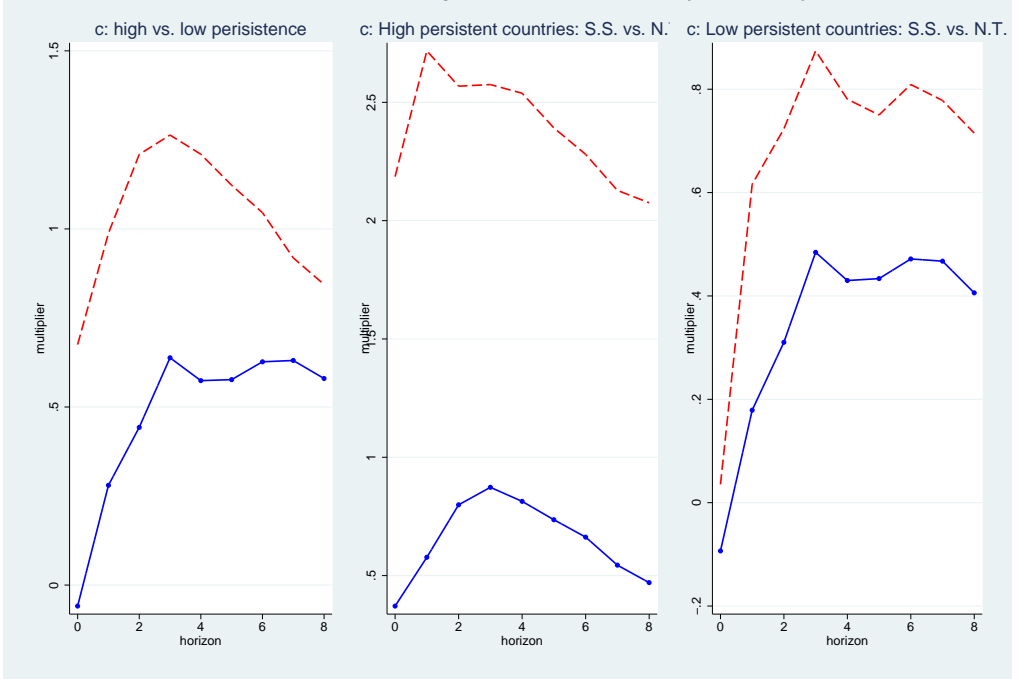

Figure 23: The effect of shock persistence (in LCU)

Note: The figures in the left compare fiscal multipliers for the countries with high (red) and low (blue) shock persistence. The middle and right panel shows respectively within certain persistence group, the fiscal multipliers during N.T. and S.S. episodes. All variables in the regression are denominated in LCU. The countries with auto-correlation higher than 0.7 are classified as high persistence group. 


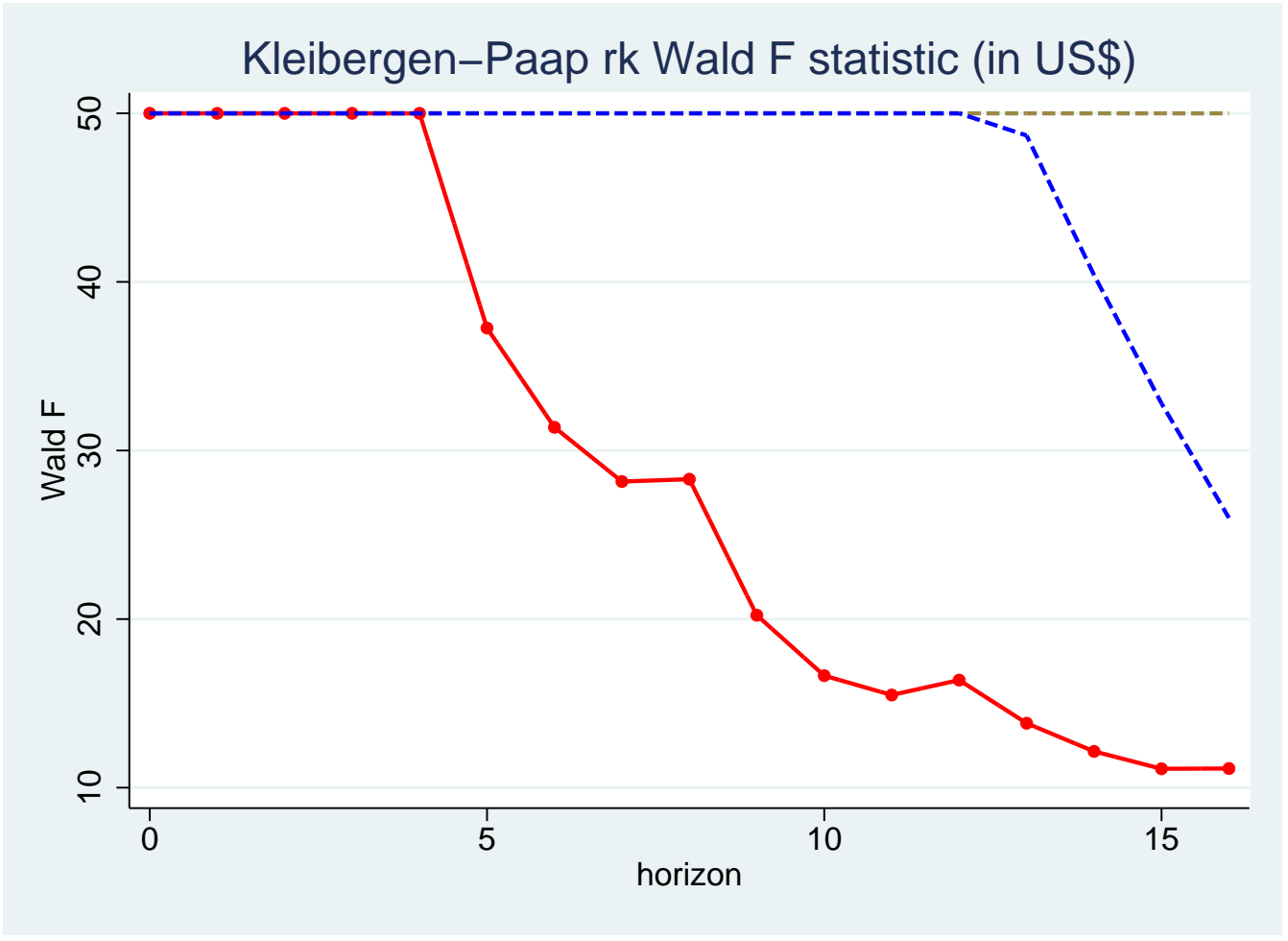

Figure 24: Weak Instrument Test

Note: The variables in the regression are denominated in US\$, except real change rate as indexed numbers and current account ratio as percentage. The figure shows the Kleipergan-Paap rk F statistics minus 23 in both the linear (black curve) and nonlinear regressions (red curve for S.S. and blue curve for N.T.). 


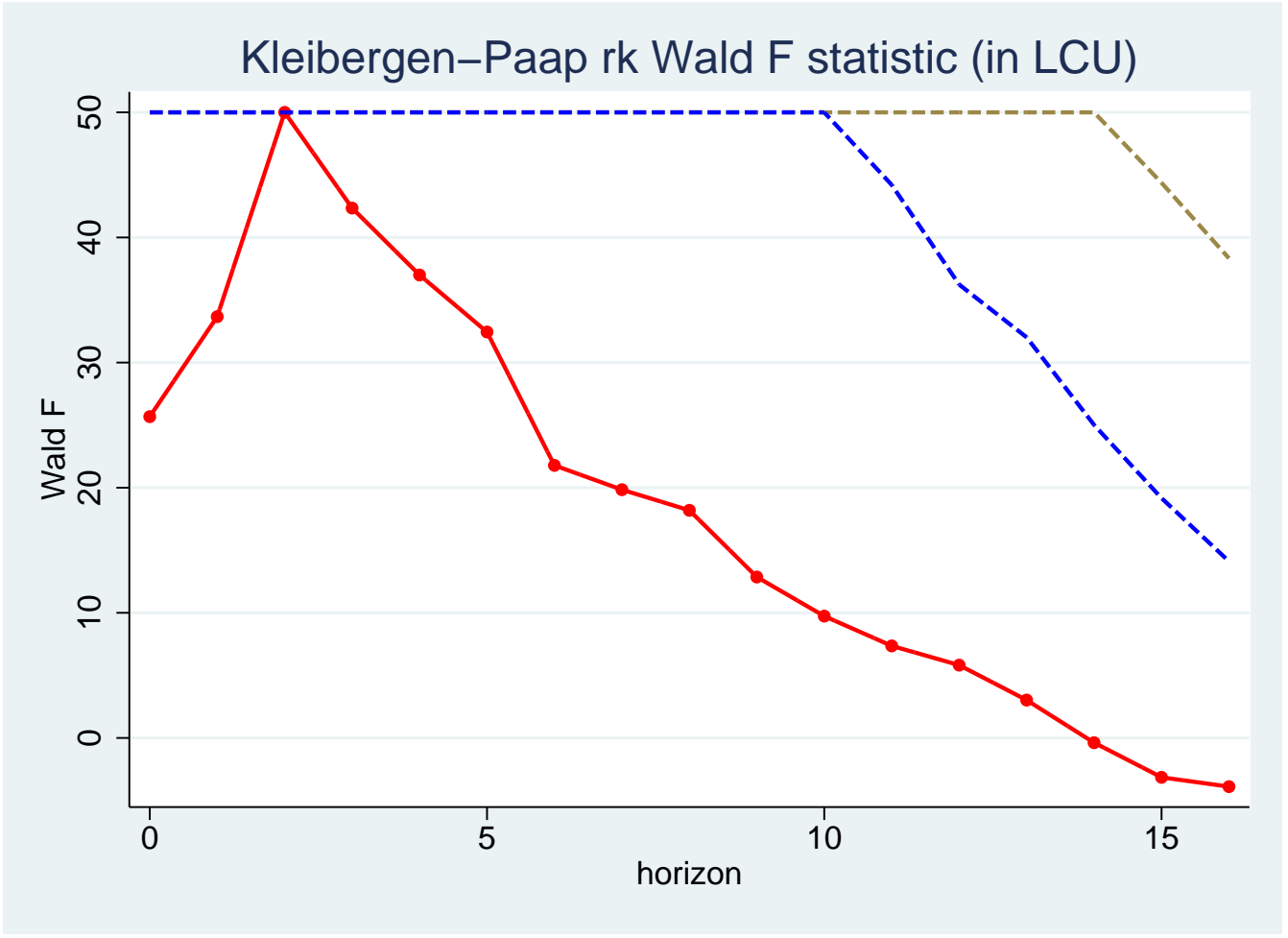

Figure 25: Weak Instrument Test

Note: The variables in the regression are denominated in $L C U$, except real change rate as indexed numbers and current account ratio as percentage. The figure shows the Kleipergan-Paap rk F statistics minus 23 in both the linear (black curve) and nonlinear regressions (red curve for S.S. and blue curve for N.T.). 


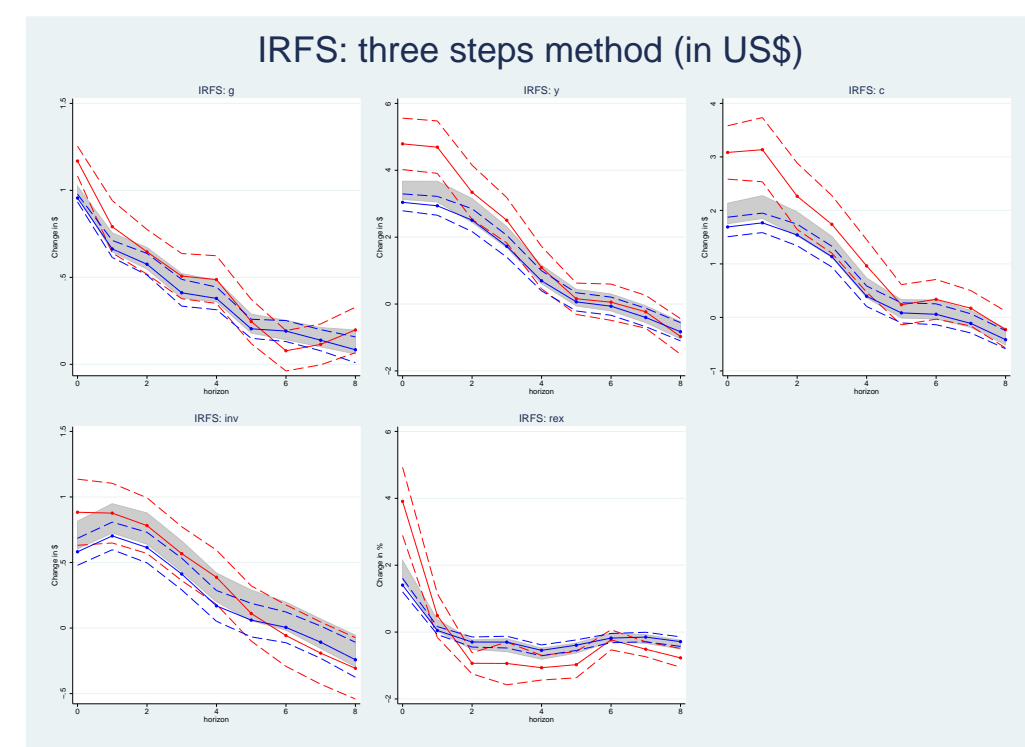

FM: three steps method (in US\$)
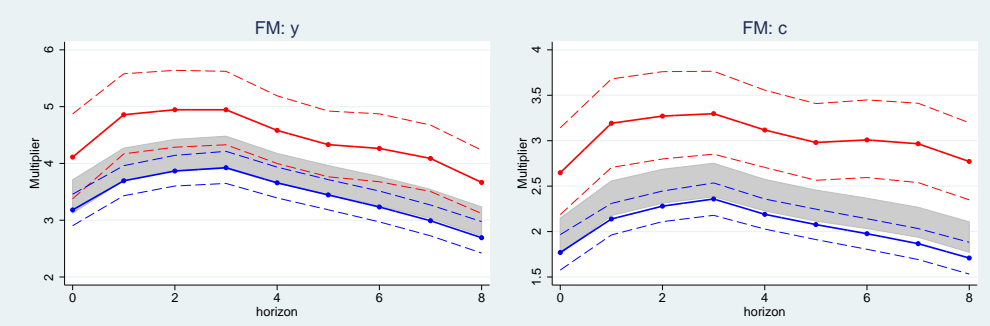

FM: inv

FM: rex
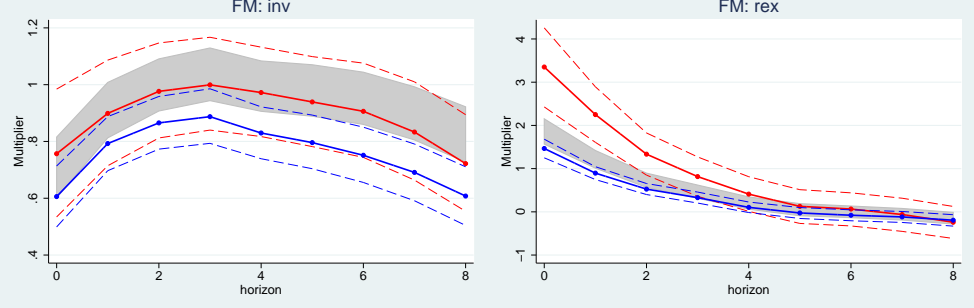

Figure 26: Sensitivity to the "three steps method" (in US\$)

Note: The variables in the regression are denominated in US\$, except real change rate as indexed numbers and current account ratio as percentage. The upper panel is the 1st and 2nd step regressions. In the lower panel, I construct the fiscal multipliers by bootstrap simulation. The standard error is derived using the Newey-West variance-covariance matrix from the impulse response estimations. Red curves are cumulative multipliers during sudden stop episodes; blue curves are cumulative multipliers in normal times. Dashed curves represent $80 \%$ confidence bands based on HAC standard deviations. 


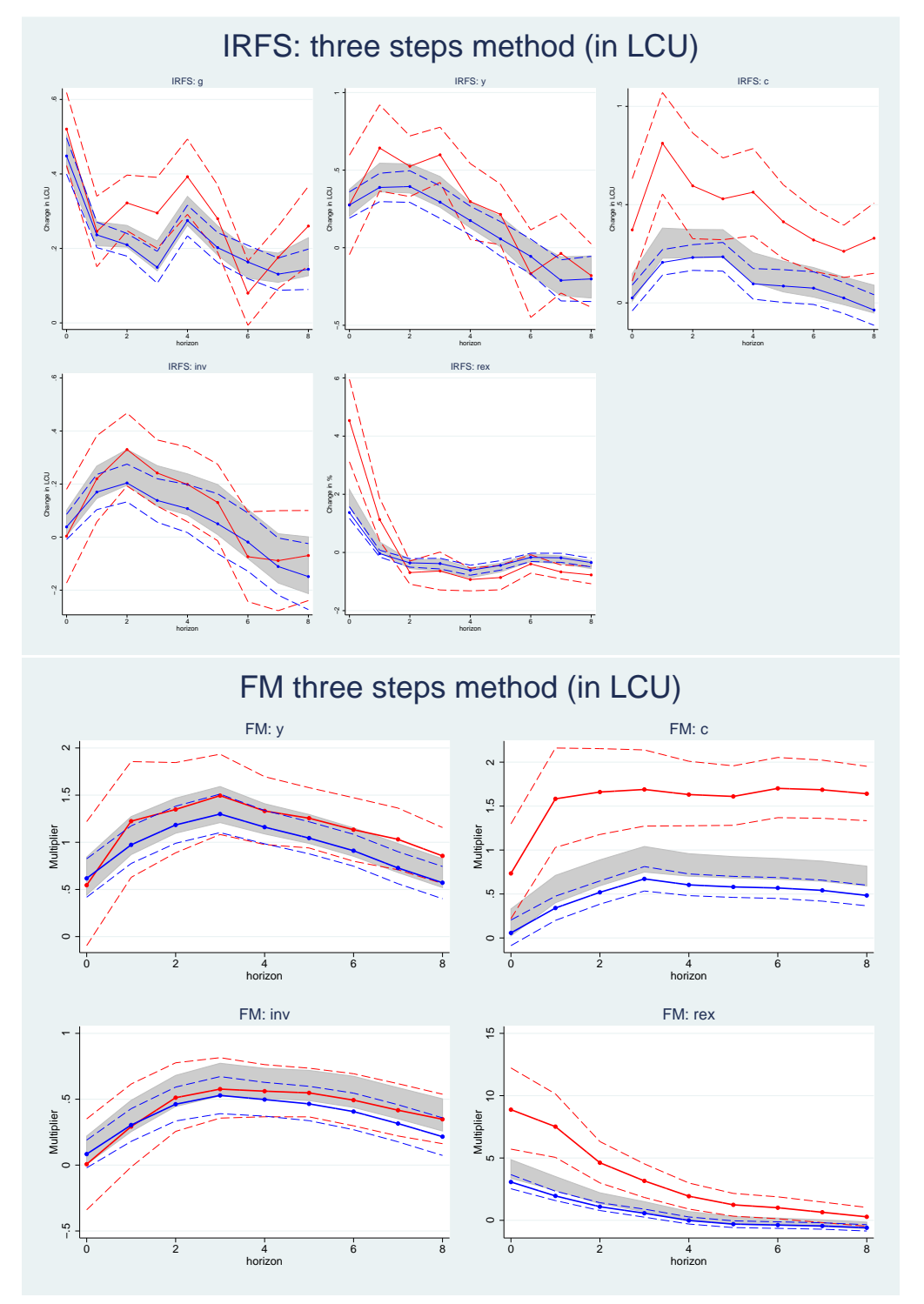

Figure 27: Sensitivity to the "three steps method" (in LCU)

Note: The variables in the regression are denominated in $L C U$, except real change rate as indexed numbers and current account ratio as percentage. The upper panel is the 1st and 2nd step regressions. In the lower panel, I construct the fiscal multipliers by bootstrap simulation. The standard error is derived using the Newey-West variance-covariance matrix from the impulse response estimations. Red curves are cumulative multipliers during sudden stop episodes; blue curves are cumulative multipliers in normal times. Dashed curves represent $80 \%$ confidence bands based on HAC standard deviations. 

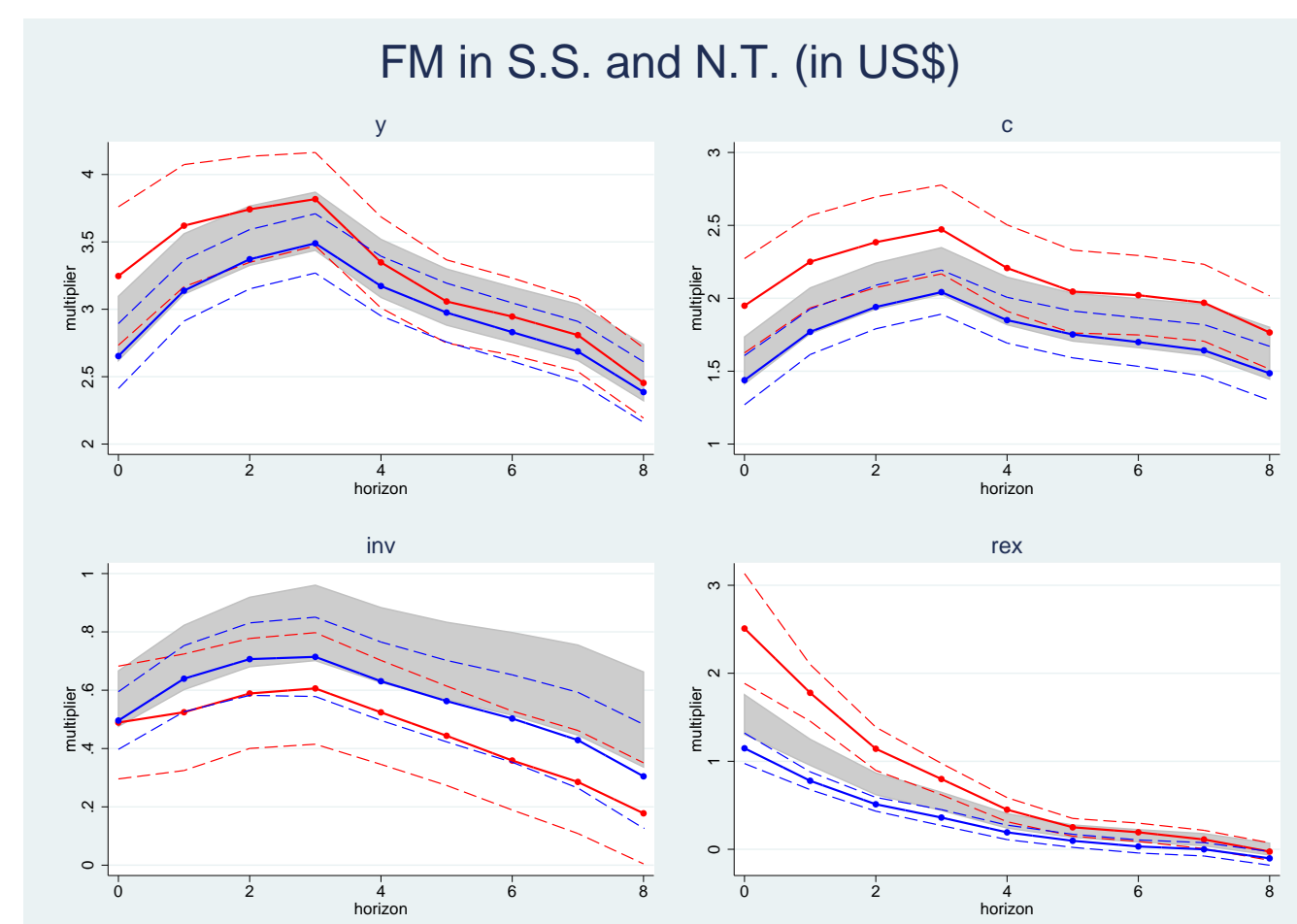

Figure 28: Alternative Instrument (in US\$)

Note: The variables in the regression are denominated in US\$, except real change rate as indexed numbers and current account ratio as percentage. In this exercise, I directly use the current government spending observations $g_{t}$ as the instrument for endogenous regressors in the "one step estimation". Red curves are cumulative multipliers during sudden stop episodes; blue curves are cumulative multipliers in normal times. Dashed curves represent $80 \%$ confidence bands based on HAC standard deviations. 


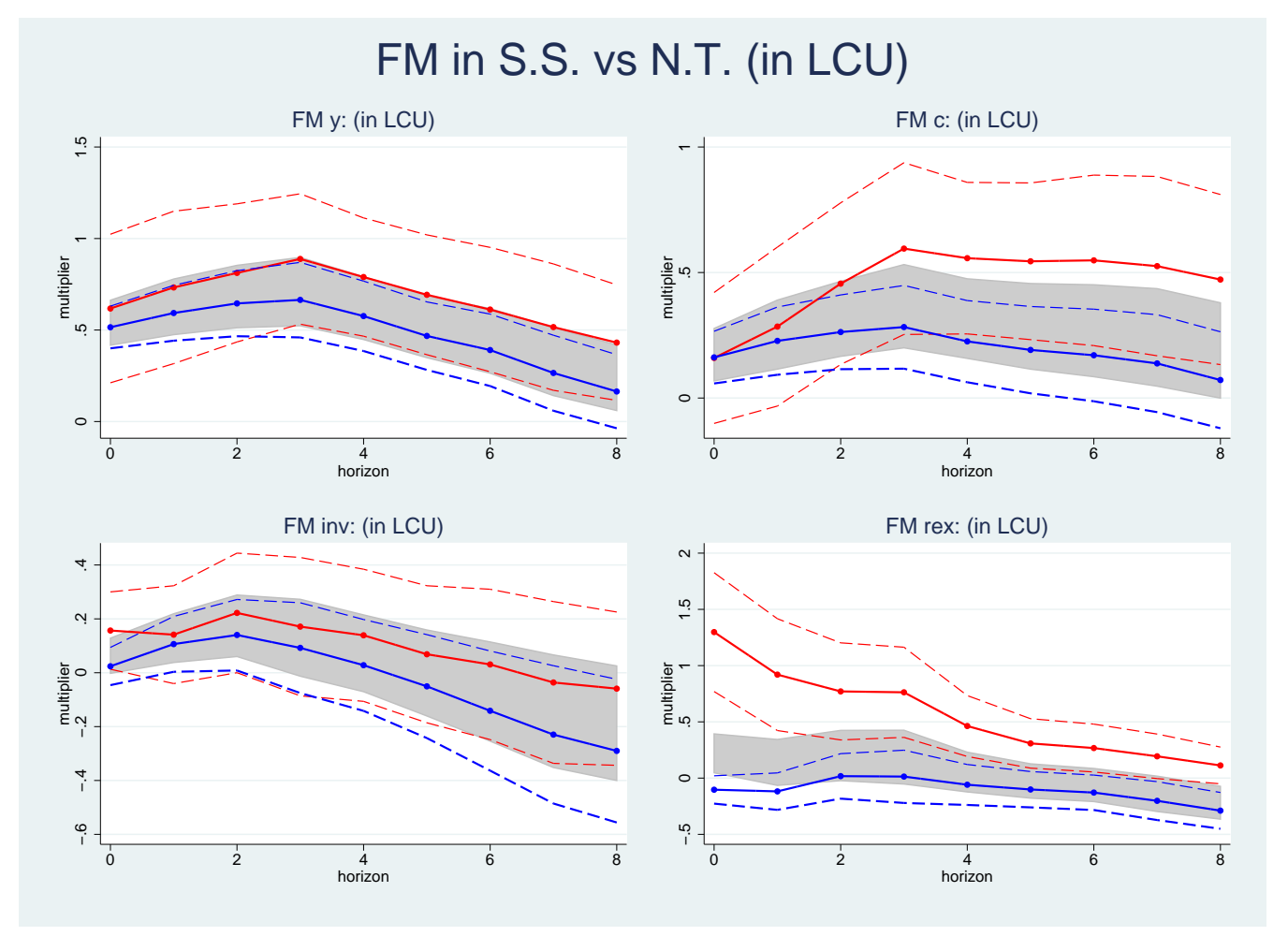

Figure 29: Alternative Instrument (in LCU)

Note: The variables in the regression are denominated in $L C U$, except real change rate as indexed numbers and current account ratio as percentage. In this exercise, I directly use the current government spending observations $g_{t}$ as the instrument for endogenous regressors in the "one step estimation". Red curves are cumulative multipliers during sudden stop episodes; blue curves are cumulative multipliers in normal times. Dashed curves represent $80 \%$ confidence bands based on HAC standard deviations. 


\section{E.3 The Three-Period Model}

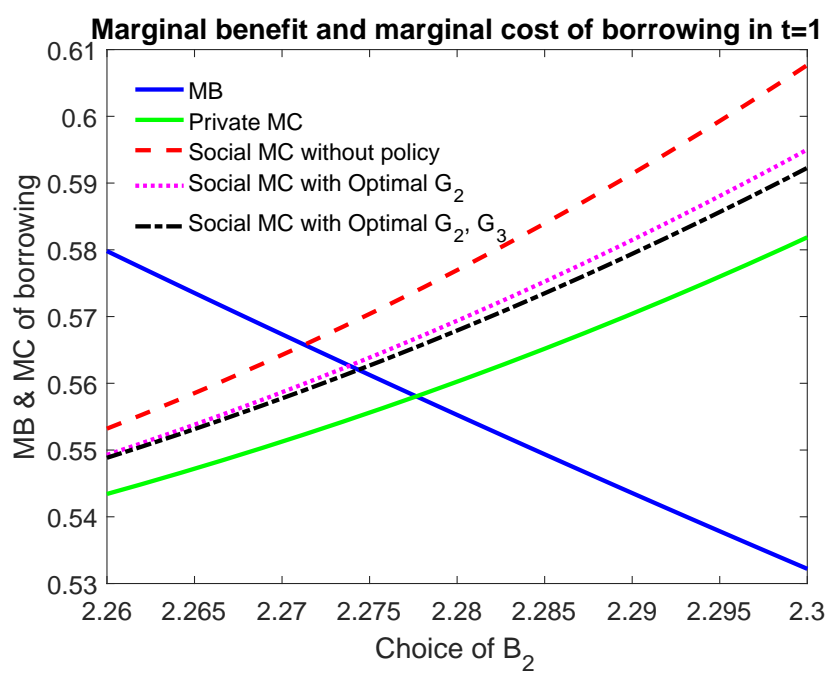

Figure 30: The Optimal Borrowing in Period 1: Marginal Benefits and Marginal Costs

Note: The marginal benefit of borrowing in period 1 is $u_{C T}(1)$. The private marginal cost is $u_{C T}(2)$. The social marginal cost, on the other hand, incorporates the possibility of financial constraint binding in period 2, with externality $u_{C T}(2) \frac{\kappa \mu_{2}^{S P}}{1-\kappa \mu_{2}^{S P}} \frac{\partial \beta \Lambda_{2,3}\left[p_{3}^{N} F_{k}(3)\right]}{\partial c_{2}^{T}}$. The government spending mitigates the severity of crisis, thus reduce the social marginal cost at all debt states.
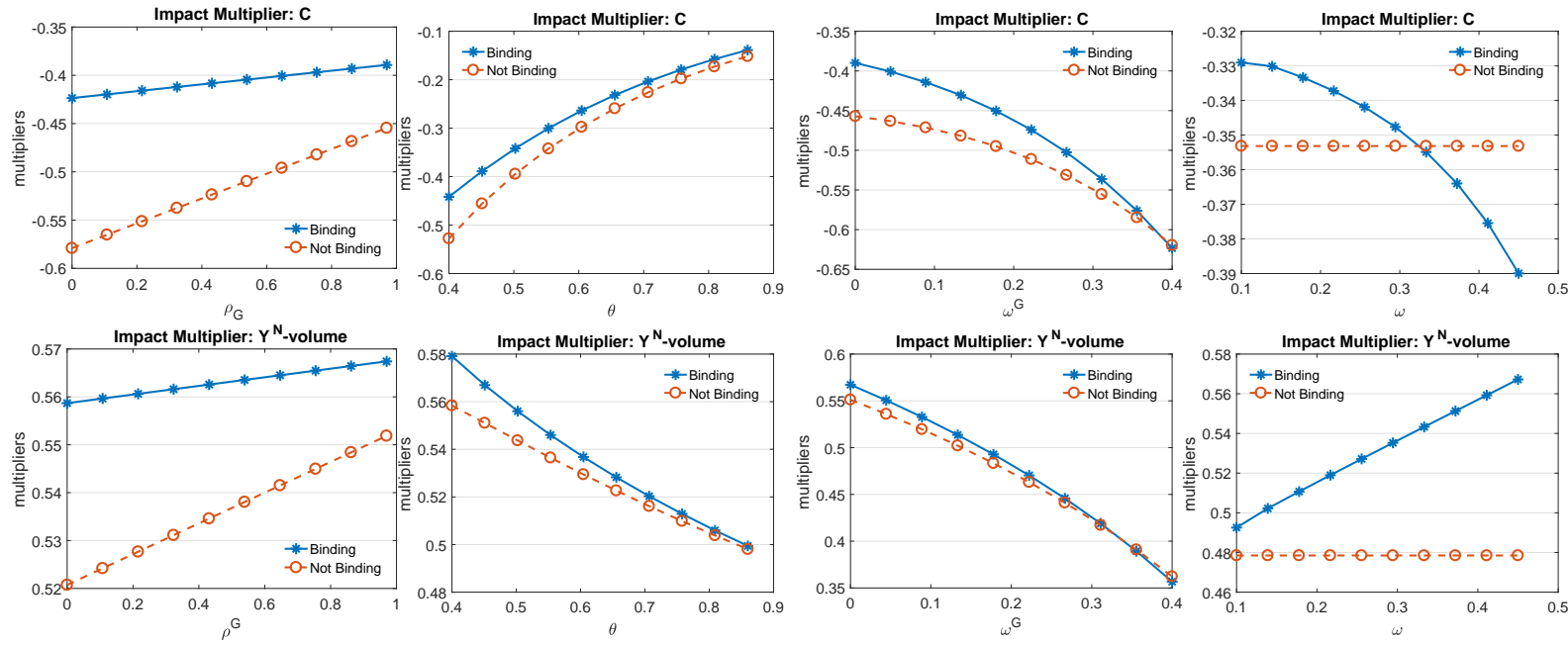

Figure 31: The Spending Multiplier in the Three-Period Model

Note: These figures show the fiscal multipliers on $c_{2}$ and $y_{2}^{N}$ in the three-period model. The multipliers here (defined as $\left.\frac{\Delta x_{2}}{\Delta g_{2}}\right)$ depend on the state at the beginning of period 2: $\left(b_{2}, y_{2}^{T}, g_{2}\right)$. The non-binding (binding) state is the one when $y_{2}^{T}=1.01\left(y_{2}^{T}=0.99\right)$ while $b_{2}$ and $g_{2}$ are kept the same at their mean values. The benchmark parameter values are $\rho_{G}=0.95, \theta=0.45, \omega^{G}=0, \omega=0.35$, and I change one parameter at a time. $I$ assume with the persistent effect of government purchase: $g_{3}=\bar{g}^{1-\rho_{G}} g_{2}^{\rho_{G}}$ where $\bar{g}$ is the steady state. 


\section{E.4 Full Model}
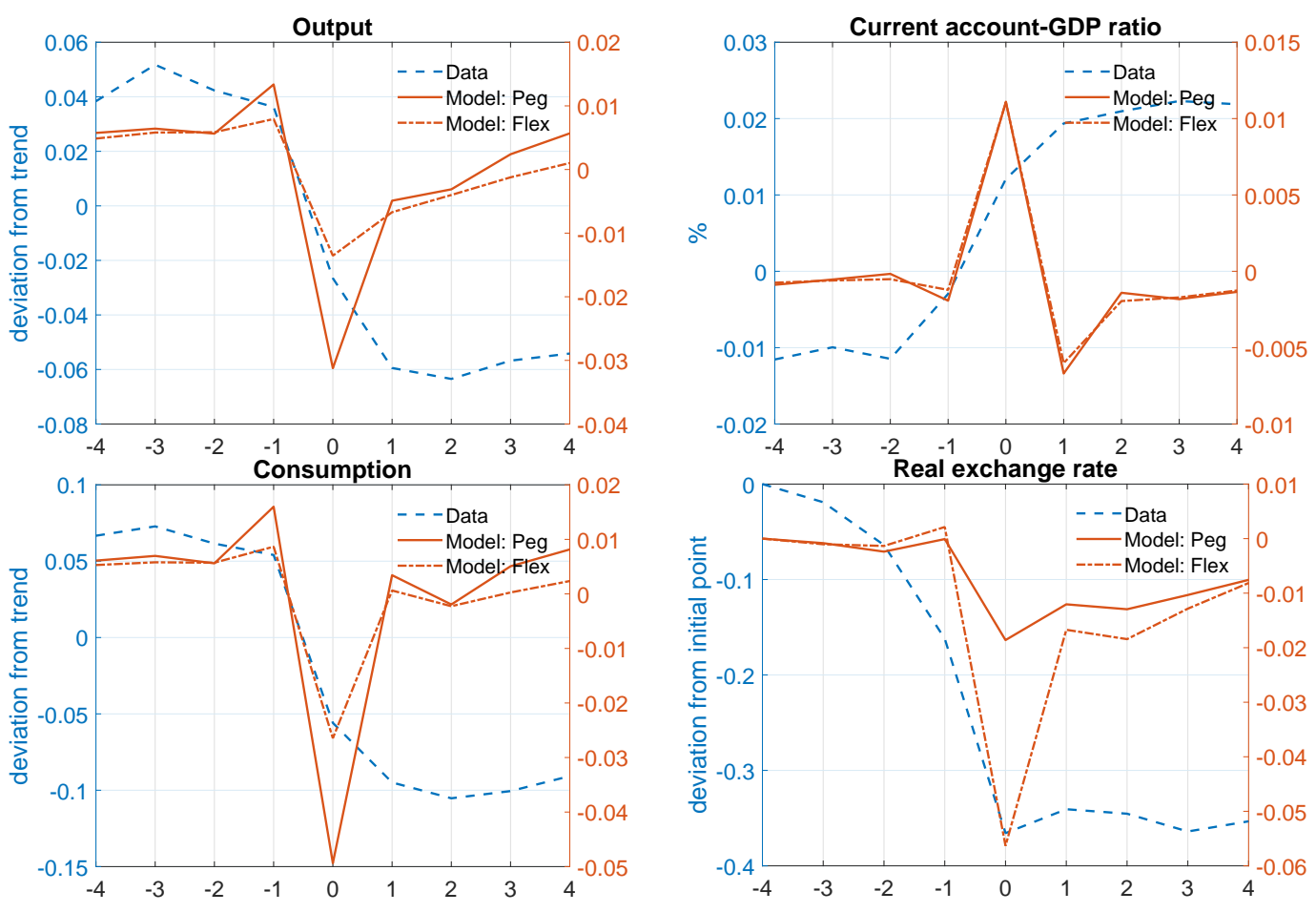

Figure 32: Sudden Stop Event Analysis

Note: The figure plots the averaged 9-periods event window of sudden stop episodes from the data and the model. The sudden stop is defined in the same way as before. The dashed series show the average of 6 most typical and severe sudden stop crises: Argentina 2002 Q1, Mexico 1995 Q1, Ecuador 1999 Q1, Malaysia 1998 Q1, Korea 1998 Q1, and Thailand 1998 Q1. For the data, the left axis is the percentage deviation from their HP-filtered trends; for the model, the right axis shows each variable's deviation from its mean. 

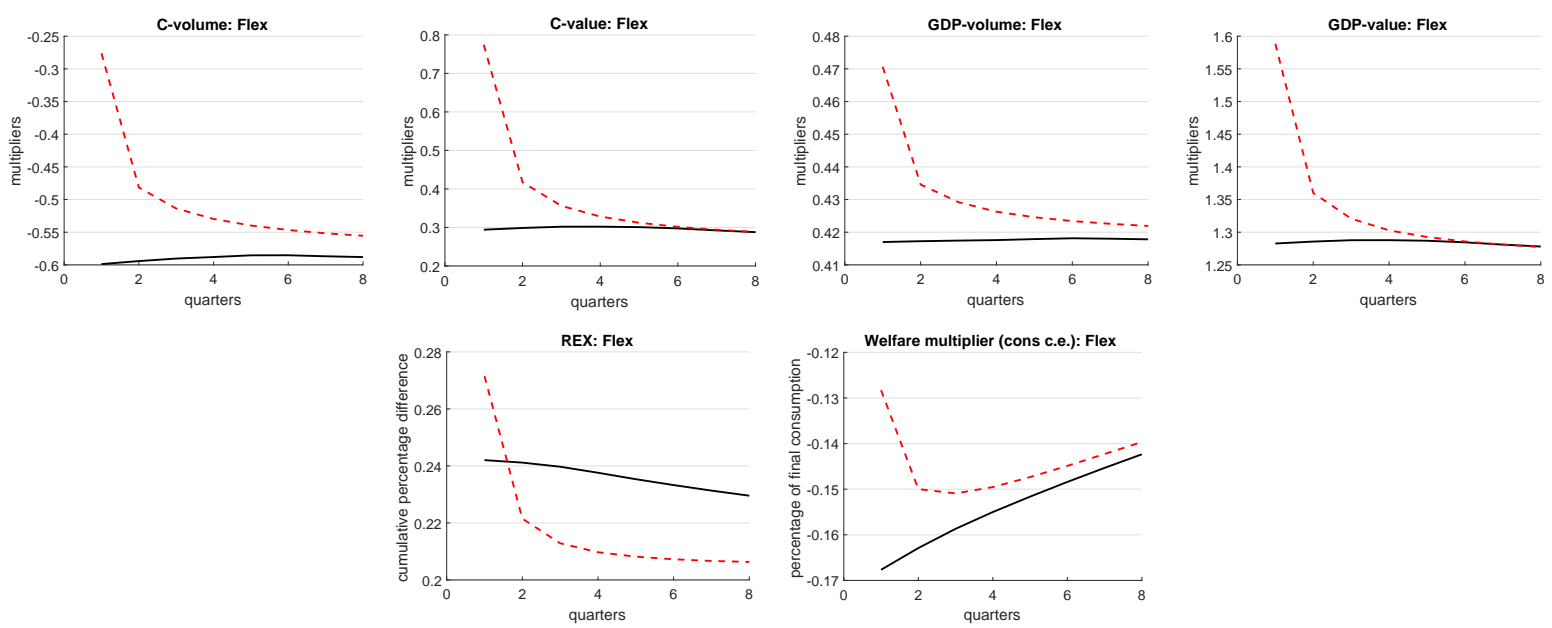

Figure 33: Cumulative Multipliers: Flex

Note: These are the median paths of theoretical multipliers starting from the "boom" (red dashed) and the "bust" (black solid) states for an economy with flexible exchange rate $\gamma^{E}=1$. The simulation of fiscal multipliers is the same as generating GIRF where I compare the simulation path with and without a unit government spending shock. The upper panel is the cumulative GDP and consumption multiplier. The real exchange rate is in term of cumulative percentage differences between the path with a government spending shock and the path without the shock. The welfare multiplier is the certainty equivalence that equalizes agents' utility between these two paths.
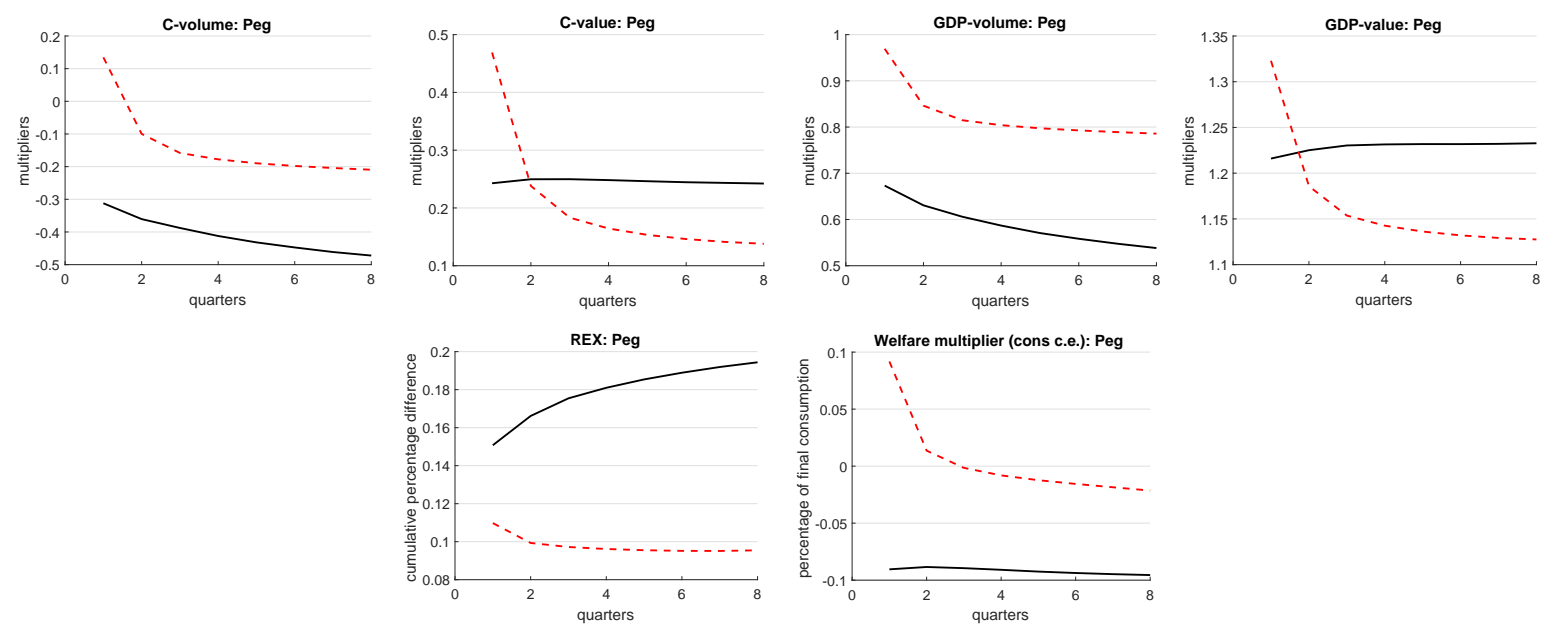

Figure 34: Cumulative Multipliers: Pegged

Note: These are the median paths of theoretical multipliers starting from the "boom" (red dashed) and the "bust" (black solid) states for an economy with pegged exchange rate $\gamma^{E}=0$. See figure 33 for detailed information. 

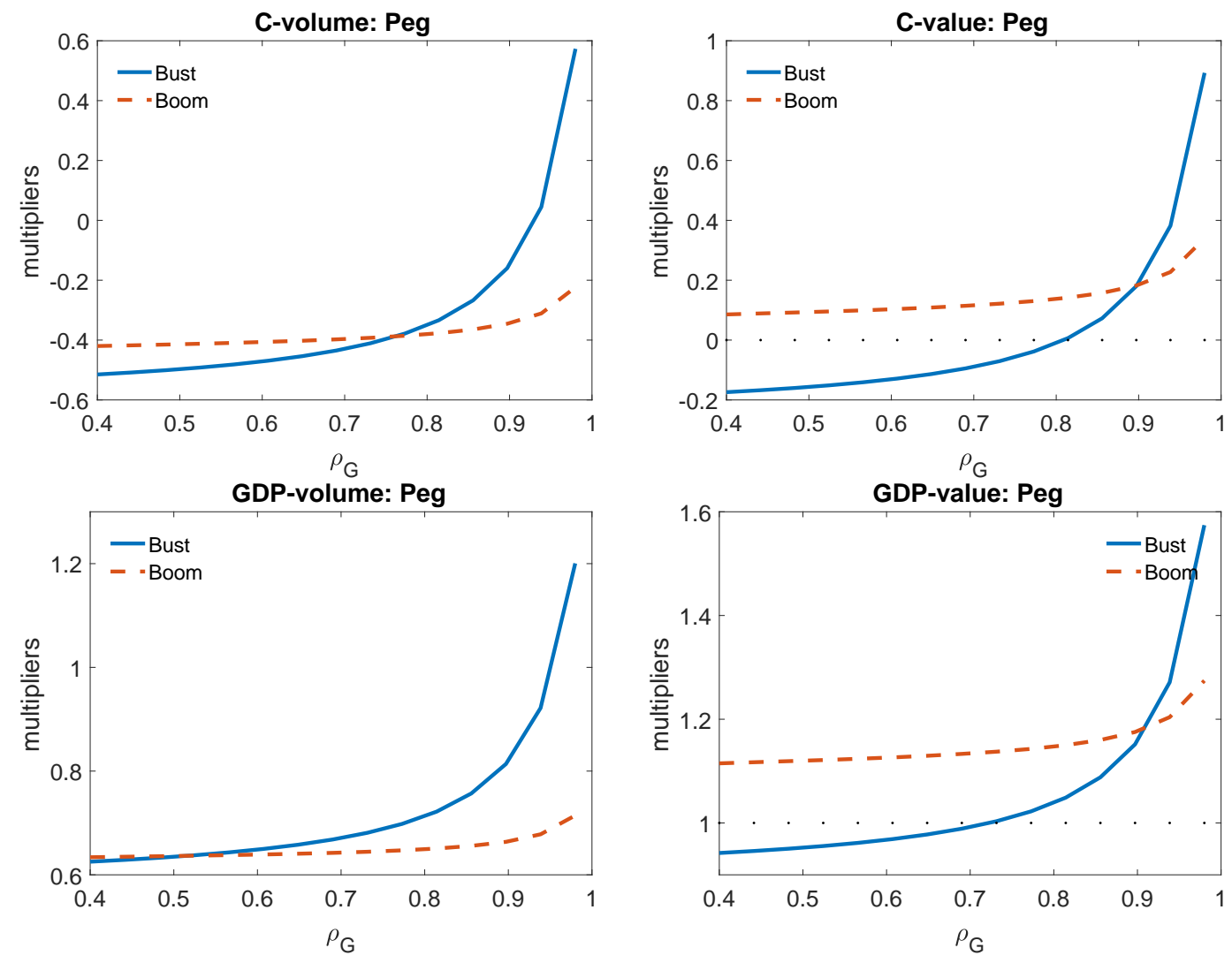

Figure 35: Multipliers for Different Shock Persistence

Note: The figure plots the median value of impact multipliers under different degree of shock persistence. This is the model with DNWR and pegged exchange rate regime. The boom and bust state are defined by simulation, the same as before. 

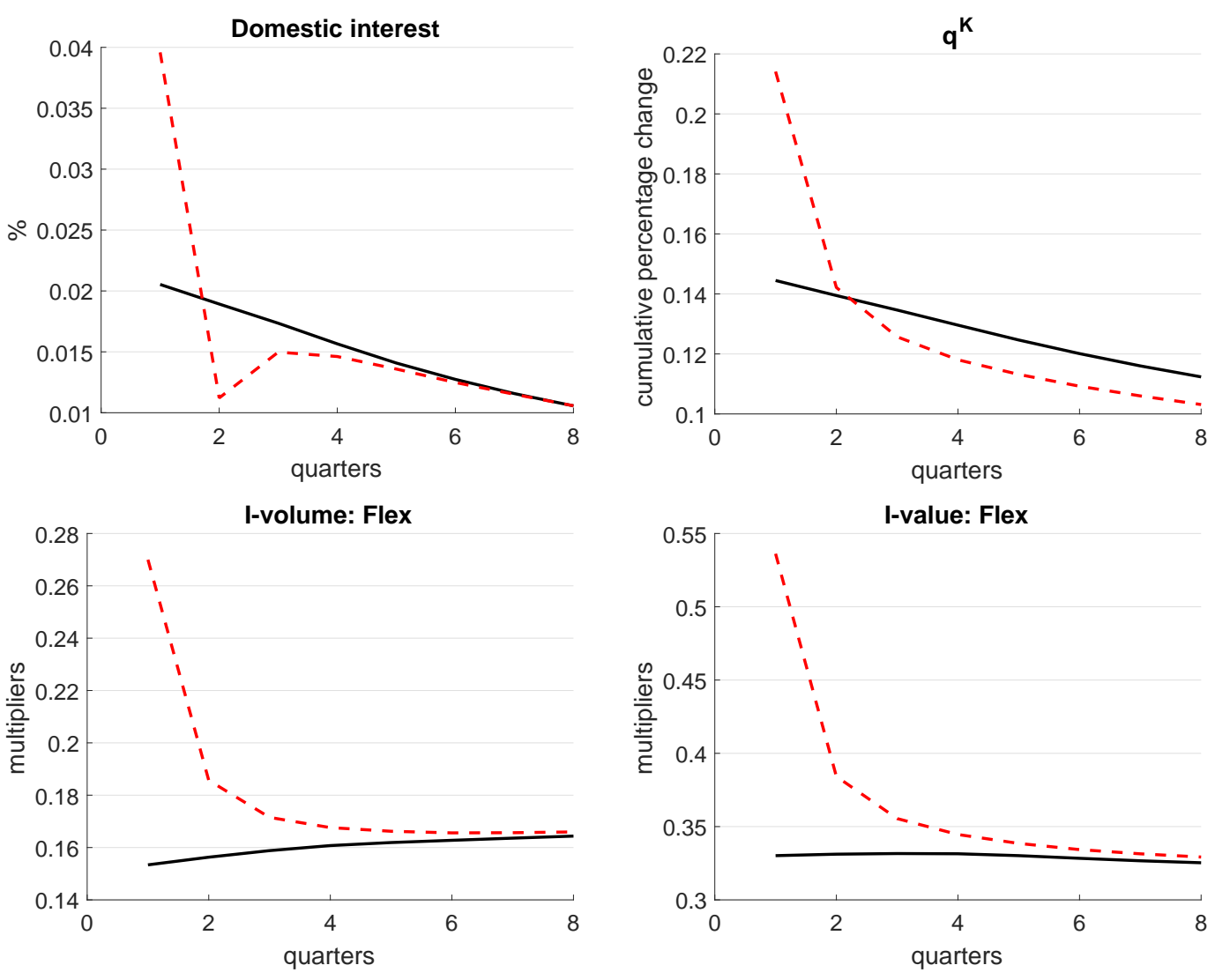

Figure 36: Multipliers for the investment economy: Flexible exchange rate

Note: The figures plot the median paths of simulation starting from the boom (red dashed) and bust (black solid) states for an investment economy with flexible exchange rate $\gamma^{E}=1$. The numbers for in the upper left panel is the increase of domestic interest rate (in percentage) after a government spending shock. The numbers in the right panel reports the cumulative change of capital price between the path with and without government spending shocks. The numbers in the bottom panels are cumulative multipliers of investment in local and foreign currencies. 

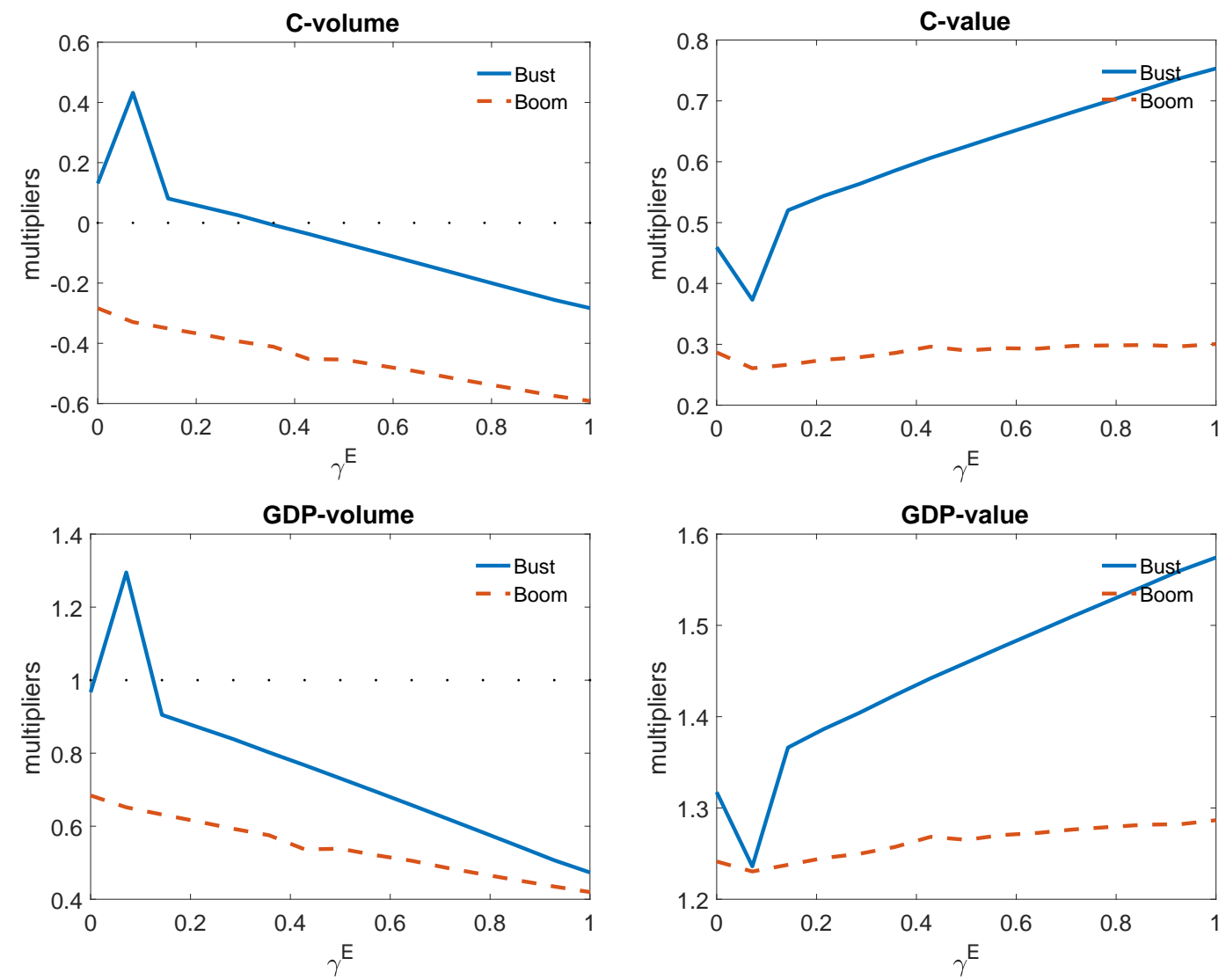

Figure 37: Impact Multipliers for Different $\gamma^{E}$

Note: The figure plots the median value of impact multipliers under different exchange rate policy coefficients. The boom and bust state are defined by simulation, the same as before. 

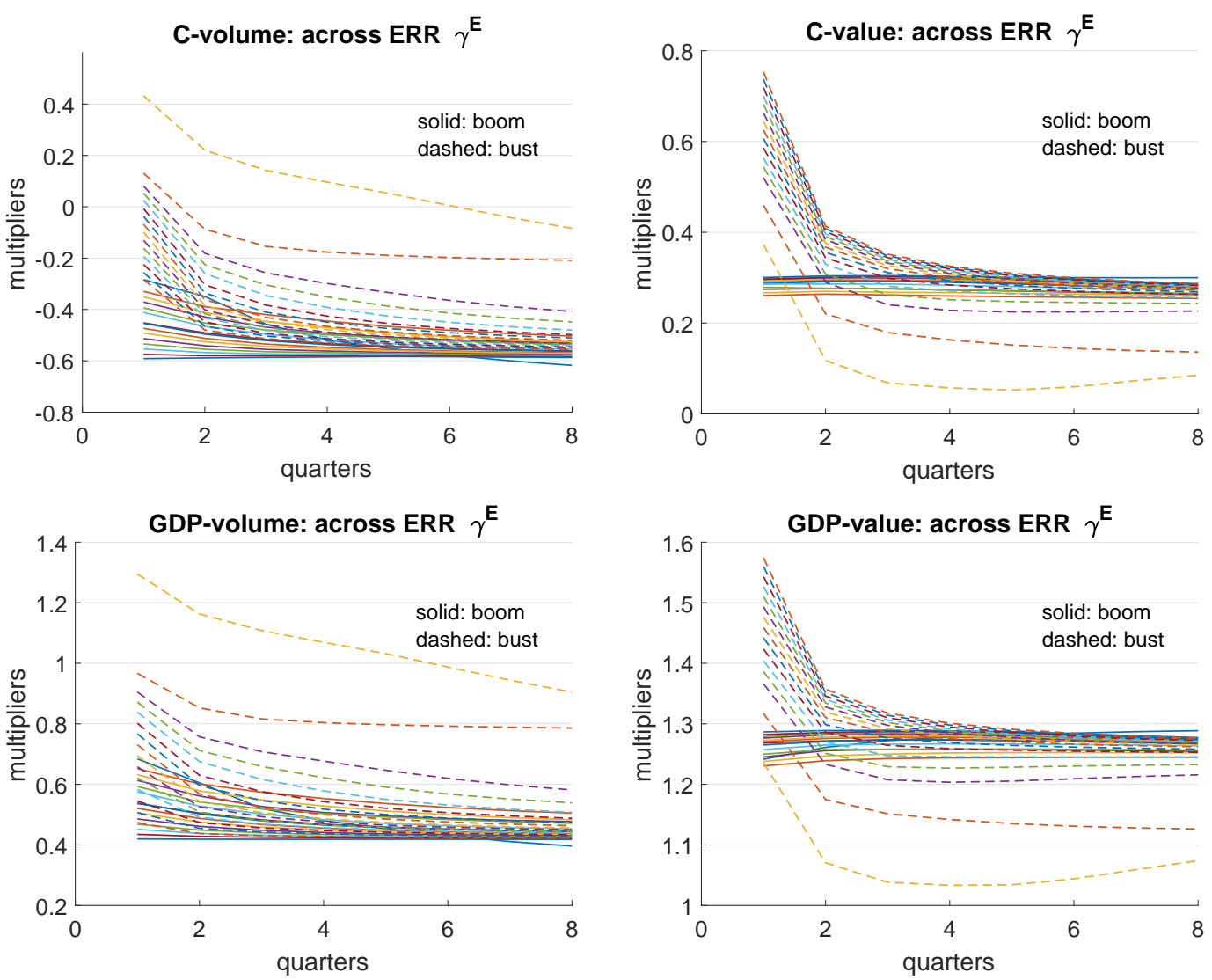

Figure 38: Cumulative Multipliers for Different $\gamma^{E}$

Note: The figure plots the median value of cumulative multipliers under different exchange rate policy coefficients. The dashed (solid) curves are multipliers when the economy starts from the bust (boom). The boom and bust states are defined by simulation, the same as before. 